\title{
Spatial Relationship between the Trichloroethylene Degrading Bacteria Dehalococcoides Sp., Sulfate Reducers and Archaea during Reductive Dechlorination
}

\author{
Pujya Wagle Gautam \\ West Virginia University
}

Follow this and additional works at: https://researchrepository.wvu.edu/etd

\section{Recommended Citation}

Gautam, Pujya Wagle, "Spatial Relationship between the Trichloroethylene Degrading Bacteria Dehalococcoides Sp., Sulfate Reducers and Archaea during Reductive Dechlorination" (2013). Graduate Theses, Dissertations, and Problem Reports. 580.

https://researchrepository.wvu.edu/etd/580

This Thesis is protected by copyright and/or related rights. It has been brought to you by the The Research Repository @WVU with permission from the rights-holder(s). You are free to use this Thesis in any way that is permitted by the copyright and related rights legislation that applies to your use. For other uses you must obtain permission from the rights-holder(s) directly, unless additional rights are indicated by a Creative Commons license in the record and/ or on the work itself. This Thesis has been accepted for inclusion in WVU Graduate Theses, Dissertations, and Problem Reports collection by an authorized administrator of The Research Repository @ WVU. For more information, please contact researchrepository@mail.wvu.edu. 
Spatial Relationship between the Trichloroethylene Degrading Bacteria Dehalococcoides Sp., Sulfate Reducers and Archaea during Reductive Dechlorination

\title{
Pujya Wagle Gautam
}

\author{
Thesis submitted to the \\ College of Benjamin M Statler College of Engineering and Mineral resources \\ at West Virginia University \\ in partial fulfillment of the requirements \\ for the Degree of \\ Masters of Science \\ in \\ Civil and Environmental Engineering
}

Jennifer L Weidhaas, Ph.D., P.E. Committee Chairperson

Radhey S. Sharma, Ph.D.

Lian-Shin Lin, Ph.D., P.E.

Department of Civil and Environmental Engineering

Morgantown, West Virginia

2013

Key words: bedrock fracture, bioremediation, DHC, sandy aquifer, silt aquifer, reductive cometabolism, qPCR, TCE. 


\section{ABSTRACT \\ Spatial Relationship between the Trichloroethylene Degrading Bacteria Dehalococcoides Sp., Sulfate Reducers and Archaea during Reductive Dechlorination

\author{
Pujya Wagle Gautam
}

Trichloroethylene (TCE) released to the environment is of great concern due to its toxicity and carcinogencity. The microorganisms involved in bioremediation of TCE such as methanogens (organisms within the domain Archaea), sulfate reducing bacteria (SRB) and Dehalococcoides sp. (DHC) are of particular interest in this study. Three different types of bench scale reactors were constructed to model different aquifer types such as sandy, silty and fractured bedrock aquifers (hereafter type 1, 2 or 3 reactors, respectively). This study evaluated the effect of TCE concentration in different types of reactors on the distribution of selected microorganisms with distance from the source of the TCE. It also examined the spatial relationship between Dehalococcoides sp., Archaea and SRB with respect to reducing equivalents (e.g., food) in different types of aquifer environment contaminated with TCE. The DNA analysis was performed by using quantitative polymerase chain reaction (qPCR) and fluorescent in situ hybridization (FISH). In this study concentrations of Archaea were higher in all reactors than other microorganisms under study. In the type 1 reactor, with increasing concentrations of TCE, DHC concentrations and SRB concentrations increased. In type 2 and 3 reactors, there were no observed correlations between initial concentrations of TCE and the concentration of the studied microbes. The highest DHC concentration was present near the food source in type 1 and 2 reactors. In type 3 reactors the concentration of microorganisms was higher outside the tube (e.g., fracture) than inside. The spatial relationship between Dehalococcoides sp. and various microorganisms that compete for bioremediation substrates supplied is helpful to understand when and where to bioaugment an aquifer undergoing bioremediation of TCE with Dehalococcodies sp. 


\section{Acknowledgements}

My greatest gratitude goes to my supervisor Jennifer L Weidhaas, Ph.D, P.E. who offered her continuous advice, encouragement and undertook tremendous responsibility in supervising the completion of my research and thesis. I thank her for the systematic guidance, patience, motivation, enthusiasm, great effort and immense knowledge she put into training me in the scientific field. I could not have imagined having a better advisor and mentor for my study. It was with her encouragement and help that I could be confident in doing the whole job.

I also would like to thank Dr. Lian-Shin Lin and Dr. Radhey Sharma for their valuable time and serving on my committee.

I acknowledge David Turner, Senior Lab Instrumentation Specialist, Civil and Environmental Engineering, for contributing his time to make the reactors to support this study. Also I would like to thank Dr Jianbo Yao, Division of Animal \& Nutritional Sciences and his students for allowing me to use nanodrop quantification spectrophotometer to complete analysis at his laboratory. My thanks go to the chemistry department for allowing me to use the Gas chromatography instrument and Dr Karen Martin, Imaging facility of Mary Babb Randolph Cancer Center at Health science department for training me in image analysis. I am thankful to Dr. Ryan Dupont (USU) and Dr. Paul Hatzinger (Shaw) for providing Dehalococcoides cultures studies.

Finally, I take this opportunity to express the profound gratitude to my dear husband Lekhnath Gautam, my beloved parents, siblings and my son Prithul Gautam for their love, encouragement, understanding and continuous support during all this years. I really appreciate the help of my friends and fellow students: Thomas, Autumn, Isabel, Dong Yang (Sunny) and Chenjie. Last but not least, my thanks go to all the other faculty and staff in Civil and Environmental Engineering at WVU especially, Dr. Karen Buzby, and Research Assistant Will Ravenscroft for their help. 


\section{Table of contents}

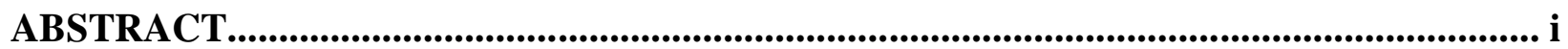

Acknowledgements............................................................................................................................. ii

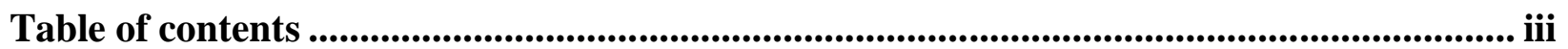

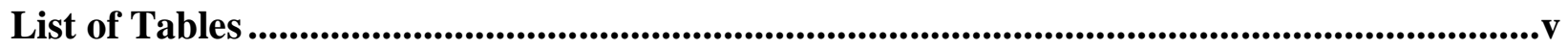

List of figures.................................................................................................................................................. vi

List of Abbreviations............................................................................................................................. ix

CHAPTER 1 INTRODUCTION .................................................................................................1

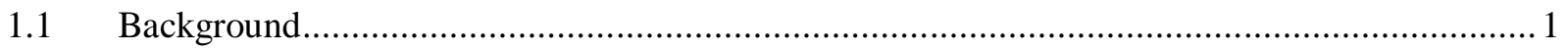

1.2 Exposure and environmental effects of TCE ..................................................................

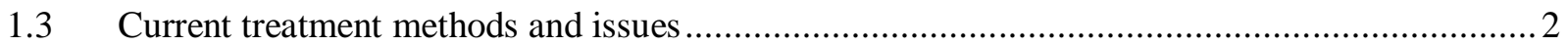

$1.4 \quad$ Research objectives and hypotheses …………………………………………………...

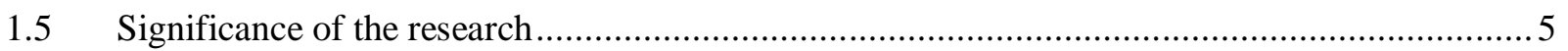

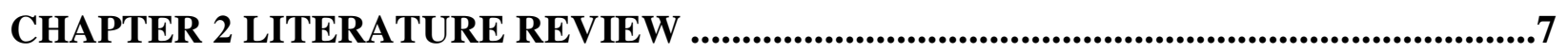

2.1 Trichloroethylene production, use, properties and treatment …………………………….....

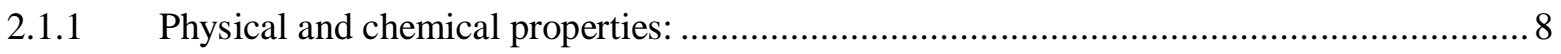

2.2 Physical and chemical TCE treatment technologies ………...................................................

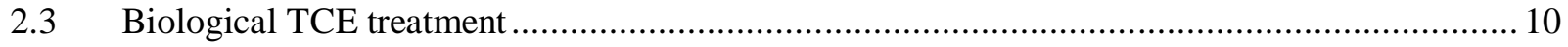

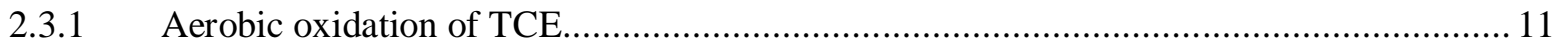

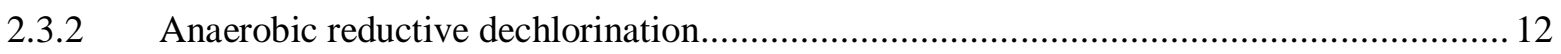

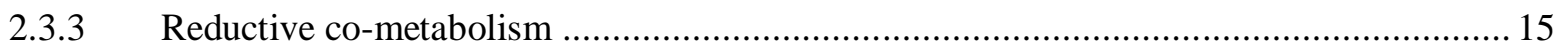

$2.4 \quad$ Electron acceptor/electron donor and redox potential........................................................ 16

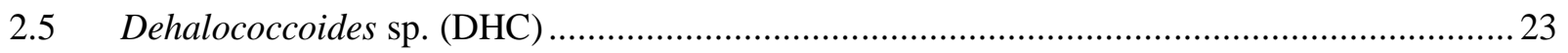

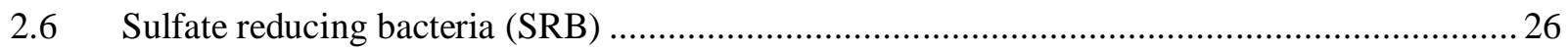

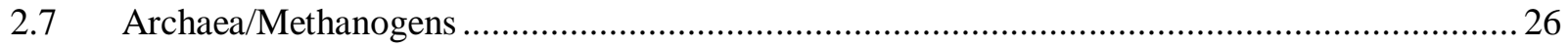

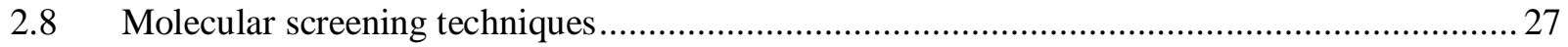

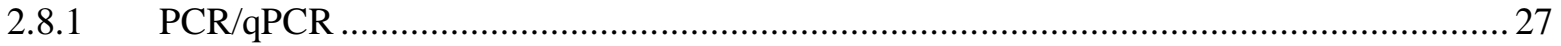

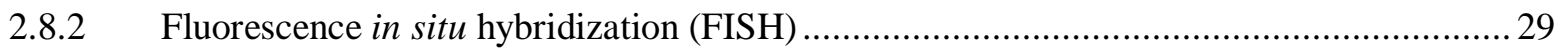

CHAPTER 3 MATERIALS AND METHODS....................................................................31 


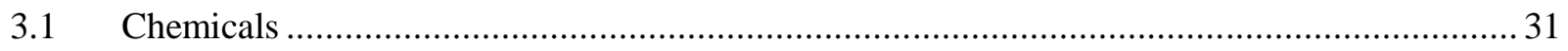

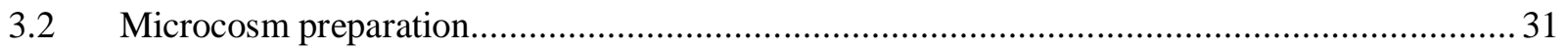

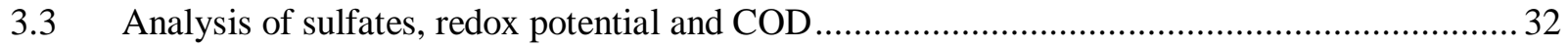

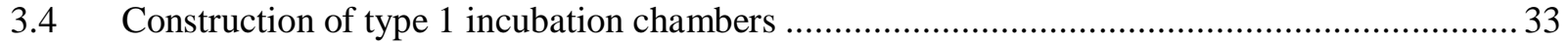

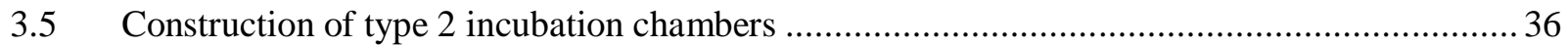

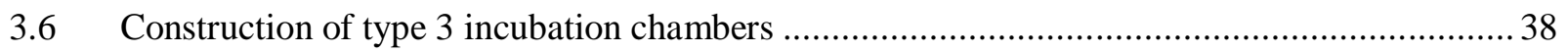

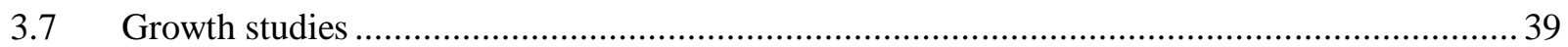

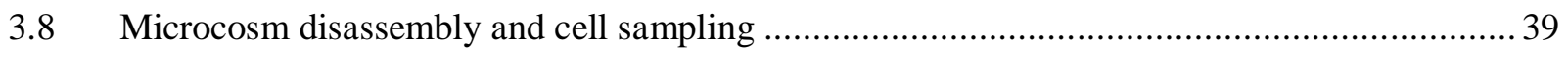

$3.9 \quad$ DNA extraction method testing and selection ............................................................... 40

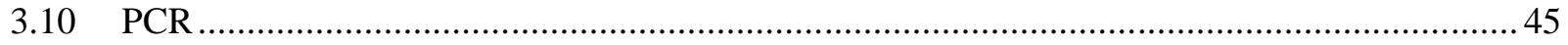

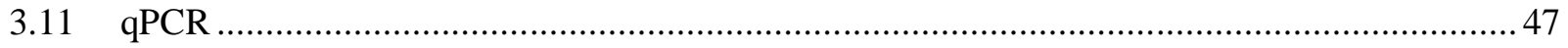

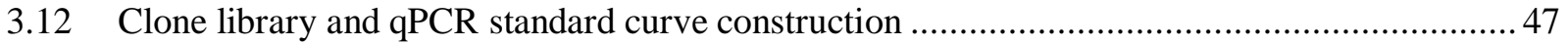

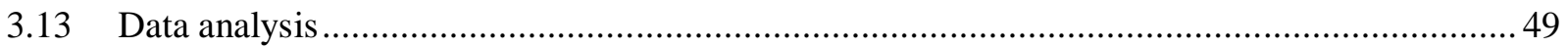

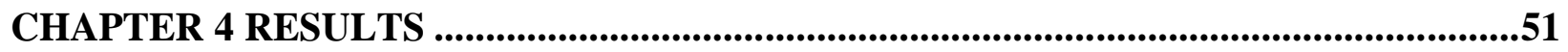

4.1 Analysis of chemical degradation and culture in seed reactor ............................................ 51

4.2 Evaluation of DNA extraction methods by PCR ...........................................................53

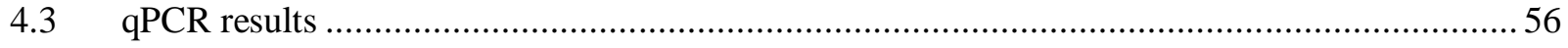

4.3.1 Specific objective 1: To test the hypothesis that increasing TCE concentrations influence

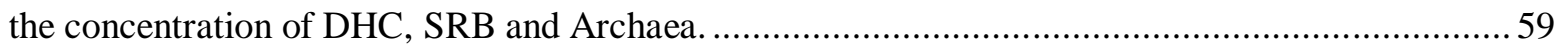

4.3.2 Specific objective 2: To test the hypothesis that the concentration of DHC, SRB and Archaea decrease with increasing distance from the source of reducing equivalents (i.e., food) ...... 64

4.3.3 Specific objective 3: To test the hypothesis that after bioaugmentation DHC, SRB and

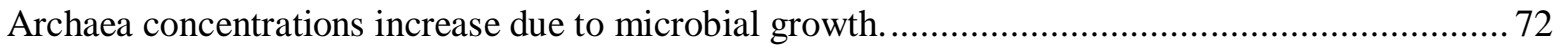

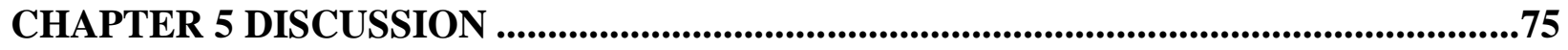

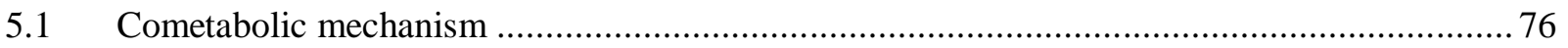

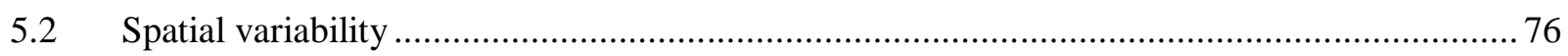

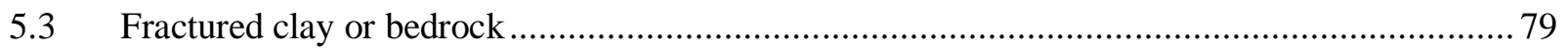

CHAPTER 6 CONCLUSIONS AND RECOMMENDED FUTURE RESEARCH .............81

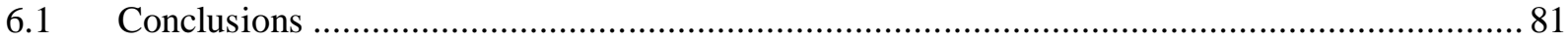

6.2 Recommendations for Future Research........................................................................... 82

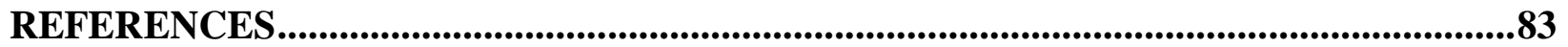

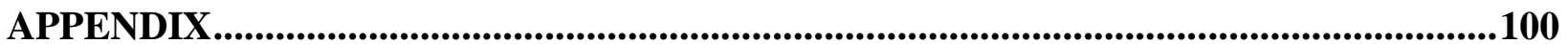




\section{List of Tables}

Table 1.1. States with the highest reported mass of trichloroethylene..................................1

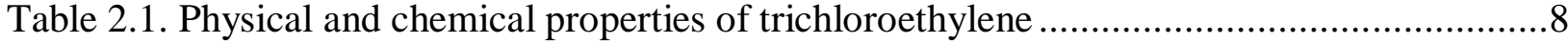

Table 2.2. Dechlorinating bacteria using TCE as an electron acceptor .................................14

Table 2.3. Typical redox half-reactions in anaerobic mixed culture with Gibbs free energy .......21

Table 2.4. DHC species documented to degrade chlorinated compounds .............................25

Table 3.1. Specific PCR/qPCR primers and probes ........................................................46

Table 4.1. DNA concentration, purity and amplification results of various DNA extraction

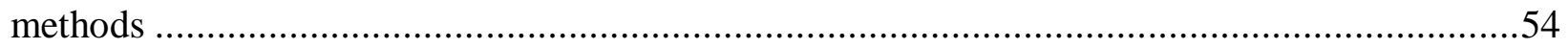

Table 4.2. Detection of DHC, SRB and Archaea in the type 1, 2 and 3 control reactors ............57

Table 4.3. Detection of the different orders of methanogens and total Archaea in the seed reactor

Table 4.4. Comparison of the average concentration of microorganisms in all areas after 7 days of incubation with different initial nutrient conditions and TCE concentrations

Table A1. Standard Curve for Sulfate Analysis ........................................................... 100

Table A2. Standard Curve for COD Analysis ............................................................ 101

Table A3. Detailed results for DHC, SRB and Archaea from qPCR analysis in various reactor

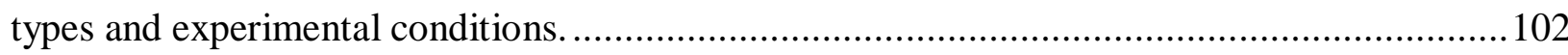

Table A4. Statistical tests for different reactors and microorganisms .................................108 


\section{List of figures}

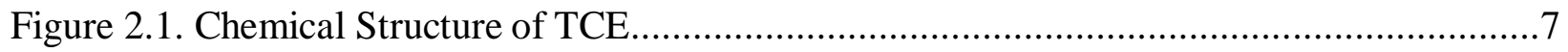

Figure 2.2. Sequential reductive dechlorination of trichloroethylene under anaerobic condition.13

Figure 2.3. Flow diagram of fermentation pathway. .18

Figure 2.4. Redox potential range for favorable dehalogenation, sulfate reduction and methanogenesis. .23

Figure 3.1. Schematic diagram and photograph of the type 1 incubation chambers (figure not to scale)..... .34

Figure 3.2. Schematic diagram and photographs of the type 2 incubation chambers .37

Figure 3.3. Schematic diagram and photograph of the type 3 incubation chambers 38

Figure 3.4. Schematic diagram of microscope slide (figure not to scale) A) diagram of the three areas sampled for qPCR analysis in type 1 and 2 reactors, and B) the capillary area sampled for qPCR analysis in the type 3 reactor. ...................................................................................... 40

Figure 3.5. Standard curve for DHC (A), SRB (B) and Archaea (C).......................................49

Figure 4.1. Sulfate concentrations in the seed reactors over the operational period .....................51 Figure 4.2. Comparison of culture characteristics of DAPI stained DHC in (A) The KB-1/VC- $\mathrm{H}_{2}$ culture from literature at 1000X magnification (Duhamel, 2004) and (B) from this study at 100X magnification observed with epifluorescence microscope with emission wavelength of 450$500 \mathrm{~nm}$. .53

Figure 4.3. FISH microscopic images of culture from seed reactor (A) DHC only at magnification of 100X and wavelength 500-570 nm (green) (B) all cells stained with DAPI in same field as A at 450-500 $\mathrm{nm}$ wavelength (blue).

Figure 4.4. Nanodrop DNA quantification of: (A) Type 1 reactor (B) Type 2 reactor and (C) Type 3 reactor for method 3 ii.

Figure 4.5. Detection of (A) bacterial 16S rRNA, (B) Dehalococcoides 16S rRNA, (C) dsrA genes of sulfate reducers and (D) Archaea 16S rRNA. .56 Figure 4.6. DHC, SRB and Archaea gene concentrations with varying TCE concentrations after 7 days in type 1 reactor (average and standard deviation of duplicates in all areas of reactor), type 2 reactor and type 3 reactor. 
Figure 4.7. Relationship between DHC, SRB and Archaea gene concentration with respect to different TCE concentration in different reactor types after 7 days; A: type 1 reactor (average of all areas), B: type 2 reactor (average of all areas) and C: type 3 reactor (average of all inside and outside capillary tube). Regression with * is statistically significant $(\mathrm{P}<0.05)$. 63 Figure 4.8. DHC (A), SRB (B) and Archaea (C) gene concentrations with distance from the agar plug and with different TCE concentrations after 7 days in Type 1 reactor (average and standard deviation of duplicates in three different areas of reactor). 66 Figure 4.9. Concentration of microorganisms with distance from the agar plug and with differing TCE concentrations after 7 days in the type 2 reactor. DHC (A), SRB (B) and Archaea (C).....68 Figure 4.10. Mean and standard deviations of the log gene concentrations of DHC (A), SRB (B) and Archaea (C) with different concentration of TCE after 7 days in the type 3 reactor. .70 Figure 4.11. Relationship between DHC gene concentration with respect to different TCE concentration in type 1 and type 2 reactors after 7 days; A: area 1, B: area 2. Regression with * is statistically significant $(\mathrm{P}<0.05)$. .71

Figure 4.12. Relationship between SRB gene concentration in three different areas with respect to different TCE concentration in type 1 reactor after 7 days. Regression with * is statistically significant $(\mathrm{P}<0.05)$. .71

Figure 4.13. Average and standard deviations of the log concentrations of DHC, SRB and Archaea gene copies $/ \mathrm{cm}^{2}$ in type 1 reactor (A), type 2 reactor (B) and type 3 reactor (C)over time .74

Figure 5.1. Possible location of microorganisms in type 1 reactor in which most microbes are grown near the food amendment competing for electron donors while they still grow farther from food amendment where TCE is present due to diffusion. ................................................78 Figure 5.2. Possible location of microorganisms in type 2 reactor in which TCE and food amendment are together and the microbes compete for them. At farther zone from food there is less and no growth of those microorganisms. 79 Figure 5.3. Fracture flow microorganisms in type 3 reactor in which TCE and food amendment are together but the space to migrate towards the food is very low. Microbes compete for the TCE located inside the clay as well as water, due to compact structure of clay particle those microbes try to find food. .80 
Figure A1. Standard curve for sulfate analysis ..................................................... 100

Figure A2. Standard curve for COD analysis .............................................................. 101

Figure A3. The log concentrations of DHC, SRB and archaea in type 1 and 2 reactor with all distances.

Figure A4. Relative abundance of dechlorinators maintained over the course of 7 days (type 3) reactor. Relative abundance was calculated from qPCR data with genus-specific primer sets.. 112 Figure A5. Archaea cells observed on confocal microscope after FISH stained with DAPI and Arch-647 Alexa probe from the seed reactor .112 Figure A6. Sulfate reucing bacteria observed on confocal microscope after FISH stained with DAPI and SRB-555 Alexa probe from the seed reactor

Figure A7. Co-distribution of DHC, sulfate reucing bacteria and Archaea in a sludge granual from the seed reactor observed by confocal microscope after FISH staining with DAPI and DHC fluorescein probe, SRB-555 Alexa probe and Arch-647 Alexa probe together (from right to left first is DAPI stained, second DHC, third SRB (upper row), Archaea and last one is all dyes together (lower row). 


\section{List of Abbreviations}

ATSDR

CERCLA

CLSM

COD

DAPI

DCE

DHC, Dhc

DNAPL

$d s r$

Eh

ESTCP

FISH

GAC

GC

$\mathrm{K}_{\mathrm{oc}}$

$\mathrm{K}_{\mathrm{ow}}$

MCL

NPL

NRC

PBS

PCE

PCR

qPCR

SRB

SERDP

TCE

$\mathrm{VC}$

VOC
Agency for Toxic Substances and Disease Registry

Comprehensive Environmental Response, Compensation, and Liability

Act

Confocal laser scanning microscope

chemical oxygen demand

Diamidino-2-phenylidole dihydrochloride

dichloroethylene

Dehalococcoides mccartyi

dense non-aqueous phase liquid

dissimilatory sulfate reduction

reduction potential

Environmental Security Technology Certification Program

Fluorescence in-situ hybridization

granular activated carbon

gas chromatography

soil-organic carbon partition coefficient

octanol-water partition coefficient

maximum contaminant level

National Priorities List

National Research Council

phosphate buffer saline solution

tetrachloroethene (or perchloroethene)

polymerase chain reaction

quantitative polymerase chain reaction

sulfate reducing bacteria

Strategic Environmental Research and Development Program

trichloroethylene

vinyl chloride

volatile organic compound 


\section{CHAPTER 1 INTRODUCTION}

\subsection{Background}

Trichloroethylene (TCE), CAS number 79-01-6, is a toxic volatile organic compound with excellent solvent properties. It has been extensively used as an industrial chemical. For example TCE has been used as a solvent, metal degreaser, dry cleaning agent, paintstripper, varnish, and in printing ink and industrial paint, among other industrial processes (WHO, 1984; ATSDR, 1997; Doherty, 2000; ATSDR, 2004; EPA consumer factsheet, 2006; NCPH, 2007). The production of TCE was 145 million $\mathrm{kg}$ in 1991 (EPA consumer factsheet, 2006). Deliberate and accidental discharge of TCE to water, groundwater and soil at hazardous waste sites has resulted in the spread of TCE in the environment (ATSDR, 2007). TCE is the most frequently detected groundwater contaminant in the United States (Fischer et al., 1987). NRC has reported that TCE only has been found in over 303 groundwater aquifers in the US (NRC, 2012). This compound was designated a priority pollutant by the U.S. Environmental Protection Agency (EPA) in 1976. As of 2007, TCE was detected at 1002 of 1689 National Priority List sites, making it one of the most commonly found contaminants at Superfund sites (ATSDR, 2007). According to Toxic Release Inventory, TCE released to water and land was over 131,995 kg from 1987 to 1993 (EPA consumer factsheet, 2006). The highest concentration was reported in 1982 and the largest releases occurred in Pennsylvania and Illinois (Table 1.1) (EPA consumer factsheet, 2006). The largest direct release to water occurred in West Virginia (Table 1.1) (EPA consumer factsheet, 2006).

Table 1.1. States with the highest reported mass of trichloroethylene releases to water and land, 1987 to 1993 (EPA, Consumer Factsheet)

\begin{tabular}{ccc}
\hline State* & Water $(\mathrm{kg})$ & Land $(\mathrm{kg})$ \\
\hline PA & 0 & 15172.7 \\
IL & 0 & 13930 \\
GA & 1697.3 & 7952.3 \\
TX & 0 & 9525.4 \\
MA & 0 & 9035.6 \\
WV & 12,822 & 0 \\
\hline
\end{tabular}

* State totals only include facilities with releases greater than $4536 \mathrm{~kg}$. 
Due to its high solubility in water (i.e., $1.366 \mathrm{~g} / \mathrm{L}$ at $25^{\circ} \mathrm{C}$ ) and environmental persistence, TCE contamination is of great concern. A small amount of TCE is sufficient to contaminate a large amount of groundwater (Aggarwal et al., 2006). Long estimated half lives of TCE (i.e., months to years) (ATSDR, 2004; HSDB, 2012) suggest TCE groundwater contamination will exist for long periods of time. Although extensive research has been completed over the past 3 decades concerning TCE remediation, contamination of groundwater resulting from use of the compound remains a significant problem (Schaumburg, 1990; Shen \& Wilson, 2007).

\subsection{Exposure and environmental effects of TCE}

Trichloroethylene contamination is of great concern because the compound is a known human carcinogen (USEPA, 2012). Exposure to high doses of TCE affects the kidneys and lungs and can result in central nervous system depression, liver changes and cardiac arrhythmias (ATSDR, 2004). The Safe Drinking Water Act Amendments of 1986 established regulation of TCE in drinking water with a maximum contamination level (MCL) of 5 parts per billion (ppb) (USEPA, 2004).

TCE is heavier than water and when released to the subsurface in waste water or groundwater, it sinks down in an aquifer in the form of DNAPL (dense non aqueous phase liquid), when high volumes of TCE are released at once. Remediation becomes difficult once DNAPLs migrate into groundwater aquifers. Fortunately, it has been observed from the previous studies that TCE can be degraded chemically and biologically under aerobic, anaerobic and cometabolic conditions (Castro \& Belser, 1990; Maymo-Gatell et al., 1997; McCarty, 1997; Glod et al., 1997; O'Loughlin \& Burris, 1999; Inguva \& Shreve, 1999; Arnold \& Roberts, 2000).

\subsection{Current treatment methods and issues}

Ex situ and in situ remediation efforts with various alternative treatment technologies for TCE have been reported for both remediation of soils and groundwater. Detailed in the next two sections are a high level summary of available ex situ and in situ remediation technologies. 


\subsubsection{Ex situ TCE remediation technologies}

Current water treatment plant operations such as coagulation, sedimentation, precipitation, softening, filtration and chlorination are ineffective at reducing the concentration of TCE to meet MCL standards set by the EPA. Although physical and chemical methods of soil and groundwater remediation, including soil venting, air sparging, air stripping, pump and treat techniques, granular activated carbon (GAC) adsorption have been considered as effective methods to reduce TCE levels in water (Russell et al., 1992; Sipkema et al., 1999); they may not be selected for a variety of reasons (e.g., cost, site complexity, remediation goals). The combination of air stripping and granular activated carbon adsorption of TCE from groundwater has become a popular and effective treatment technology due to lower construction costs of the air stripper and increased life expectancy of the adsorbent (Russell et al., 1992).

\subsubsection{In situ TCE remediation technologies}

Potential in situ TCE remediation technologies include, abiotic oxidation and reduction and biological degradation (e.g., in situ bioremediation). Increasing interest has been growing in biological processes because the indigenous microbes or introduced microbes in subsurface environments have the potential of converting TCE to harmless products (i.e., ethane, ethene, chlorine) rather than transferring them from one part of the environment to another (e.g., air stripping). Removal of TCE through bioremediation using microorganisms has become an established technology and is considered as a viable remediation option. Biological degradation of TCE has been demonstrated under aerobic and anaerobic conditions (Bouwer \& McCarty, 1983; Oldenhuis et al., 1989). When biodegration of TCE by indigenous microbes is not occurring, in situ application of microbes such as Dehalococcoides mccartyi sp. (recently renamed from Dehalococcoides ethenogenes sp.) (Loffler F.E. et al., 2012), in a remediation approach called bioaugmentation, results in distribution of microorganisms that have the capacity to degrade the chlorinated compounds to non toxic forms in the contaminated area of concern (Russell et al., 1992; Tyagi et al., 2011). Bioaugmentation has been most widely applied for microbial degradation of TCE to ethane and ethene under anaerobic reductive dechlorination 
conditions (Vogel et al., 1987) and is the focus of this research. The other major TCE biodegradation approach involves aerobic cometabolism.

The microorganisms associated with or involved in bioremediation of TCE in natural or engineered remediation approaches including methanogens (organisms within the domain Archaea), sulfate reducing bacteria (SRB) and Dehalococcoides sp. (DHC) are of particular interest in this study. In a mixed culture, such as that found in groundwater undergoing bioremediation, methanogens, SRB and DHC have to compete with one another for complete reduction of TCE when complex food substrates (e.g. whey powder, sodium lactate, vegetable oil) are provided in a remediation approach called biostimulation.

DNAPL migration in an aquifer depends on the DNAPL's chemical properties and the nature and geological structure within the aquifer. Remediation of chlorinated solvent sites are complex, controversial, expensive and time consuming (Stroo \& Ward, 2010) because of DNAPL's likelihood to migrate a large distance and create large dissolved phase groundwater plumes. In situ remediation has a wide range of challenges and problems. Previous research indicated the challenges encountered could include geology and hydrology or the location and distribution of chlorinated solvent contamination, as well as unique chemical and biochemical changes (Simkin \& Norris 2010). The major problems associated with the biostimulation and bioremediation studied in this reasearch are:

1. Cometabolic mechanism: Physical, chemical and biological processes that occur during remediation.

2. Spatial variability: The spatial variability in the distribution of microorganisms (DHC, SRB and Archaea) and limited amount of spatial information on the relationship between TCE and microorganisms with distance from food source.

3. Fractured clay or bedrock: The dispersion of TCE over large volume and diffusion of TCE in the inaccessible or low permeability zones such as fractured clay or bedrock where TCE can become trapped posing a difficulty for treatment.

The scope of this study was to determine the spatial distribution of selected microrganisms capable of TCE reductive dechlorination with respect to other microbes that compete for food 
sources (e.g., SRB and Archaea). Concentrations of Archaea were monitored and used as surrogate for methanogens. Several bench scale models of different aquifer types (e.g., sandy, clay fracture and silt aquifers) were used to evaluate the spatial distribution, survival, growth and competition of microorganisms associated with TCE degradation in situ with distance from codisposed food and TCE.

\subsection{Research objectives and hypotheses}

The overall objective of this study is to examine the spatial relationship between Dehalococcoides sp., Archaea and SRB with respect to TCE and reducing equivalents (e.g., food) in different types of aquifers contaminated with TCE.

The hypotheses that were tested include:

1. Increasing TCE concentrations influence the concentration and distribution of DHC, SRB and Archaea with distance from the TCE

2. The concentrations of DHC, SRB and Archaea decrease in concentration with increasing distance from the source of reducing equivalents (i.e.,food),

3. After bioaugmentation DHC, SRB and Archaea concentrations increase due to microbial growth.

Studies were designed to test the hypotheses presented above and experiments were conducted to (1) quantify the abundance of DHC, SRB, and Archaea by quantitative polymerase chain reaction (qPCR) and fluorescent in situ hybridization (FISH); (2) observe the spatial relationship between the selected microorganisms with distance from the substrate (food); and (3) determine the concentration of these microbes at low and high concentration of TCE and sulfate. Three types of reactors, each modeling different hydrogeological conditions were constructed and used to address the hypotheses presented above.

\subsection{Significance of the research}


The results of this study can help in the design of remediation systems and the timing of in situ bioaugmentation of contaminated aquifers. Specifically, understanding the spatial relationship between Dehalococcoides sp. and various microorganisms that compete for bioremediation substrates supplied to stimulate biodegradation of this toxic compound will aid environmental engineers during the design of remediation systems. It can be helpful to understand when and where to bioaugment an aquifer undergoing bioremediation of TCE with Dehalococcodies sp. It can contribute to the improvement of engineered and natural processes applied to in situ bioremediation of TCE contaminated sites (sandy, clay and silt types of aquifer) and to improve the implementation of techniques such as biostimulationand bioaugmentation.

The research conducted to address the hypothesis presented in section 1.4 is presented in the following chapters. Specifically, a general introduction to TCE as an environmental contaminant; available physical, chemical and biological treatment methods; redox potential with electron donor and electron acceptor; selected microorganisms in dechlorination process; and molecular screening techniques; is presented in Chapter 2. The materials and methods used to develop experiments addressing the hypothesis are presented in Chapter 3. The results of the experiments addressing the hypotheses and a discussion of the results in the context of the current literature are presented in Chapter 4 and Chapter 5. Included in Chapter 6 is the conclusion made from the study and the recommendations for future work. Finally, a tabulation of additional data from the studies is presented in the Appendix. 


\section{CHAPTER 2 LITERATURE REVIEW}

\subsection{Trichloroethylene production, use, properties and treatment}

Trichloroethylene is a chlorinated aliphatic hydrocarbon with the chemical formula $\mathrm{C}_{2} \mathrm{HCl}_{3}$ (Figure 2.1). It is a non flammable colorless liquid with sweet odor (ATSDR, 1997). The toxic solvent has been widelyused in metal degreasing, solvent extraction processes, textile cleaning and as a carrier solvent (WHO, 1984; ATSDR, 1997). Trichloroethylene is also used in chemical production as intermediate, as a refrigerant and in some consumer products like typewriter correction fluid, paint removers, adhesives, spot removers and rug-cleaning fluids (ATSDR, 1997). In the past, it was used as a general anesthetic (ATSDR, 1997). The improper use and disposal in the past has contributed widespread distribution of this toxic and carcinogenic compound in the subsurface as well as soil and groundwater contamination (ATSDR, 1997; Moran et al., 2007). According to the 2007 report by the Agency for Toxic Substances and Disease Registry, TCE contamination was found in at least 1,022 of 1,689 National Priorities List (NPL) sites. The report also estimated from various studies that between 9 and 34 percent of the drinking water supply sources in US may have TCE contamination (ATSDR, 2007).

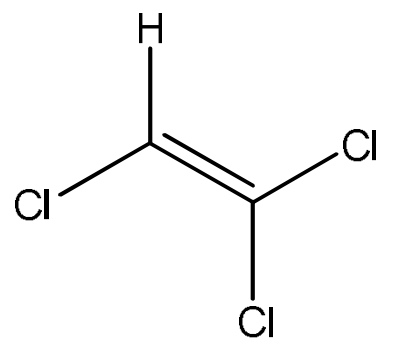

Figure 2.1. Chemical Structure of TCE

TCE contamination in the environment is of great concern because it is a human carcinogen (Lash et al., 2000; EPA, 2012). Exposure to high doses of TCE affects kidneys and lungs (ATSDR, 2004) and can result in central nervous system depression, liver changes and cardiac arrhythmias (ATSDR, 1997). Safe Drinking Water Act Amendments of 1986 stipulate the maximum contamination level (MCL) of TCE in drinking water is 5 parts per billion ppb (USEPA, 2004). 


\subsubsection{Physical and chemical properties:}

Pure TCE has high aqueous solubility and higher density than water (Table 2.1). Therefore, when released into the subsurface environment in large quantities, it migrates downward in an aquifer due to gravitational force as a DNAPL. Water insoluble compounds tend to partition into another phase for example, volatilizing or adsorbing to organic material. The octanol-water partition coefficient $\left(\mathrm{K}_{\mathrm{ow}}\right)$ is the ratio of a chemical's concentration in the octanol phase to its concentration in the aqueous phase. Log $\mathrm{K}_{\mathrm{ow}}$ value for TCE is less than 3 (Table 2.1) suggesting this compound does not sorb strongly to the soil (McCarty, 2010). Because of its low solubility and high affinity for soil organic matter, TCE tends to be retained in the soil and slowly released into groundwater (Burris et al., 1995; Mohammad \& Kibbey, 2005). By means of dissolution, advection and dispersion, it moves between soil and water and can create large groundwater plumes (Russell et al., 1992). TCE is made up of three chlorine atoms with carbon-carbon double bond, so it is a highly oxidized compound and resists further oxidation (Russell et al., 1992).

Table 2.1. Physical and chemical properties of trichloroethylene

\begin{tabular}{lll}
\hline $\begin{array}{l}\text { Physical or chemical } \\
\text { parameter }\end{array}$ & Physical or chemical property value & References \\
\hline Other Names & $\begin{array}{l}\text { Acetylene trichloride, ethinyltrichloride, } \\
\text { ethylene trichloride, 1-chloro-2,2- } \\
\text { dichloroethylene,TCE,1,1-dichloro-2- } \\
\text { chloroethylene, 1,1,2-trichloroethylene, }\end{array}$ & \\
& Trichloroethene & \\
& 131.40 & Russell et al., \\
Molecular weight & & $1992 ;$ ATSDR, \\
& Chloroform like, sweet & 1997 \\
Odor & Clear, colorless & ATSDR, 1997 \\
Color & Liquid at room temperature & ATSDR, 1997 \\
Physical state & $1.465 \mathrm{~g} /$ ml & ATSDR, 1997 \\
Density at $20{ }^{\circ} \mathrm{C}$ & & Russell et al., \\
& & $1992 ;$ ATSDR, \\
& & 1997
\end{tabular}




\begin{tabular}{|c|c|c|}
\hline Boiling Point & $86.7^{\circ} \mathrm{C}$ & $\begin{array}{l}\text { Russell et al., } \\
\text { 1992; ATSDR, } \\
1997\end{array}$ \\
\hline Water Solubility & at $25^{\circ} \mathrm{C}: 1.366 \mathrm{~g} / \mathrm{L}$ & ATSDR, 1997 \\
\hline Partition coefficient: $\log \mathrm{K}_{\mathrm{ow}}$ & 2.42 & Russell et al., \\
\hline $\log K_{o c}$ & $2.03-2.66$ & $\begin{array}{c}\text { 1992; ATSDR, } \\
1997\end{array}$ \\
\hline Henry's Law Constant & $0.011 \mathrm{~atm}-\mathrm{m}^{3} / \mathrm{mol} @ 25^{\circ} \mathrm{C}$ & ATSDR, 1997 \\
\hline
\end{tabular}

\subsection{Physical and chemical TCE treatment technologies}

For TCE contaminated soil and groundwater remediation, there are two ways for TCE removal in the environment: abiotic and biotic. In abiotic methods TCE is reduced or oxidized through chemical and physical means while the biotic removal methods emphasize the use of microorganisms in contaminated soil and water. Chemical, physical and biological processes under aerobic, anaerobic and cometabolic conditions have been shown to degrade TCE (Castro \& Belser, 1990; Maymo-Gatell et al., 1997; McCarty, 1997; Glod et al., 1997; O'Loughlin et al., 1999; Inguva \& Shreve, 1999; Arnold \& Roberts, 2000).

Physical and chemical methods of treatment and remediation of surface and subsurface water include soil venting, air sparging, air stripping, pump and treat techniques, and granular activated carbon (GAC) adsorption. They have been considered as the effective methods to reduce TCE levels in water ((Russell et al., 1992; Sipkema et al., 1999) but they may not be selected for a variety of reasons. For example, air stripping needs large volumes of air, shifts the contaminant to another medium (atmosphere) and requires large environmental remediation costs (Russell et al., 1992); granular activated carbon (GAC) do not fully remove the contaminant volume or toxicity (Nelson \& Bourquin, 1990; Russell et al., 1992) and soil venting technology might cause waste mixture to the soil surface and might be need treatment of off-gases to maintain air quality standards (Russell et al., 1992). The combination of air stripping and granular activated carbon adsorption has become popular and effective treatment technologies due to lower construction costs of the air stripper and increase life expectancy of the adsorbent (Russell et al., 1992). 
Another method of TCE remediation in groundwater is chemical reductive dechlorination in which a chlorinated hydrocarbon is reduced by a reactive compound, such as metal sulfides, that can degrade TCE (Butler \& Hayes, 1999; Lee \& Batchelor, 2003). In this case, an anaerobic environment may be created and the substrate addition may indirectly cause and sustain abiotic reductive dechlorination.

\subsection{Biological TCE treatment}

Biological remediation of TCE via in situ application of microorganisms (i.e., bioaugmentation) or encouragement of the growth of the native TCE degrading microorganisms that have the capacity to degrade the chlorinated compounds to non toxic forms is a feasible, low cost alternative to physical and abiotic methods (Russell et al., 1992; Tyagi et al., 2011).

Bioremediation is an attractive technology to physical and chemical remediation technologies because certain microorganisms (i.e., Dehalococcoides mccartyi sp) (Loffler F.E. et al., 2012) can completely degrade TCE to $\mathrm{CO}_{2}$, water, and chlorine instead of simply a transfer from one medium to another (Russell et al., 1992). Enzymes and cofactors produced during biological degradation enhance the reaction rate. Different types of naturally occurring bacteria enzymatically reduce chlorine atoms to chloride and nontoxic metabolites (Field \& SierraAlvarez, 2004). The most relevant microbial degradation processes occurring during bioremediation of TCE include (1) aerobic oxidation, (2) direct anaerobic reductive dechlorination and (3) reductive cometabolism. There are two reactions in the anaerobic reductive bioremediation process: direct anaerobic reductive dechlorination and cometabolic anaerobic reductive dechlorination.

Cometabolism is a process in which the chlorinated compound is reduced by a non-specific enzyme or co factor produced during microbial metabolism of another compound (primary substrate) in an anaerobic environment but does not yield any energy or growth benefit for the microbe mediating the reaction (USEPA, 2000). A special type of co-metabolism involves the oxidation of chlorinated solvents by various oxygenase enzymes, which is known as cooxidation (Alvarez-Cohen \& Speitel, 2001). Under anaerobic conditions, a common form of co- 
metabolism is the reaction of reduced enzyme cofactors with chlorinated solvents, resulting in their reductive dehalogenation (Krone et al., 1989; Gantzer \& Wackett, 1991). These organisms and their biological degradation mechanisms are discussed in the sections below. Anaerobic reductive dechlorination and/or reductive cometabolism are the methods that were ultilized in these studies.

\subsubsection{Aerobic oxidation of TCE}

Through aerobic oxidation, highly chlorinated VOCs like carbon tetrachloride, penta- and hexachloroethane, and PCE are not bio-oxidizable (Nelson et al., 1988; Wackett \& Gibson, 1988; Tsien et al., 1989; Vannelli et al., 1990; Field \& Sierra-Alvarez, 2004).With increasing number of chlorine atoms or carbon-chlorine bonds, the microbial degradation rate of chlorinated VOC decreases. Highly chlorinated species such as tetrachloroethylene (PCE) degrade anaerobically more rapidly, whereas less chlorinated species such as dichloroethylene (DCE) are more rapidly degraded by aerobic processes and may accumulated in anaerobic environments (Lee et al., 1998).

Aerobic co-oxidation is a widespread process with great importance for bioremediation. Microorganisms (e.g., Pseudomonas sp, Methylococcus sp) use chlorinated solvents as electron donors and carbon sources to support growth, or they cometabolically transform them while degrading other substrates, a process known as co-oxidation (Field \& Sierra-Alvarez, 2004). TCE or higher chlorinated ethenes can be degraded by aerobic co-oxidation mechanisms (Wackett et al., 1994; Alvarez-Cohen \& Speitel, 2001). Aerobic degradation of TCE, DCEs and vinyl chloride (VC) involves oxygenase enzymes (Nelson et al., 1986; Field \& Sierra-Alvarez, 2004). These enzymes are present in a large number of microbial species such as toluene, methane, or ammonia oxidizing bacteria (Nelson et al., 1988; Wackett \& Gibson, 1988; Tsien et al., 1989; Vannelli et al., 1990; Russell et al., 1992; Alvarez-Cohen \& Speitel, 2001); (Nelson et al., 1986; Coleman et al., 2002). Suitable primary substrates for energy and/or carbon sources for these microorganisms include methane, ethane, ethene, propane, propene, ammonia, toluene and phenol (Wilson \& Wilson, 1985; Nelson et al., 1986; Folsom et al., 1990; Vannelli et al., 1990;

Semprini, 1997; Van Agteren et al., 1998; Alvarez-Cohen \& Speitel, 2001; Arp et al., 2001). In 
this case, there is no formation of vinyl chloride and complete mineralization takes place (Russell et al., 1992). The most studied organism capable of TCE co-oxidation is the methane co-oxidising bacteria Methylosinus trichosporium that produce the enzyme methane monooxygenase (MMO) (Russell et al., 1992). Methanotrophs, under aerobic conditions utilize methane $\left(\mathrm{CH}_{4}\right)$ as their primary substrate and cometabolically biodegrade chlorinated solvents. Methanotrophs are generally most active at the interface between aerobic and anaerobic zones (Lorah \& Voytek, 2004). The methane produced under anaerobic conditions is utilized by methanotrophs to oxidize TCE in aerobic zones and form epoxides that are chemically unstable and can be transformed rapidly by abiotic hydrolysis to nonvolatile products, including aldehydes and acids (Lorah \& Voytek, 2004).

\subsubsection{Anaerobic reductive dechlorination}

Anaerobic reductive dechlorination is one of the most common and most efficient bioremediation approaches for TCE. Ground water can be limited in oxygen, so biological treatment of TCE by reductive dehalogenation can be a very effective biological process for degradation of highly chlorinated compounds in environments that are not susceptible to oxidative transformation.

Microorganisms have demonstrated degradation of TCE by sequential replacement of chlorine atoms of TCE via reductive dehalogenation under anaerobic conditions (Freedman \& Gossett, 1989; DiStefano et al., 1991; Mohn \& Tiedje, 1992; Maymo-Gatell et al., 1997; McCarty, 1997; Rosner et al., 1997; Kengen et al., 1999). Reductive dehalogenation is the mechanism yielding ethene and chloride in anaerobic environments where organic electron donors or hydrogen are present. In the mechanism, one electron and one hydrogen atom are transferred onto the carbon atom and $\mathrm{HCl}$ is released (Holliger et al., 2004). Large chlorinated solvents such as PCE can be dehalogenated to less chlorinated forms by microorganisms under anaerobic conditions by sequential replacement of chlorine atoms by hydrogen atoms as shown in Figure 2.2 (Freedman

\& Gossett, 1989; DiStefano et al., 1991; Vogel et al., 1994; McCarty, 1997; Maymo-Gatell et al., 1997). 


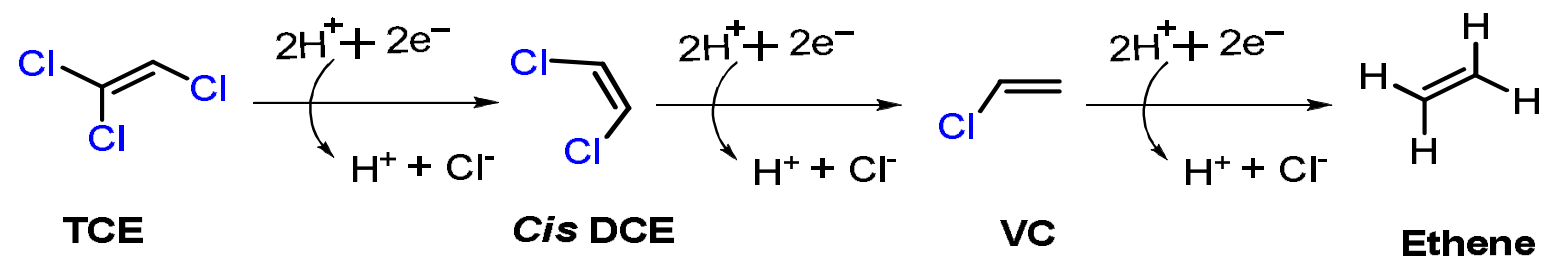

Figure 2.2. Sequential reductive dechlorination of trichloroethylene under anaerobic condition

Microorganisms from several phylogenetic groups (Table 2.2) are able to reduce PCE to TCE, and TCE to cis-1,2-dichloroethene (cis-DCE) (Neumann et al., 1995; Schumacher et al., 1997; Sung et al., 2003) which reduces to VC and finally VC to non toxic ethane (Freedman \& Gossett, 1989; Maymo-Gatell et al., 1997; McCarty, 1997; Kengen et al., 1999; Morrill et al., 2005) (Figure 2.2). Dechlorination of TCE to cis-DCE is a relatively fast process but is significantly slower as number of chlorine decreases (step from VC to ethene) (Maymó-Gatell et al., 1999; Middeldorp et al., 1999). The intermediate product VC is more toxic than TCE (Pill et al., 1991). VC is a known human carcinogen (Russell et al., 1992).

Different phylogenetically diverse microorganisms use TCE as a terminal electron acceptor and gain energy from reductive dechlorination (Freedman \& Gossett, 1989; Holliger et al., 1993; Sharma \& McCarty, 1996; McCarty, 1997) (Table 2.2), including dehalorespiring (Schumacher et al., 1997; Maymó-Gatell et al., 1995; Scholz-Muramatsu et al., 1995; Sun et al., 2002; Grostern \& Edwards, 2006; Grostern et al., 2009), sulfate-reducing bacteria (Wrenn \& Rittmann, 1996) and methanogens (Vogel et al., 1987). However, only the members of the genus Dehalococcoides mccartyi sp. (recently renamed from Dehalococcoides ethenogenes (Loffler F.E. et al., 2012) is able to degrade toxic chlorinated compound to the environmentally acceptable final products of chloride and ethane or ethene (Table 2.2) through sequential reductive dechlorination in presence of appropriate electron donors (e.g., lactate), and nutrients under anaerobic conditions (Sung et al., ; Maymo-Gatell et al., 1997; Richardson et al., 2002; Cupples et al., 2003; He et al., 2003a, Freedman \& Gossett, 1989; Holliger et al., 1993). 
Table 2.2. Dechlorinating bacteria using TCE as an electron acceptor

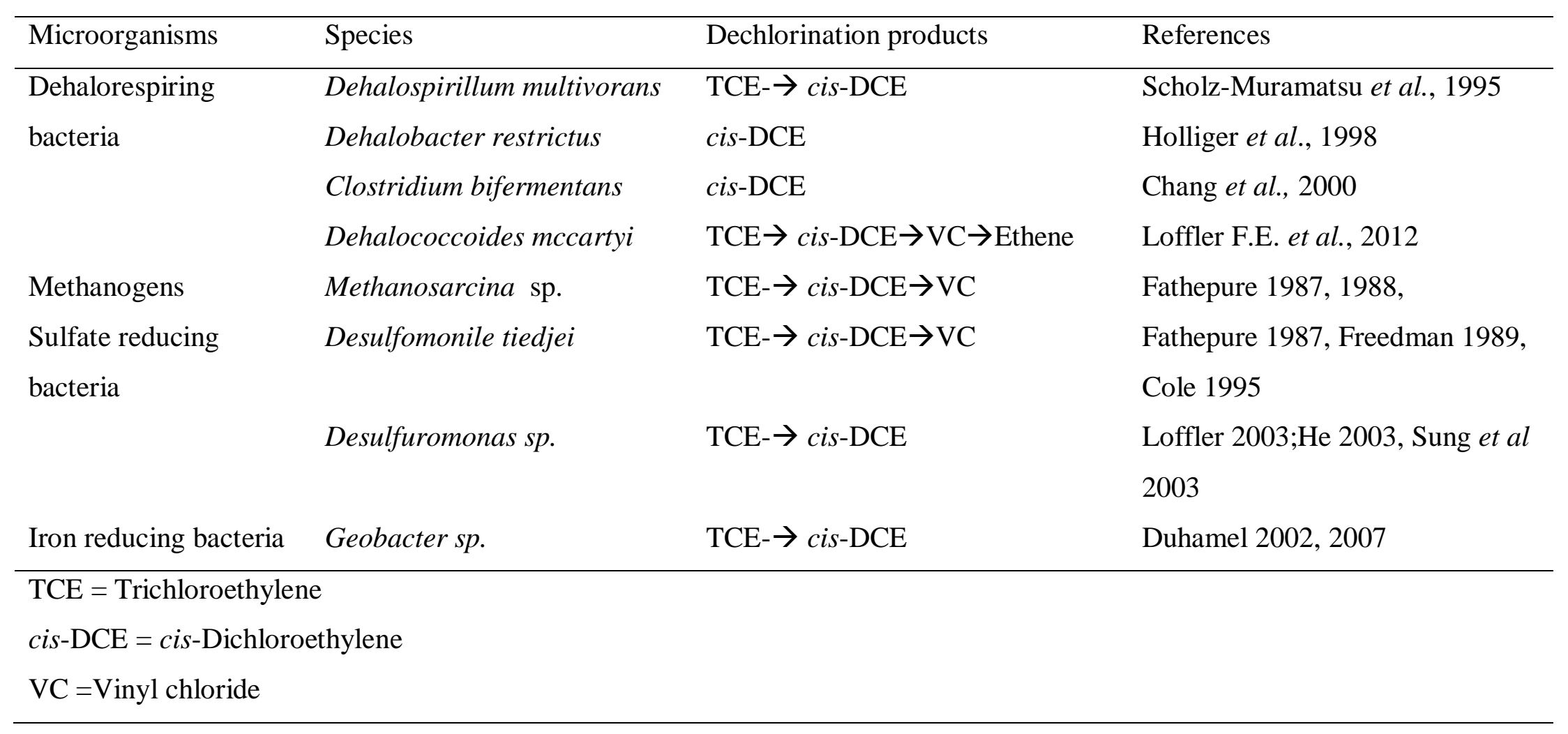


In dehalorespiration, TCE serves as terminal electron acceptor while hydrogen supplied by fermentation of organic substrates serves as the direct electron donor (DiStefano et al., 1992).

\subsubsection{Reductive co-metabolism}

Microorganisms that do not gain energy from degradation of contaminants; facilitate a process called "cometabolism" (Alvarez Cohen 1991). They cometabolically transform chlorinated compounds while they are degrading non-halogenated primary substrates. Slow reductive dechlorination of chloroethenes and other haloorganic compounds is a cometabolic process facilitated by hydrocarbon-degrading bacteria (Alvarez Cohen 1991; Ensley 1991; Semprini 1997). The last transformation step from VC to ethene occurs slowly in a cometabolic process (Holliger et al., 2006). Cometabolic reductive dechlorination can occur with the help of cofactors, such as vitamin B12 and coenzyme that catalyzes the replacement of chlorines by hydrogen atoms (Fathepure \& Boyd, 1988). Current literature suggests that anaerobic reductive dechlorination is carried out by only a few classifications of microorganisms, including certain species of methanogens, sulfate-reducing bacteria (Bagley DM, Gossett JM. 1989; Chapelle et al., 1993; Bradley \& Chapelle, 1996) and dehalorespiring bacteria (Maymo-Gatell et al., 1997). These types of bacteria do not precede energy-yielding reaction but are co-metabolic (Lee et al., 1998). The reactive co-enzymes are typically found more commonly in methanogens (Fathepure \& Boyd, 1988; Maymo-Gatell et al., 1997; Yager et al., 1997).

Since TCE is not a growth substrate, it can be degraded via co-metabolism in which an

oxygenase, the corresponding enzyme for initiating growth substrate oxidation, fortuitously transforms TCE (Folsom et al., 1990; Arcangeli \& Arvin, 1997). Methanogens and sulfate reducing bacteria typically have slower TCE degradation rates than DHC (Bagley DM, Gossett JM. 1989).

Reductive cometabolism under anaerobic conditions has been observed for groundwater contaminants such as chloroform, carbon tetrachloride and all chlorinated ethanes, mainly by methanogenic and acetogenic mixed cultures, and by sulfate and iron reducers (Egli et al., 1987; Egli et al., 1988; Chen et al., 1996). Slow conversion of TCE by methanogens and acetogenes 
with $\mathrm{H}_{2}$ as the electron donor has been observed (Fathepure et al., 1987; Egli et al., 1988; Fathepure \& Boyd, 1988). Fathepure \& Boyd, 1988 suggested in his study that the dechlorination of chloroethylenes in situ could be enhanced simply by stimulating methanogenesis. The reductive dechlorination of TCE to cis- DCE by sulfate reducing bacteria has been reported by Bagley and Gossett. Dechlorinating capability and rate of a sulfate-reducing enrichment is slower than in mixed methanogenic enrichments (Bagley DM, Gossett JM. 1989). Chapelle et al., 1996 in the site study found that reductive dehalogenation was mostly favored in methanogenic and sulfate-reducing zones. Fathepure and Boyd (1987) suggested that PCE dechlorination by Methanosarcina sp. is a cometabolic process.

In an anaerobic environment, Dehalococcoides coexist with sulfate reducing bacteria, acetogens and methanogens, who all compete for available hydrogen. However these other microorganisms might also assist DHC directly by providing necessary micronutrients to dechlorinators during the dechlorination process (Duhamel et al 2007, Yager1997). The hydrogen and acetate produced from the transformation of electron-donating substrates during fermentation have been shown to be used by Dehalococcoides (Yang \& McCarty, 1998; Duhamel \& Edwards, 2007). At lower concentrations of the hydrogen, for anaerobic reductive dechlorination to occur, dechlorinators must successfully compete against other microorganisms that also utilize hydrogen (Yang \& McCarty, 1998). The extent of dechlorination has been shown to increase as the amount of primary carbon substrate increases (Fathepure \& Boyd 1988). Without an electron donor, reductive dechlorination cannot be sustained (Fathepure \& Boyd, 1988; Freedman \& Gossett, 1989). VC, the toxic intermediate, is cometabolically reduced by Dehalococcoides ethenogenes (Maymó-Gatell et al., 2001).

\subsection{Electron acceptor/electron donor and redox potential}

Hydrogen produced by fermentation is often the primary electron donor for dehalogenation (DiStefano et al., 1992; Smatlak et al., 1996; Fennell et al., 1997). Dehalogenating bacteria compete for hydrogen with other hydrogen-consuming microorganisms in natural aquatic sediment systems such as Fe(III)-reducing, $\mathrm{Mn}(\mathrm{II})$-reducing, nitrate-reducing, sulfate-reducing, and methanogenic bacteria during anaerobic condition (Chapelle et al., 1993; Smatlak et al., 
1996; Yang \& McCarty, 1998). Methanogens coexist with sulfate reducing bacteria in most environmental systems depending on rate of hydrogen production and availability of sulfate (Lovley et al., 1982). Although fermentation products such as acetate have been identified as direct electron donors, the microorganisms require hydrogen as the electron donor for complete dechlorination (Maymo-Gatell et al., 1997). So, hydrogen may be the most important electron donor for anaerobic dechlorination. The hydrogen and acetate produced from the transformation of electron-donating substrates during fermentation are used by Dehalococcoides for dechlorination (Yang \& McCarty, 1998; Duhamel \& Edwards, 2007).

Lactate in the form of sodium lactate is commonly used as a substrate for anaerobic dechlorination in field bioremediation application and was utilized in this study. Sodium lactate disassociates to form lactate and a sodium ion as follows:
$\mathrm{C}_{3} \mathrm{H}_{5} \mathrm{NaO}_{3} \rightarrow \mathrm{C}_{3} \mathrm{H}_{5} \mathrm{O}_{3}^{-}+\mathrm{Na}^{+}$
Equation 1

The lactate molecule can then be fermented by more than one process shown in Figure 2.3. 


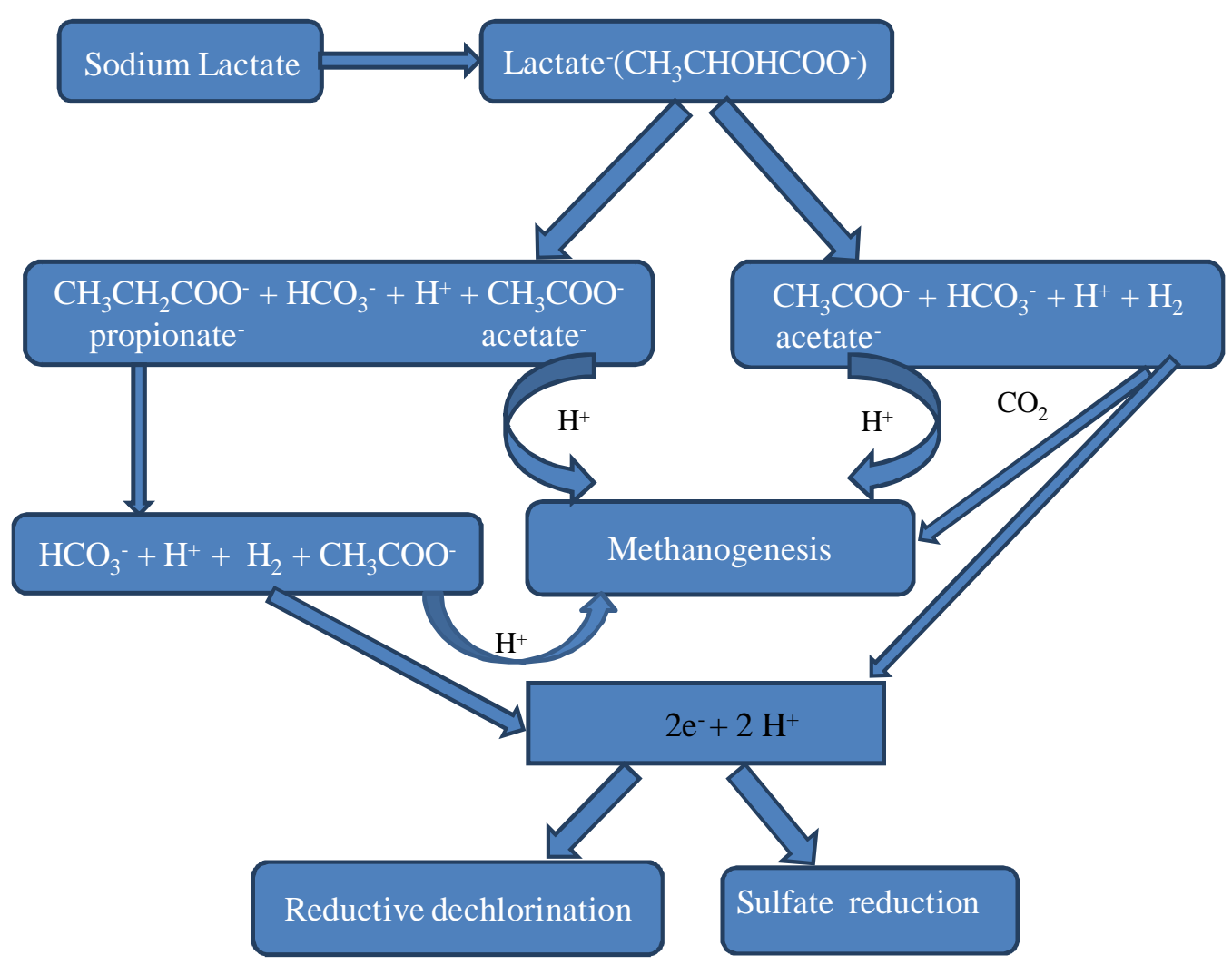

Figure 2.3. Flow diagram of fermentation pathway

The following reactions show the steps for the production of hydrogen through microbial degradation of lactate and its associated fermentation products (Macbeth et al., 2004). The first step of the lactate degradation pathway is shown in Equation 2.

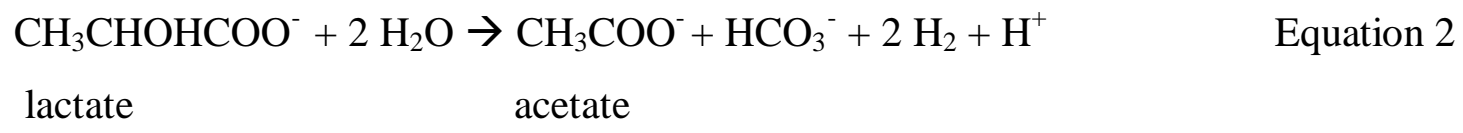

Bicarbonate ion and a hydrogen ion may form carbon dioxide and water:

$\mathrm{HCO}_{3}^{-}+\mathrm{H}^{+} \rightarrow \mathrm{CO}_{2}^{-}+\mathrm{H}_{2} \mathrm{O} \quad$ Equation 3

Combining equations (1) and (2), the fermentation of lactate to acetate and hydrogen can be written as the following balanced reaction:

$\mathrm{CH}_{3} \mathrm{CHOHCOO}^{-}+2 \mathrm{H}_{2} \mathrm{O} \rightarrow \mathrm{CH}_{3} \mathrm{COO}^{-}+\mathrm{CO}_{2}^{-}+\mathrm{H}_{2} \mathrm{O}+2 \mathrm{H}_{2} \quad$ Equation 4 
The acetate produced in this reaction may be used directly as an electron donor for reduction reactions or may be further fermented to produce hydrogen.

In the propionate pathway (second step), lactate degrades to propionate $\left(\mathrm{CH}_{3} \mathrm{CH}_{2} \mathrm{COO}^{-}\right)$, acetate, and carbonate (Equation 5). Further, propionate degrades to acetate (Equation 6) and the acetate is further oxidized to carbonate and hydrogen under extremely reducing conditions (Equation 7) (Macbeth et al., 2004)

$\begin{array}{lll}\mathrm{CH}_{3} \mathrm{CHOHCOO}^{-} \rightarrow & \mathrm{CH}_{3} \mathrm{CH}_{2} \mathrm{COO}^{-}+\mathrm{CH}_{3} \mathrm{COO}^{-}+\mathrm{HCO}_{3}^{-}+\mathrm{H}^{+} & \text {Equation } 5 \\ \text { (lactate) } & \text { (propionate) } & \end{array}$

$\mathrm{CH}_{3} \mathrm{CH}_{2} \mathrm{COO}^{-}+3 \mathrm{H}_{2} \mathrm{O} \rightarrow \mathrm{CH}_{3} \mathrm{COO}^{-}+\mathrm{HCO}_{3}^{-}+3 \mathrm{H}_{2}+\mathrm{H}^{+} \quad$ Equation 6

$\begin{array}{ll}\mathrm{CH}_{3} \mathrm{COO}^{-}+4 \mathrm{H}_{2} \mathrm{O} \rightarrow 2 \mathrm{HCO}_{3}+4 \mathrm{H}_{2}+\mathrm{H}^{+} & \text {Equation } 7\end{array}$

Hydrogen produced by fermentative organisms from Equations 2, 4, 6, and 7 is rapidly consumed by other bacteria, including SRB, methanogens, and dechlorinating microorganisms. The overall reactions for dehalogenation, sulfate reduction and methanogens are in Table 2.3. For example, in an anaerobic reductive dechlorination, molecular hydrogen $\left(\mathrm{H}_{2}\right)$ disassociates in the following half reaction:
$\mathrm{H}_{2} \rightarrow 2 \mathrm{H}^{+}+2 \mathrm{e}^{-}$
Equation 8

Then, TCE is reduced by the substitution of a chloride ion with a hydrogen ion and the transfer of two electrons:

$2 \mathrm{e}^{-}+2 \mathrm{H}^{+}+\mathrm{C}_{2} \mathrm{Cl}_{3} \rightarrow \mathrm{C}_{2} \mathrm{HCl}_{2}+\mathrm{H}^{+}+\mathrm{Cl}^{-} \quad$ Equation 9

The dechlorination of TCE using hydrogen as the electron donor can be written as follows:

$\mathrm{H}_{2}+\mathrm{C}_{2} \mathrm{Cl}_{3} \rightarrow \mathrm{C}_{2} \mathrm{HCl}_{2}+\mathrm{H}^{+}+\mathrm{Cl}^{-} \quad$ Equation 10

In these reactions, two electrons are transferred with molecular hydrogen $\left(\mathrm{H}_{2}\right)$ as the electron donor (which is oxidized) and the chlorinated molecule as the electron acceptor (which is reduced). 
In anaerobic environments that have a low redox potential; anaerobes including fermentative bacteria, acetogenic bacteria, SRB, dehalogenating bacteria and methanogens that grow on lactate, propionate and butyrate, compete for the available common substrates $\left(\mathrm{H}_{2}\right)$. Typical redox half-reactions in an anaerobic mixed culture are listed in Table 2.3 with theoretical stoichiometric reactions describing the complete biodecomposition of compounds under methanogenic conditions. 
Table 2.3. Typical redox half-reactions in anaerobic mixed culture with Gibbs free energy (Thauer et al., 1977; Dolfing \& Janssen, 1994 and Zeikus, 1977)

\begin{tabular}{|c|c|}
\hline Equation & $\Delta \mathbf{G ~ K J / R e a c t i o n}$ \\
\hline \multicolumn{2}{|l|}{ Acetogenic reactions } \\
\hline $\mathrm{CH}_{3} \mathrm{CHOHCOO}^{-}+2 \mathrm{H}_{2} \mathrm{O} \rightarrow \mathrm{CH}_{3} \mathrm{COO}^{-}+\mathrm{HCO}_{3}^{-}+2 \mathrm{H}_{2}+\mathrm{H}^{+}$ & -4.2 \\
\hline $\mathrm{CH}_{3} \mathrm{CHOHCOO}^{-} \rightarrow \mathrm{CH}_{3} \mathrm{CH}_{2} \mathrm{COO}^{-}+\mathrm{CH}_{3} \mathrm{COO}^{-}+\mathrm{HCO}_{3}^{-}+\mathrm{H}^{+}$ & -992.2 \\
\hline $\mathrm{CH}_{3} \mathrm{CH}_{2} \mathrm{COO}^{-}+3 \mathrm{H}_{2} \mathrm{O} \rightarrow \mathrm{CH}_{3} \mathrm{COO}^{-}+\mathrm{HCO}_{3}^{-}+3 \mathrm{H}_{2}+\mathrm{H}^{+}$ & +76.1 \\
\hline $\mathrm{CH}_{3} \mathrm{CH}_{2} \mathrm{CH}_{2} \mathrm{COO}^{-}+2 \mathrm{H}_{2} \mathrm{O} \rightarrow 2 \mathrm{CH}_{3} \mathrm{COO}^{-}+2 \mathrm{H}_{2}+\mathrm{H}^{+}$ & +48.1 \\
\hline $\mathrm{CH}_{3} \mathrm{COO}^{-}+4 \mathrm{H}_{2} \mathrm{O} \rightarrow 2 \mathrm{HCO}_{3}^{-}+4 \mathrm{H}_{2}+\mathrm{H}^{+}$ & +104.6 \\
\hline \multicolumn{2}{|l|}{ Methanogenic reactions } \\
\hline $\mathrm{CH}_{3} \mathrm{COO}^{-}+\mathrm{H}_{2} \mathrm{O} \rightarrow \mathrm{HCO}_{3}^{-}+\mathrm{CH}_{4}$ & -31 \\
\hline $\mathrm{HCO}_{3}^{-}+4 \mathrm{H}_{2}+\mathrm{H}^{+} \rightarrow \mathrm{CH}_{4}+3 \mathrm{H}_{2} \mathrm{O}$ & -136 \\
\hline $4 \mathrm{HCO}_{2}^{-}+4 \mathrm{H}^{+} \rightarrow \mathrm{CH}_{4}+3 \mathrm{CO} 2+2 \mathrm{H}_{2} \mathrm{O}$ & -145 \\
\hline $4 \mathrm{CH}_{3} \mathrm{OH}+2 \mathrm{H}_{2} \mathrm{O} \rightarrow 3 \mathrm{CH} 4+\mathrm{CO} 2+4 \mathrm{H}_{2} \mathrm{O}$ & -106.5 \\
\hline $\mathrm{CH}_{3} \mathrm{OH}+\mathrm{H}_{2} \rightarrow \mathrm{CH} 4+\mathrm{H}_{2} \mathrm{O}$ & -112.5 \\
\hline $\mathrm{CH} 3 \mathrm{COO}^{-}+\mathrm{H}^{+} \rightarrow \mathrm{CH}_{4}+\mathrm{CO}_{2}$ & -36 \\
\hline \multicolumn{2}{|l|}{ Sulfate reducing reactions } \\
\hline $\mathrm{CH}_{3} \mathrm{COO}^{-}+\mathrm{SO}_{4}{ }^{2-} \rightarrow 2 \mathrm{HCO}_{3}^{-}+\mathrm{HS}^{-}$ & 651.6 \\
\hline $\mathrm{HS}^{-}+\mathrm{H}^{+} \rightarrow \mathrm{H}_{2} \mathrm{~S}$ & -5.19 \\
\hline $\mathrm{SO}_{4}{ }^{2-}+4 \mathrm{H}_{2} \rightarrow \mathrm{H}_{2} \mathrm{~S}+2 \mathrm{H}_{2} \mathrm{O}+2 \mathrm{OH}^{-}$ & 237.2 \\
\hline $\mathrm{SO}_{4}^{2-}+8 \mathrm{e}^{-}+10 \mathrm{H}^{+} \rightarrow \mathrm{H}_{2} \mathrm{~S}+4 \mathrm{H}_{2} \mathrm{O}$ & 225 \\
\hline $\mathrm{SO}_{4}^{2-}+4 \mathrm{H}_{2}+\mathrm{H}^{+} \rightarrow \mathrm{HS}^{-}+4 \mathrm{H}_{2} \mathrm{O}$ & -152 \\
\hline $\mathrm{SO}_{4}^{2-}+8 \mathrm{e}^{-}+9 \mathrm{H}^{+} \rightarrow \mathrm{HS}^{-}+4 \mathrm{H}_{2} \mathrm{O}$ & 164 \\
\hline $\mathrm{CH}_{3} \mathrm{COO}^{-}+\mathrm{SO}_{4}{ }^{2-} \rightarrow 2 \mathrm{HCO}_{3}^{-}+\mathrm{HS}^{-}$ & -47.6 \\
\hline $\mathrm{CH}_{3} \mathrm{CH}_{2} \mathrm{COO}^{-}+0.75 \mathrm{SO}_{4}{ }^{2-} \rightarrow \mathrm{CH}_{3} \mathrm{COO}^{-}+\mathrm{HCO}_{3}^{-}+0.75 \mathrm{HS}^{-}+0.25 \mathrm{H}^{+}$ & -37.7 \\
\hline $\mathrm{CH}_{3} \mathrm{CH}_{2} \mathrm{CH}_{2} \mathrm{COO}^{-}+0.5 \mathrm{SO}_{4}^{2-} \rightarrow 2 \mathrm{CH}_{3} \mathrm{COO}^{-}+0.5 \mathrm{HS}^{-}+0.5 \mathrm{H}^{+}$ & -27.8 \\
\hline $\mathrm{CH}_{3} \mathrm{CHOHCOO}^{-}+0.5 \mathrm{SO}_{4}^{2-} \rightarrow \mathrm{CH}_{3} \mathrm{COO}^{-}+\mathrm{HCO}_{3}^{-}+0.5 \mathrm{HS}^{-}$ & -80.2 \\
\hline \multicolumn{2}{|l|}{ Dehalogenating reactions } \\
\hline $\mathrm{HC}_{2} \mathrm{Cl}_{3}+\mathrm{H}_{2} \rightarrow \mathrm{H}_{2} \mathrm{C}_{2} \mathrm{Cl}_{2}+\mathrm{Cl}^{-}+\mathrm{H}^{+}$ & -168.6 \\
\hline $\mathrm{HC}_{2} \mathrm{Cl}_{3}+4 \mathrm{e}^{-}+4 \mathrm{H}^{+} \rightarrow \mathrm{C}_{2} \mathrm{H}_{4}+3 \mathrm{Cl}^{-}+\mathrm{H}^{+}$ & 558 \\
\hline $\mathrm{HC}_{2} \mathrm{Cl}_{3}+2 \mathrm{H}_{2} \rightarrow \mathrm{H}_{4} \mathrm{C}_{2}+3 \mathrm{Cl}^{-}+\mathrm{H}^{+}$ & -390.76 \\
\hline
\end{tabular}


Smatlak et al., 1996 suggested that the dechlorinators would successfully compete for hydrogen only at very low hydrogen concentrations. Minimizing methanogenic competition for the available hydrogen, dechlorination can be maximized by using organic substrates which ferment slowly, resulting in the steady release of low-levels of hydrogen (electron donor) over time (Smatlak et al., 1996). Ballapragada et al., 1997 concluded that dechlorinating bacteria compete with methanogens for hydrogen at low hydrogen concentrations of 9 to $50 \mathrm{nmol} / \mathrm{L}$.

PCE and TCE have a higher redox potential so they are electron acceptors and yield more energy on their complete dechlorination to ethene (Vogel et al., 1987). As shown in Figure 2.4, for the most rapid and extensive anaerobic reductive dechlorination to occur, redox conditions should be in the sulfate reducing to methanogenic range with the optimal hydrogen concentrations range from $2 \mathrm{nmol} / \mathrm{L}$ (mid-range of sulfate reduction) to $11 \mathrm{nmol} / \mathrm{L}$ (mid-range of methanogenesis) (Yang \& McCarty, 1998). The range of estimated redox potential for dehalogenation ranges from approximately of $580 \mathrm{mV}$ to $-250 \mathrm{mV}$ at a $\mathrm{pH}$ of 7 and a temperature of $25^{\circ} \mathrm{C}$. 


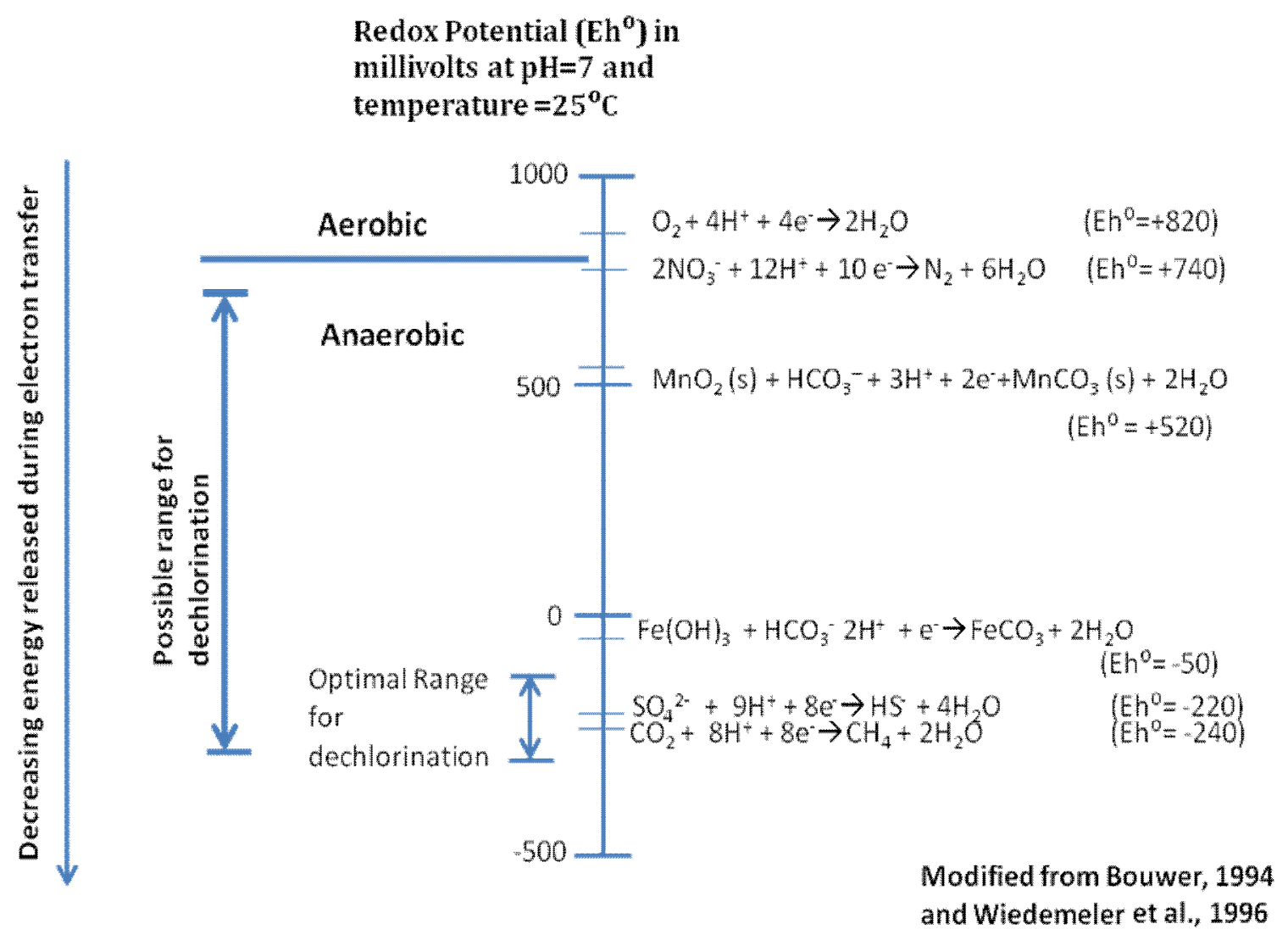

Figure 2.4. Redox potential range for favorable dehalogenation, sulfate reduction and methanogenesis.

\subsection{Dehalococcoides sp. (DHC)}

Dehalococcoides sp. are small spherical or coccoid shaped microorganisms with a diameter of approximately 300-500 nanometers (He et al., 2005), $1 \mu \mathrm{m}$ wide and 0.1-0.2 $\mu \mathrm{m}$ thick (Loffler F.E. et al., 2012). They use chlorinated carbons as the terminal electron acceptor, acetate as a carbon source and hydrogen as the electron donor which may be produced by fermentation of organic substrates such as sodium lactate. Dehalococcoides spp. has also been shown to dechlorinate chlorobenzenes, chloronaphthalenes, polychlorinated biphenyls, and dibenzodioxins (Adrian et al., 2000, Fennell et al., 2004, He et al., 2003b). DHC gets $\mathrm{H}_{2}$ from other neighboring microorganisms like acetogens and fermenting bacteria. Oxygen is toxic to them (Sharma \& McCarty, 1996; McCarty, 1997). Dehalococcoides strains grow slowly with doubling times of 0.8-3 days (Maymo-Gatell et al., 1997; Cupples et al., 2003; He et al., 2003a; Duhamel et al., 
2004 ) and the yield per $\mu$ mole of chloride released is $6.3 * 10^{7}$ to $3.1 * 10^{8}$. Enzymes associated are reductive dehalogenases (RDases) and hydrogenase $\left(\mathrm{H}_{2}\right.$ ase).

Dehalococcoides bacteria belong to Chloroflexi, or green non-sulfur bacteria (Löffler et al., 2004; Loffler F.E. et al., 2012). The DHC strains shown to degrade TCE to date are shown in Table 2.4. Strain BAV1 is the only organism that reduces PCE to ethene through direct metabolism (Maymo-Gatell et al., 1997; Maymó-Gatell et al., 2001; He et al., 2003a; He et al., 2005) and Strain 195 and FL2 reduce PCE to VC and then VC is reduced by cometabolism (Maymo-Gatell et al., 1997). 
Table 2.4. DHC species documented to degrade chlorinated compounds

\begin{tabular}{|c|c|c|c|c|}
\hline $\begin{array}{l}\text { Dehalococcoides } \\
\text { sp. strains }\end{array}$ & $\begin{array}{l}\text { RDase } \\
\text { functional gene }\end{array}$ & $\begin{array}{l}\text { Contaminants degraded } \\
\text { by DHC species }\end{array}$ & Major end products & References \\
\hline Strain 195 & $p c e \mathrm{~A}, t c e \mathrm{~A}$ & PCE, TCE, cis-DCE & VC, ethene & $\begin{array}{l}\text { Maymo-Gatell et al., } \\
1997\end{array}$ \\
\hline Strain CBDB1 & pceA & $\begin{array}{l}\text { Tetrachlorobenzene, } \\
\text { Trichlorobenzene, } \\
\text { Hexachlorobenzene, }\end{array}$ & $\begin{array}{l}\text { Trichlorobenzene or } \\
\text { dichlorobenzene }\end{array}$ & $\begin{array}{l}\text { Adrian et al., 2000; } \\
\text { Jayachandran et al., } \\
2003\end{array}$ \\
\hline Strain BAV1 & $b v c \mathrm{~A}$ & DCE, VC & ethane, ethene, chloride & He et al., 2003a \\
\hline Strain FL2 & tce A & TCE, DCE & $\mathrm{VC}$, ethene & He et al., 2005 \\
\hline Strain GT & vcrA & TCE, DCE, VC & ethene & Sung et al., \\
\hline Strain VS & $v c r \mathrm{~A}$ & TCE, cis-DCE, VC & ethene & Cupples et al., 2003 \\
\hline Strain MB & - & PCE,TCE & trans-DCE & Cheng \& He, 2009 \\
\hline $\mathrm{KB}-1 / \mathrm{VC}$ & - & PCE, TCE, cis-DCE, VC & ethene & Duhamel et al., 2004 \\
\hline
\end{tabular}




\subsection{Sulfate reducing bacteria (SRB)}

Dissimilatory microbial $\mathrm{SO}_{4}{ }^{2-}$ reduction is an important metabolic activity in many reduced environments and is mediated by a metabolically diverse group of microorganisms: the sulfatereducing bacteria (Odom et al., 1993). Sulfate reducing bacteria are named for a class of microbes which conducts disimilatory sulfate reduction and use sulfate as the terminal electron acceptor for growth (Postgate, 1979). The sulfate ion acts as oxidizing agent for the dissimilation of the organic matter (Postgate, 1979) while some species cannot use sulfate but reduce sulfur to sulfide (Hamilton, 1985). They are taxonomically diverse and physiology versatile (Barton \& Hamilton, 2007). Organic acids such as acetate, propionate, and butyrate derived primarily from fermentation serve as carbon sources for SRB. However, SRB were found to grow on environmental contaminants such as petroleum hydrocarbon constituents and halogenated compounds (Ensley \& Suflita, 1995). To date, 19 genera of SRB have been described (RooneyVarga et al., 1998). Dissimilatory sulfite reductase (DSR) is a key enzyme in dissimilatory sulfate reduction in SRB. DSR catalyses the reduction of sulfite to sulfide, a reaction found only in dissimilatory sulfate-reducing prokaryotes (Kondo et al., 2004). Currently, functional DSR genes: $d s r A B d s r A$ and $d s r B$ with similar physiological characteristics have been used as targets in qPCR (Wagner et al., 1998; Chang et al., 2001; Joulian et al., 2001; Kondo et al., 2004).

\subsection{Archaea/Methanogens}

Methanogens are prokaryotic microorganisms that fall under Domain Archaea, produce methane as an endproduct of their metabolism and are divided into five major orders, Methanobacteriales, Methanosarcinales, Methanococcales, Methanomicrobiales, and Methanopyrales (Liu \& Whitman, 2008). The cell morphologies may be sarcina, rods, spheres or coccids and spirals and are gram positive (Zeikus, 1977). Methanogens vary greatly in their morphological and physiological characteristics and are found in wide variety of anaerobic environments (Liu \& Whitman, 2008). In contrast to sulfate reducing bacteria, methanogens use a limited number of substrates for growth. Hydrogen, carbon dioxide and acetate are the most important substrates which are provided by complex anaerobic bacterial communities through fermentation 
(Hackstein, 2010). All methanogenic bacteria can use hydrogen as an energy source and utilize acetate, formate and $\mathrm{CO}_{2}$ and/or other methyl group compounds such as methanol, methylthiols and methylamines as the substrates (Thauer 1998, Zeikus, 1977). Methanogens are abundant in habitats where electron acceptors such as $\mathrm{O}_{2}{ }^{-}, \mathrm{NO}_{3}{ }^{-}, \mathrm{Fe}^{3+}$, and $\mathrm{SO}_{4}{ }^{2-}$ are limiting (Liu \& Whitman, 2008).

Methanogenic Archaea belonging to the order Methanobacteriales, Methanomicrobiales, Methanococcales, and Methanopyrales use $\mathrm{H}_{2}$ as substrate for growth and $\mathrm{CH}_{4}$ production. Some of them are capable of using formate as well as $\mathrm{H}_{2}$ to reduce $\mathrm{CO}_{2}$ to $\mathrm{CH}_{4}$ (Balch et al., 1979). Methanosarcinales have the widest substrate range and are capable of metabolizing two or more substrates (Balch et al., 1979, Zeikus, 1977). They use $\mathrm{H}_{2}$ or acetate or methyl group compounds such as methanol, methylated amines, and methylated sulfides as substrate (Balch $e t$

al., 1979, Thauer 1998, Zeikus, 1977). Methanosarcina species are difficult to isolate and maintain in pure culture (Zeikus, 1977). Methane production includes a complex biochemical pathway characterized by a number of unique coenzymes. Much of the biologically generated methane is derived from acetate in sediment and sludge digestors (Zeikus, 1977).

\subsection{Molecular screening techniques}

\subsubsection{PCR/qPCR}

Polymerase chain reaction (PCR) is a technique which generates millions of copies of genes exponentially from minute amount of deoxyribonucleic acid (DNA) in a short period of time (less than 3 hours). Even one copy of DNA sequence in a sample can be amplified and detected (Arya et al., 2005). The PCR process involves a series of chemical reactions performed at various temperatures in the so-called PCR cycle. Each cycle consists of three steps. The first step is called denaturation, where doublestranded DNA in a sample is denatured or separated into single strands by heating the sample in a thermocycler at 94 to $96{ }^{\circ} \mathrm{C}$. The second step is hybridization or annealing in which sample is cooled slightly by lowering the temperature to 50$60{ }^{\circ} \mathrm{C}$. During this second step two types of synthetic primers are added to the denatured DNA to hybridize or bind with the complementary DNA sequence if present in a sample. Primers are short single stranded DNA oligonucleotides. These primers are complementary to either the 5' or 
3' ends of target DNA. Once the primers are hybridized with the DNA; a specialized enzyme called taq polymerase is used to add free nucleotides (i.e., A, G, C and T representing adenine, guanine, cytosine and thymine respectively). Last step is extension; the temperature is increased up to $72^{\circ} \mathrm{C}$. At this point any single stranded DNA sequences are filled in by the polymerase enzyme with the remaining free nucleotides in the chemical mixture. After one round of synthesis, the amount of sample DNA is doubled. The temperature is again increased to denature the recently formed DNA duplex. Denaturation (heating) followed by hybridization and synthesis (cooling) is repeated to create or "amplify" millions of copies of the original DNA sequence. In each cycle the number of copies is doubled so the target sequence increases exponentially up to two million copies (depending on the number of cycles performed).

Quantitative polymerase chain reaction (qPCR) technology allows one to determine the amount of DNA amplified in each cycle. Quantitative real-time PCR is a highly sensitive technique that can be used for detection and quantification of specific genes of microorganisms in a DNA extraction. Numbers of copes of DNA is considered a surrogate for the number of microorganisms in a sample. There are two mechanisms for qPCR detection, both of which are based on the measurement of the increase in fluorescence as the number of copies of a microorganisms gene increase during the PCR cycle. The first method, called TaqMan TM qPCR involves a dye-containing probe that emits fluorescent light as the reaction proceeds. The second method, called SYBR Green qPCR, involves the incorporation of a dye into double stranded DNA. The SYBR Green dye fluoresces brightly when bound to double stranded DNA and weakly when associated with single stranded DNA. In both types of qPCR, the amount of emitted fluorescence is proportional to the amount of PCR products. Quantitative PCR is subject to detection limits, and is not an absolute method to determine the presence of a targeted species.

The 16S rRNA gene, encoding the 16S small ribosomal subunit, has served as a highly suitable target for studying bacterial or Archaeal species. 16S rRNA serves as phylogenetic marker to detect diversity of Bacteria and Archaea. However, in the case where multiple different orders of microbes can do one function (e.g., sulfate reduction), use of 16S rRNA gene-targeted fingerprinting method is not possible, therefore specific genetic markers (i.e., functional genes) are targeted. The average 16S rRNA gene concentrations of the methanogenic Archaea from 
wastewater anaerobic sludge in the literature ranged from $10^{6}$ to $10^{10}$ copies $/ \mathrm{ml}$ ( $\left.\mathrm{Yu} 2005\right)$. A range of $10^{2}$ to $10^{5}$ copies/ml $16 \mathrm{~S}$ rRNA DHC gene were detected in a wastewater treatment plant anaerobic sludge in the study done by Loeffler, et al. (2012) and $10^{3}$ to $10^{5} \mathrm{DHC}$ cells $/ \mathrm{ml}$ in groundwater (Lu et al., 2006 a). Similarly a range of $10^{5}$ to $10^{8}$ copies of $d s r A / \mathrm{ml}$ of nucleic acid extract from estuarine sediments was recorded by Kondo (2004). Dehalococcoides contains only one copy of the $16 \mathrm{~S}$ rDNA gene on its chromosome (Freeborn et al., 2005, http://rrndb.mmg.msu.edu) and Archaea ranged from 1 to 4 16S rDNA gene (http://rrndb.mmg.msu.edu). Therefore qPCR values repored as gene copies/ml are typlically well correlated with numbers of cells $/ \mathrm{ml}$.

\subsubsection{Fluorescence in situ hybridization (FISH)}

Fluorescence in situ hybridization (FISH) is a technique to identify specific genes within an organism's chromosome (in situ) based on the ability of an introduced single-stranded DNA or RNA to hybridize the complementary target DNA sequence contained within the organism (Amann et al., 1996; Amann et al., 2006; Amann \& Fuchs, 2008). The method comprises of four basic steps. The first step is fixation in which the target cells have to be fixed with aldehydes and alcohols (Amann et al., 2006; Amann \& Fuchs, 2008) before hybridization. The purpose of the fixation is to prevent lysis of the cells and protect the morphology of cell. The next step is hybridization of the introduced fluorescently labeled probes to the target sequence contained in the fixed cells. During hybridization both the target and the probe sequences are denatured. The labeled probe binds to the target and forms specific hybrids in presence of buffer. Blue fluorescent counter staining can be performed with aromatic diamidines like diamidino- 2phenylidole dihydrochloride (DAPI) (Zimmer \& Wähnert, 1986), which are non-specific dyes that bind to DNA sequences. In third step, washing of the sample is performed to rinse off excess probe molecules. The last step is identification of fluorescent organisms and potentially quantification by fluorescence microscope or confocal laser scanning microscope (CLSM).

FISH is fundamentally different than PCR and qPCR in that qPCR amplifies DNA millions of times making new copies and allows quantification of the genes while FISH is a visualization 
technique in which a cell is permealized, allowing a dye to enter the cell, bind to DNA thus making the cell fluorescent and allowing for quantification of cells. 


\section{CHAPTER 3 MATERIALS AND METHODS}

\subsection{Chemicals}

All materials used for growth and maintenance of microcosms were obtained from Fisher Scientific Company, LLC, (Fairlawn, New Jersey, USA city, state) unless otherwise specified and were reagent grade or better unless otherwise specified. Sodium lactate (60\% w/w syrup), TCE (99.9\%, Acros organics, New Jersey, USA), agarose (molecular genetic analysis grade), potassium sulfate and magnesium sulfate and yeast extract are used as substrates and/or as analytical standards. The reagents used for analysis of sulfate are: $\mathrm{HCl}$ (trace metal grade), $\mathrm{NaCl}$, ethanol (200 proof, Decon Labs Inc., USA), glycerol (enzyme grade) and barium chloride. The DNA extraction kits (DNeasy ® Bood \& Tissue Kit) and PCR purification kits (QIA quick® PCR Purification Kit) were obtained from Qiagen Sciences (Maryland, USA). Maxima® Probe/ROX qPCR master mix (2X) (Fermentas Life sciences Inc.), iTaq ${ }^{\mathrm{TM}}$ Universal Probes Supermix (Bio-Rad laboratories Inc, Hercules, CA, USA), Power SYBR®Green PCR master mix (2X) (Applied Biosystem, Foster city, CA, USA), iTaq ${ }^{\mathrm{TM}}$ Universal SYBR Green Supermix (Bio-Rad laboratories Inc, Hercules, CA, USA) and PCR mix (PCR MasterMix (2X), Thermo scientific) were used for amplification of DNA. For cloning and plasmid extraction, TOPO TA® cloning kit (Invitrogen, Carlsbad, CA, USA) and Pure Link ${ }^{\mathrm{TM}}$ Quick Plasmid Miniprep Kit (Invitrogen, Germany), respectively were used.

\subsection{Microcosm preparation}

Two dechlorinating cultures were used to inoculate the reactors including (1) the Bachman Road culture obtained from Dr. Ryan Dupont at Utah State University, which contains Dehalococcoides mccartyi sp. (Loffler F.E. et al., 2012) and (2) the SDC-9 ${ }^{\mathrm{TM}}$ culture from Dr. Paul Hatzinger of The Shaw Group, Inc., which contains Dehalococcoides mccartyi (Loffler F.E. et al., 2012). These cultures were transferred into $500 \mathrm{ml}$ sterile glass bottle with $400 \mathrm{ml}$ solution and amended with fresh minimal salt medium containing: $4.3 \mathrm{~g} / \mathrm{L}$ of $\mathrm{NH}_{4} \mathrm{Cl}, 50 \mathrm{~g} / \mathrm{L}$ of $\mathrm{KH}_{2} \mathrm{PO}_{4}$, $20 \mathrm{~g} / \mathrm{L} \mathrm{of} \mathrm{MgCl}_{2} \cdot 6 \mathrm{H}_{2} \mathrm{O}, 1 \mathrm{~g} / \mathrm{L}$ of $\mathrm{CaCl}_{2} \cdot 2 \mathrm{H}_{2} \mathrm{O}, 100 \mathrm{mg} / \mathrm{L}$ of $\mathrm{FeCl}_{2} \cdot 4 \mathrm{H}_{2} \mathrm{O}, 5 \mathrm{~g} / \mathrm{L} \mathrm{NaHCO} 3 ; 0.0002 \%$ (200 mg/L) of resazurin; and $0.05 \%$ of yeast extract and $10 \mathrm{mls}$ of a trace element solution 
(Hendrickson et al., 2002; Loffler et al., 1997). The trace element solution contained $100 \mathrm{mg} / \mathrm{L}$ $\mathrm{MnCl}_{2} .4 \mathrm{H}_{2} \mathrm{O}, 170 \mathrm{mg} / \mathrm{L} \mathrm{CoCl}_{2}, 118 \mathrm{mg} / \mathrm{L} \mathrm{ZnSO}_{4}, 19 \mathrm{mg} / \mathrm{L} \mathrm{H}_{3} \mathrm{BO}_{4}, 20 \mathrm{mg} / \mathrm{L} \mathrm{Na} \mathrm{MO}_{4} .2 \mathrm{H}_{2} \mathrm{O}$. Resazurin (Acros) was used as a visual indicator of low-redox-potential conditions. Sodium lactate $(10 \mathrm{mM})$ was added as electron donor from a neat stock (60\% syrup) and 10 to $20 \mathrm{mg} / \mathrm{L}$ of TCE from stock solution $(1 \mathrm{~g} / \mathrm{L})$ was added to microcosms initially and periodically throughout the incubation period (approximately every 7 days). Additionally, $10 \mathrm{mg} / \mathrm{L}$ sulfate was added to the reactor whenever the sulfate concentration was low. The reactors were filled with little headspace and purged with nitrogen gas. The reactors were incubated at room temperature on shaker at 120 RPM and wrapped in tin foil to limit photo degradation of TCE.

Cell growth was determined by observing the turbidity in the reactor, by microscopic examination with an epifluorescent microscope and qPCR. Microscopic examination was performed by pipeting $5 \mu \mathrm{l}$ of culture onto a microscope slide. The cells were fixed to the slide by passing the bottom of the microscope slide through a flame. Then $5 \mu 1$ of DAPI solution (4',6diamidine-2'-phenylindoledihydrochloride, $50 \mu \mathrm{g} / \mathrm{ml}$, Roche) was added and the slide was allowed to air dry in the dark. The slide was viewed with epifluorescence microscope with filter sets 2 and 9 (Zeiss Axiostar Plus) at a magnification of 100X. The images were captured with a Motic Images plus version 2.0 software. Samples were analyzed at time zero and then a week (5 to 15 days) for sulfate reduction after addition of sulfate to the reactor. The $\mathrm{pH}$ in the seed reactor was checked every week by $\mathrm{pH}$ paper.

\subsection{Analysis of sulfates, redox potential and COD}

Sulfate was analyzed according to Kolmert et al., 2000. Standard sulfate solutions were prepared from the range of known concentrations 0 to $5 \mathrm{mM}$ by dissolving $\mathrm{K}_{2} \mathrm{SO}_{4}$ in DI water. The calibration curve was fitted with a third degree polynomial curve over the range 0 to $5 \mathrm{mM}$ sulfate (Figure A1 in Appendix A). The sample was analyzed by mixing $1 \mathrm{ml}$ of conditioning reagent (contains $150 \mathrm{~g} \mathrm{NaCl}, 100 \mathrm{ml}$ glycerol (126 g), $60 \mathrm{ml}$ concentrated $\mathrm{HCl}$ and $200 \mathrm{ml} 95 \%$ ethanol and is made up to $1 \mathrm{~L}$ with deionized water) to $1 \mathrm{ml}$ of sample (sample was diluted to fit into the range of the standard curve (0 to $5 \mathrm{mM}$ ). Then $60 \mathrm{mg}$ barium chloride powder was added to it and mixed by shaking for $30 \mathrm{sec}$. This mixture was transferred into cuvette and measured 
absorbance at $420 \mathrm{~nm}$ against a blank using a spectrophotometer (Biomate 3, Fisher). From the mean absorbance values and standard curve made over the range of 0 to $5 \mathrm{mM}$, sulfate was calculated from the polynomial equation. The $0-5 \mathrm{mM}$ concentration corresponds to typical sulfate concentrations in cultures of sulfate-reducing bacteria; hence no or little dilution of samples was needed.

Redox potential was measured by using oxidation reduction potential meter (Eutech Instruments pH 190 series).

COD was measured by Test Method B -Micro COD by sealed digestion and spectrometry as described in the protocol by ASTM 2012. First, $1.2 \mathrm{ml}$ of potassium dichromate digestion solution was placed in a culture tube. Then $2.8 \mathrm{ml}$ of silver sulfate catalyst solution was added and mixed. It was allowed to cool. Samples were always syringe filtered through $0.45 \mu \mathrm{m}$ filter (Fisherbrand) to remove cells. Then $2 \mathrm{ml}$ of filtered sample was added and the tube was shaken vigorously. The mixture was placed in a heating device at $150{ }^{\circ} \mathrm{C}$ for 2 hour. It was cooled at room temperature. Then spectrophotometric readings were done by measuring absorbance at 420 nm. The COD value was determined from standard curves constructed from various concentrations $(0,5,10,20,30,40,50,75$ and $100 \mathrm{mg} / \mathrm{L})$ of potassium hydrogen phthalate (Figure A2 in Appendix A). 0.425 g potassium hydrogen phthalate was added to $500 \mathrm{ml}$ water to make $1 \mathrm{~g} / \mathrm{L}$ as stock solution. The stock solution was used to make standards of various concentrations.

\subsection{Construction of type 1 incubation chambers}

Incubation chamber description: 10.5 X 6.5 X $1 \mathrm{~cm}$ plexiglass reactors were used for incubation chamber type 1 as shown in Figure 3.1 below. As shown in Figure 3.1 each reactor contained a chamber capable of holding $10 \mathrm{ml}$ of solution (" 1 " in the figure), a microscope slide for sealing the chamber (" 2 " in the figure), and a small hole at back of the chamber for addition of the culture (" 3 " in the figure). Chambers were sterilized between inoculations by bleaching. $10 \%$ bleach was sprayed into the chambers for 20-30 sec. 


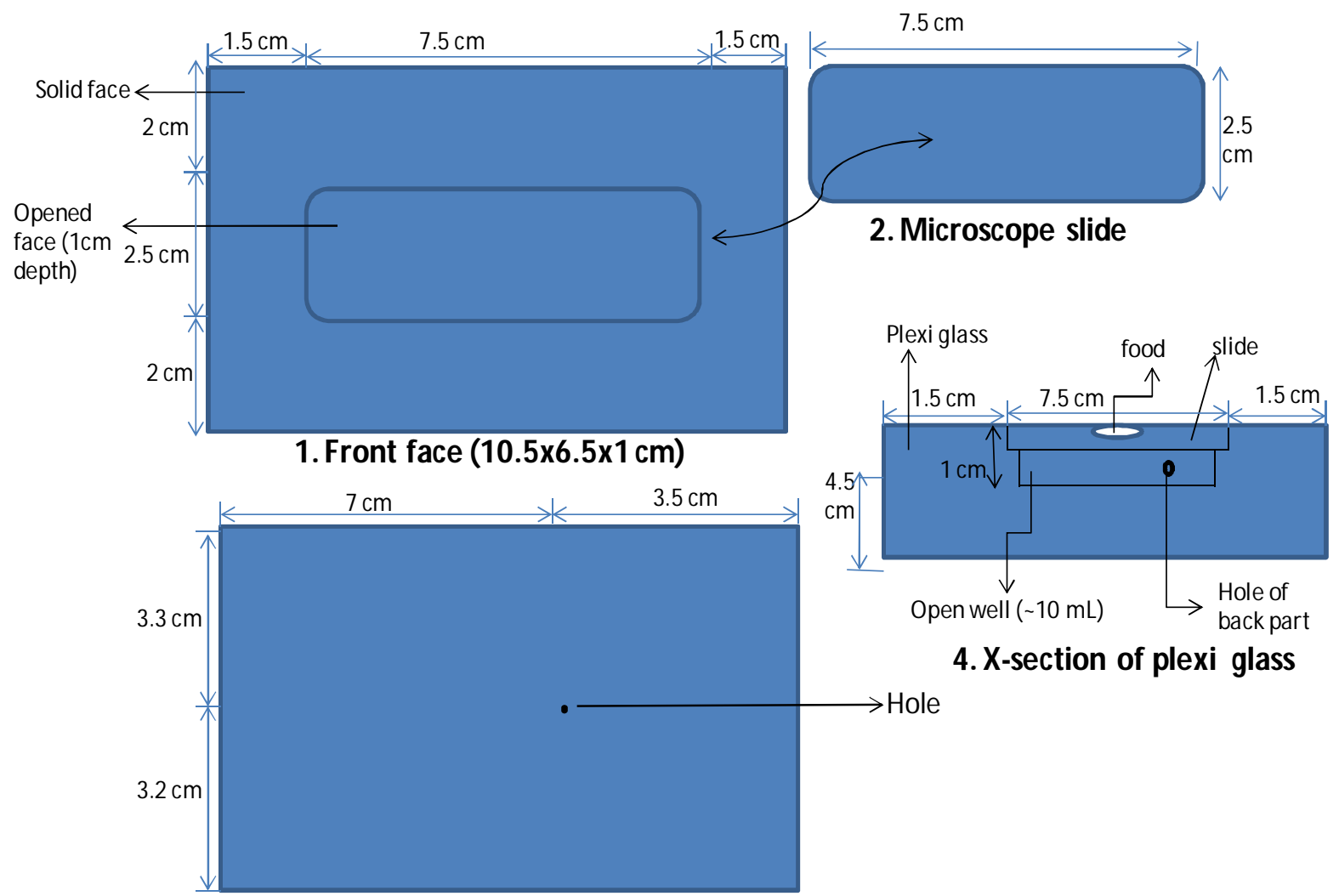

3. Back face
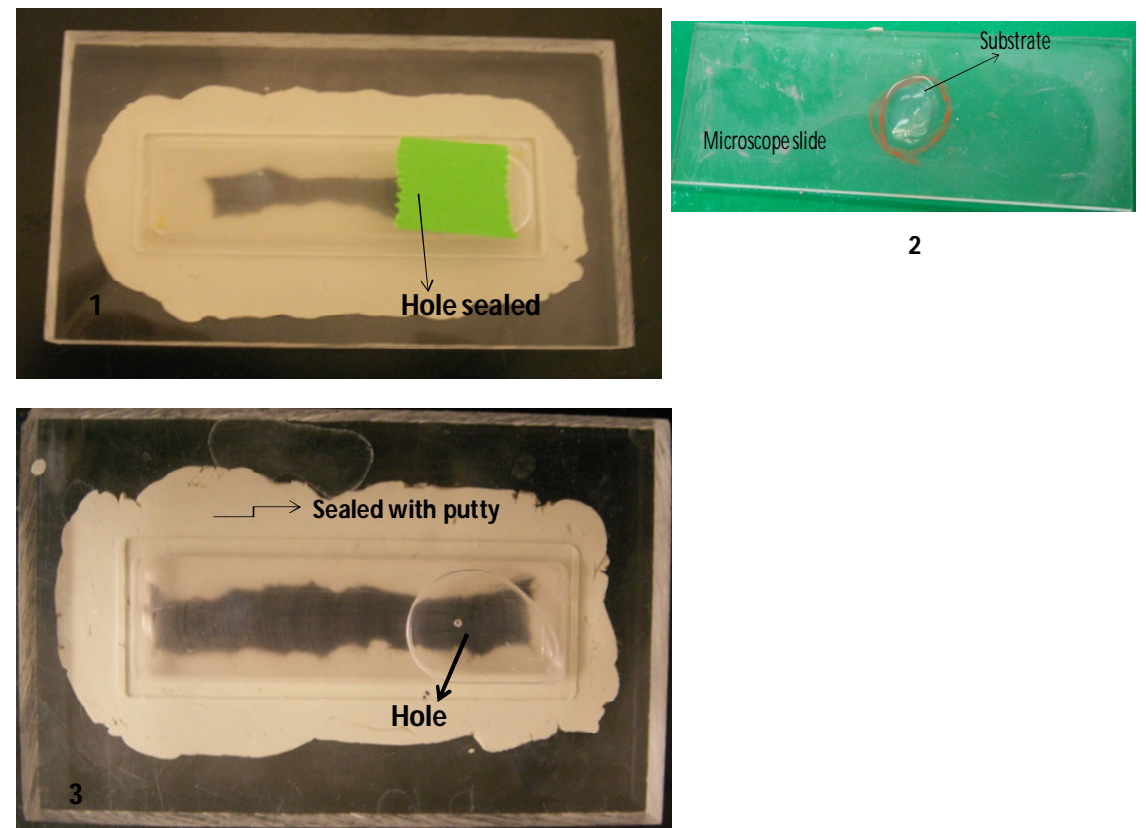

Figure 3.1. Schematic diagram and photograph of the type 1 incubation chambers (figure not to scale). 
Culture used for inoculation: $2 \mathrm{ml}$ of dechlorinating culture was taken from the reactor and centrifuged for $10 \mathrm{~min}$ at $5000 \mathrm{x} \mathrm{g}$. Supernatant was discarded and the pellet was washed by adding $1 \mathrm{ml}$ of $1 \mathrm{X}$ PBS buffer (Phosphate Buffered Saline, 10X Solution), then vortexing, followed by centrifugation again for $10 \mathrm{~min}$ at $5000 \mathrm{x} \mathrm{g}$. The supernatant was discarded. The washed culture was then resuspended in $200 \mu 1$ of 1 X PBS solution. A total of $100 \mu 1$ of culture, containing on average $8.69 * 10^{10} 16 \mathrm{~S}$ rRNA gene copies/ml was added to type 1 reactors as inoculum.

Media: A total of $50 \mathrm{mg}$ agar (electrophoresis grade) along with $2 \mathrm{mg}$ of magnesium sulfate was mixed in $1 \mathrm{ml}$ of yeast extract solution to make a 5\% v/v gel. It was heated in a water bath at 100 ${ }^{\circ} \mathrm{C}$ until it melted. To the melted agar-yeast extract solution, $75 \mu 1$ of sodium lactate was added and immediately different concentrations of TCE $(0.1,10,50$ and $100 \mathrm{mg} / \mathrm{L})$ were added and mixed by stirring with pipette tip. A total of $9 \mathrm{ml}$ of $1 \mathrm{X}$ phosphate buffer solution (PBS) was added at the open well of the incubation chamber 1 (Figure 3.1). A total of $70 \mu 1$ of the mixture (TCE, agarose, sulfate and sodium lactate mix) was pipetted onto the slide, allowed to harden (approximately 2 seconds) and then the slide was immediately inverted upside down (approximately within 5 seconds after drop of agar was added) in the reactor containing the PBS solution which was sparged with nitrogen gas (Air Gas Mid America Inc, Bowling Green, Kentucky). The reactor was sealed by plumber's putty (Oatey plumber's putty) at the edges of the microscope slide and the plexiglass well. The putty was applied at the outside the chamber so there was no contact between the putty and the PBS in the incubation well. The side opposite the microscope slide with the solid face contained a small hole used to inject the culture and the headspace was filled with approximately $1 \mathrm{ml}$ of $1 \mathrm{X}$ PBS with $100 \mu \mathrm{l}$ of culture from resuspension and the hole was sealed with tape (Figure 3.1). It was then incubated at $25{ }^{\circ} \mathrm{C}$ for 1 week, in the dark. Resazurin was added to the 1X PBS solution to aid in the observation of the redox condition. Resazurin is an oxazine dye. It is blue in its oxidized state and upon reduction it changes color to pink (partially reduced) and then clear (completely reduced) as oxygen becomes limiting in the chamber (Twigg, 1945; Guerin et al., 2001). In first stage of reduction due to loss of the oxygen atom, it changes to pink and in second step it completely changes to colorless (Guerin et al., 2001). The reactors on the first day of inoculation was blue; turned to pink after 6 hours and after 24-30 hours of inoculation it turned to colorless until incubation period. 
Controls: Negative controls included (1) a growth inhibited control made by adding $2 \mathrm{mg}$ of sodium azide to the agar mixture, (2) a no microorganism added control, and (3) a no TCE added control. Various other treatments included (1) a high TCE, high sulfate, and high culture treatment, (2) a high TCE, low sulfate, and low culture treatment, (3) a high TCE, low sulfate, high culture treatment and (4) a high TCE, high sulfate, low culture treatment.

\subsection{Construction of type 2 incubation chambers}

Two glass cover slips were taped to opposite sides of a microscope slide leaving approximately 2 $\mathrm{cm}$ space between the cover slips (Figure 3.2). The substrate was prepared as described above and $70 \mu \mathrm{l}$ of the media as described in Section 3.5 was added in the middle of two cover slips. The agar/TCE mixture was immediately covered by another cover slip from the top (Figure 3.2). A total of $10 \mu \mathrm{l}$ of inoculum (from stock reactor) after washing with 1X PBS solution (washing steps are described in section 3.4) was injected from the edge of cover slip and covered the entire microscope slide with parafilm to make anaerobic condition. The microscope slide was then placed on two caps within a petri dish (Figure 3.2), which contained $10 \mathrm{ml}$ of water to maintain humid conditions in the incubation chamber during incubation. Further humid conditions were maintained by sealing around the edge of petri dish wrapping with parafilm. The type 2 incubation chambers were incubated at $25^{\circ} \mathrm{C}$ in an incubator in the dark for 1 week. Resazurin was added for the observation of the redox condition during injection of the culture. Due to opacity of the chamber, the color change was not visible from outside. When the chamber was opened on last day of incubation, it was colorless. The controls were same as described in Section 3.5 . 


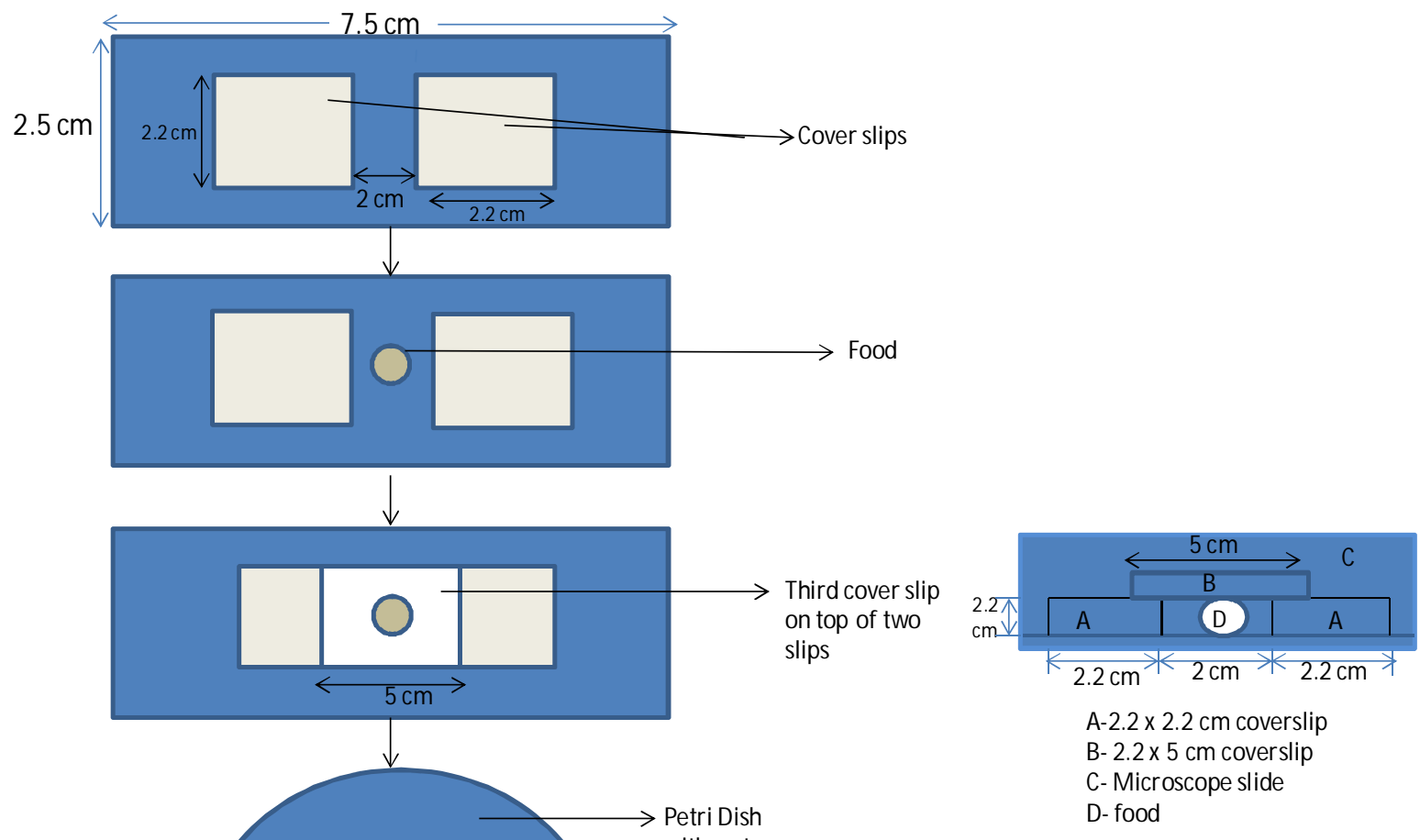

X-section of type 2 reactor

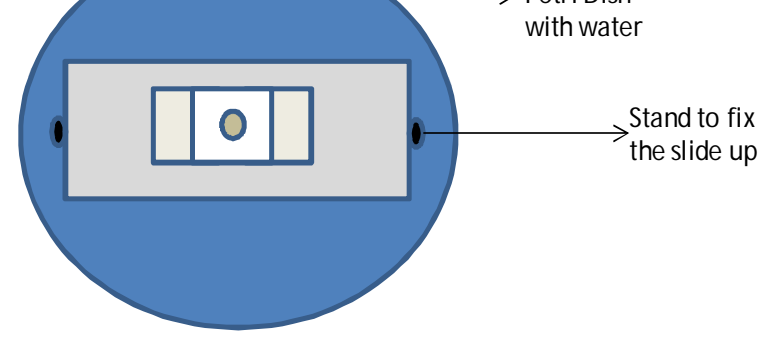

Food in between two cover slips

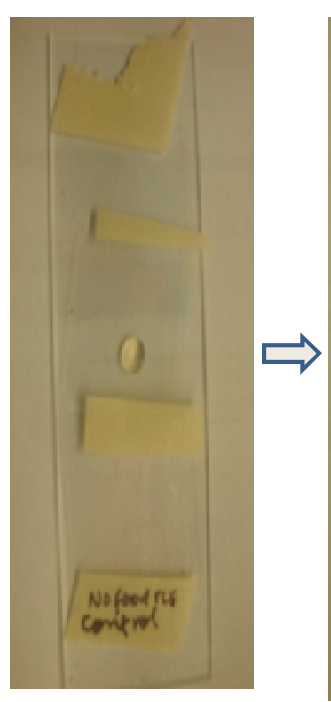

Food covered from top by a cover slip
Sealed with

parafilm and placed in a humid chamber

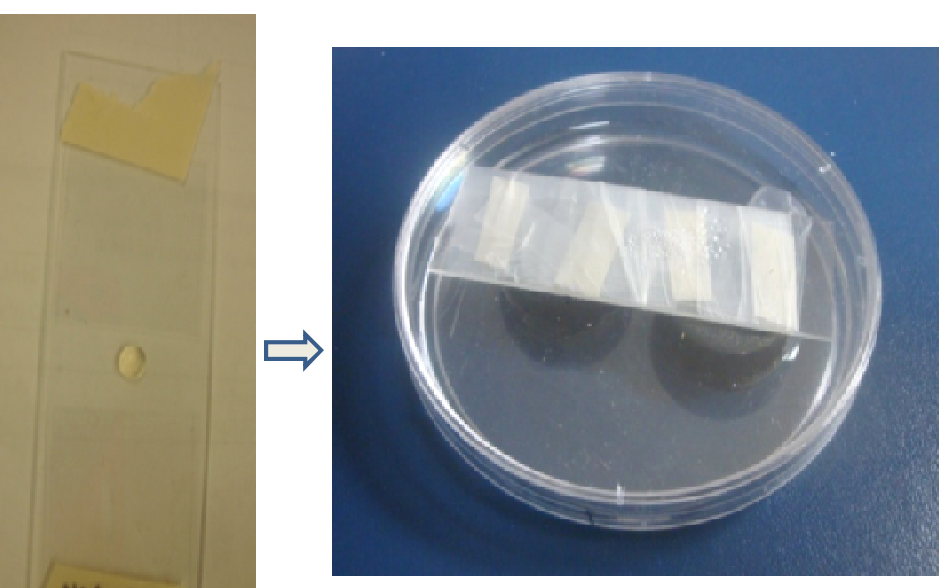

Figure 3.2. Schematic diagram and photographs of the type 2 incubation chambers 


\subsection{Construction of type 3 incubation chambers}

The substrate was prepared as described in Section 3.5. Approximately $10 \mu 1$ of the agar/TCE mixture was pipetted by capillary tube (Figure 3.3), placed on the microscope slide and immediately covered by cover slip from the top (Figure 3.3). A total of $10 \mu 1$ of inoculum (from stock reactor) after washing with PBS solution (washing steps as described in section 3.4) was injected from the edge of cover slip and covered by parafilm to make anaerobic conditions and then placed on two caps within a Petri dish (Figure 3.3), which contained $10 \mathrm{ml}$ of water to maintain humid conditions in the incubation chamber during incubation. Further humid conditions were maintained by sealing the entire microscope slide with parafilm. The capillary containing chambers were incubated at $25{ }^{\circ} \mathrm{C}$ in an incubator in the dark for 1 week. Resazurin was added for the observation of the redox condition during injection of the culture. Due to opacity of the chamber, the color was not visible from outside. When the chamber was opened on last day of incubation, it was colorless. The controls were same as described in Section 3.5.
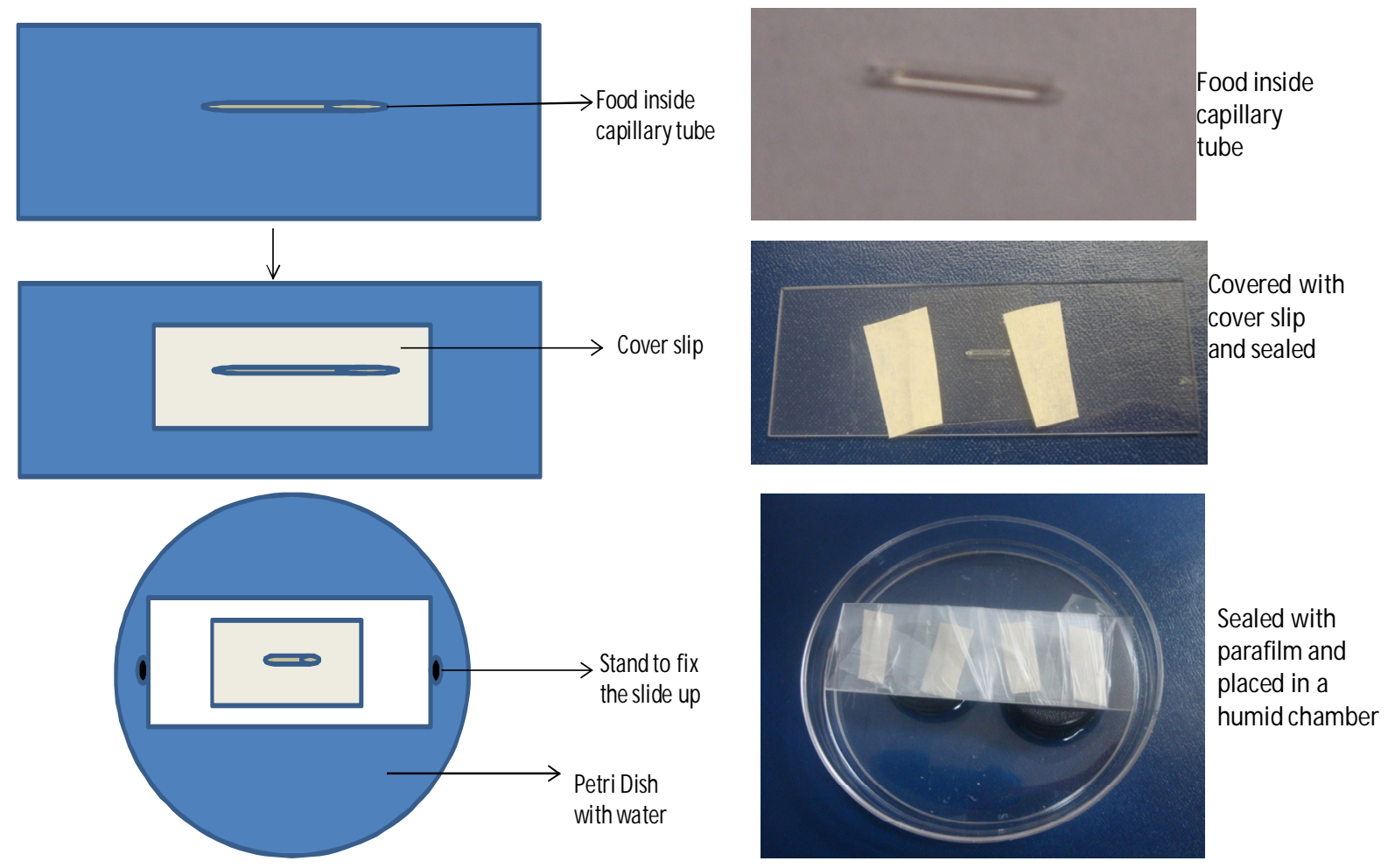

Figure 3.3. Schematic diagram and photograph of the type 3 incubation chambers 


\subsection{Growth studies}

All the reactors were set up by same way as discussed in above 3.5, 3.6 and 3.7 section but incubated over different days: 0 day, 1 day, 2 days, 3 days, 5 days and 7 days. After set up of the type 3 reactor, the day 0 sample was taken after $0.5 \mathrm{hrs}$. For the type 1 and 2 reactors the day 0 sample was taken after 2 hrs.

\subsection{Microcosm disassembly and cell sampling}

After 1 week, or as necessary, microcosms were disassembled and the microcosm biofilms were sampled for the three groups of microorganisms under study. In type 1 microcosms, first the liquid inside the chamber was removed by syringe from hole. Then all the putty was removed and the microscope was slowly dissembled from the chamber to minimize disturbance of the cells on the microscope slide. In type 2 and 3 reactors, the parafilm was unwrapped and the cover slip was slowly pulled out with the help of sterile tweezer. Microorganism biofilms were scraped off the glass microscope slides with a scraper blade that had been sterilized by autoclave at 121 ${ }^{\circ} \mathrm{C}$ for 15 minutes (Figure 3.4A and B) and were transferred to $1.5 \mathrm{ml}$ Eppendorf tubes, containing $100 \mu \mathrm{L}$ of $10 \mathrm{mM}$ Tris (pH 7.7) and vortexed. Cells scrapped from the type 3 reactors for DNA extraction, was conducted by first holding the tube by bleach sterilized tweezers and dipping it into $70 \%$ bleach for 5 seconds, to remove cells from the exterior of the capillary tube. Then it was inserted inside the $1.5 \mathrm{ml}$ Eppendorf tube containing $100 \mu \mathrm{l}$ of $10 \mathrm{mM}$ Tris (pH 7.7) and vortexed. The agar was visible inside the tube after vortexing also. The external area near the tube on the microscope slides was then scrapped off like in other 2 of types of reactors. During DNA extraction as described in method 3 of section 3.9, the agar iside the tube was melted and dissolved in the liquid and was not observed inside the tube. 


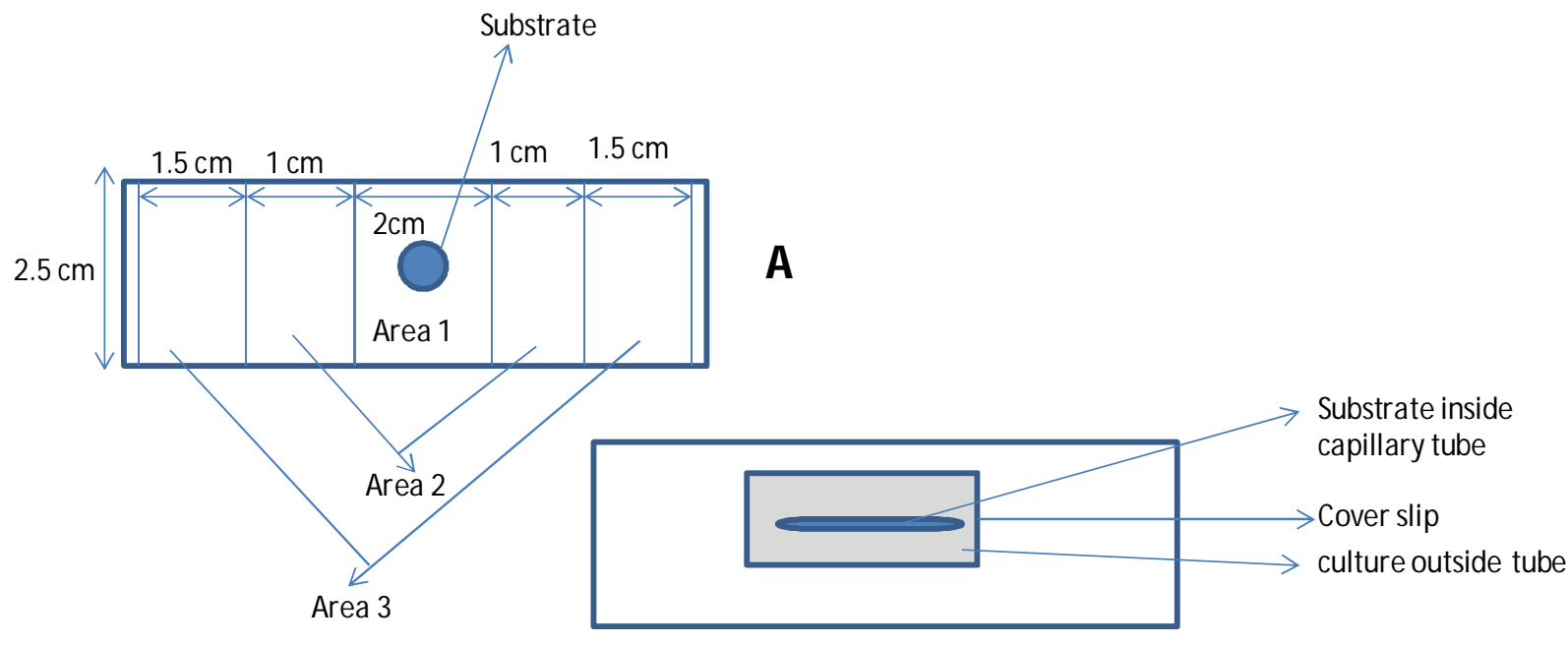

B

Figure 3.4. Schematic diagram of microscope slide (figure not to scale) A) diagram of the three areas sampled for $q P C R$ analysis in type 1 and 2 reactors, and B) the capillary area sampled for $q P C R$ analysis in the type 3 reactor.

\subsection{DNA extraction method testing and selection}

Various DNA extraction methods were then tested to determine which technique yielded the highest quantity and best quality DNA from the microscope slides or scrapped cells. The protocols tested are presented below. Where necessary, the yield and quality of the DNA generated by each method was assessed by monitoring absorption at $260 \mathrm{~nm}$, using a Nanodrop® ND-1000 version 3.7.1 spectrometer (Fisher). All reagents listed below were molecular biology grade unless otherwise noted. After extraction all DNA was stored at $-20{ }^{\circ} \mathrm{C}$ until use.

\section{Method 1: Boil}

The scraped material was resuspended in $100 \mu \mathrm{l}$ of sterile double-distilled DNase, RNase free water in a $1.5 \mathrm{ml}$ sterile tube and incubated for 20 minutes in a water bath at $99{ }^{\circ} \mathrm{C}$, then centrifuged for 5 minutes at $4000 \mathrm{x}$ g. The supernatant was transferred to a separate $2 \mathrm{ml}$ sterile tube and was directly used for PCR or qPCR (Sepp R et al., 1994). Also, to the pellet remaining in the original $2 \mathrm{ml}$ sterile tube that was boiled, $100 \mu \mathrm{l}$ of sterile double-distilled DNase, RNase free water was added and the tube was left on vortex at low speed to dissolve any remaining 
DNA in the cell pellet for 2 hours. The yield and quality of the DNA was assessed as described above.

\section{Method 2: Phenol:chloroform:isoamyl alcohol treatment}

DNA extraction by this method was accomplished using the phenol/chloroform/isoamyl alcohol protocol as described by Gall et al., 1993 and Poljak et al., 1995 and with some modifications (elution buffer and the volume). The scraped material was resuspended in $200 \mu$ of digestion buffer (50 mM Tris-HCl, $1 \mathrm{mM}$ EDTA and $1 \%$ Tween-20) with $800 \mu \mathrm{g} / \mathrm{ml}$ of proteinase $\mathrm{K}$ in a sterile $1.5 \mathrm{ml}$ tube and then incubated at $56^{\circ} \mathrm{C}$ for 1 hour in a water bath. Then $200 \mu \mathrm{l}$ of phenol:chloroform:isoamyl alcohol, 25:24:1 (v:v:v) and $10 \mathrm{mM}$ Tris-HCL (pH 8.0) was added to each tube and shaken vigorously for 1 minute followed by centrifugation at $6000 \mathrm{x}$ g for 10 minutes. After centrifugation, the supernatant (which contains DNA) was transferred into another $2 \mathrm{ml}$ tube; and $0.1(100 \mu \mathrm{l})$ volume of sodium acetate $(3 \mathrm{M}, \mathrm{pH} 5)$ with $900 \mathrm{ul}$ of cold $70 \%$ ethanol was added. The mixture was incubated at $-20^{\circ} \mathrm{C}$ for 40 minutes. After

centrifugation at $14,000 \times \mathrm{g}$ for 7 minutes at $4{ }^{\circ} \mathrm{C}$, the supernatant was discarded and the precipitate (DNA) was air dried (Poljak et al., 1995) and re-dissolved in $40 \mu 1$ of $10 \mathrm{mM}$ Tris. The yield and quality of the DNA was assessed as described above.

\section{Method 3: Freeze-Thaw and Boil-Cool}

The scraped material was resuspended in $100 \mu \mathrm{l}$ of $10 \mathrm{MM}$ Tris- $\mathrm{HCl}(\mathrm{pH} 8.3)$ in a sterile $1.5 \mathrm{ml}$ tube, briefly vortexed and frozen at $-70^{\circ} \mathrm{C}$ for 1 hour. Afterwards, the sample was thawed at room temperature, incubated at $100^{\circ} \mathrm{C}$ in a water bath for 20 minutes, chilled on ice for 10 minutes, briefly vortexed and spun down at 4,000 x g for 2 minutes (Poljak et al., 1995). The yield and quality of the DNA was assessed as described above.

(i) The scraped material was resuspended in $100 \mu 1$ of $10 \mathrm{MM}$ Tris- $\mathrm{HCl}(\mathrm{pH} 8.3)$ in a sterile $1.5 \mathrm{ml}$ tube, briefly vortexed and frozen at $-70^{\circ} \mathrm{C}$ for 1 hour. Afterwards, the sample was thawed at room temperature, incubated at $100^{\circ} \mathrm{C}$ in a water bath for 20 minutes, chilled on ice 
for 10 minutes, briefly vortexed and spun down at 4,000 x g for 2 minutes (Poljak and Barlic 1998). The yield and quality of the DNA was assessed as described above.

(ii) This method was followed according to de Roda Husman et al., 1995. The cells were suspended in $100 \mu \mathrm{l}$ of $10 \mathrm{mM}$ Tris-HC1 (pH 8.1) in a sterile $1.5 \mathrm{ml}$ tube. The cell suspension was vortexed and frozen at $-20{ }^{\circ} \mathrm{C}$ overnight. It was thawed at room temperature, boiled for 20 minutes approximately at $99^{\circ} \mathrm{C}$ in a water bath, cooled on ice for 10 minutes and spun down at $4000 \mathrm{x} g$ for 2 minutes. The yield and quality of the DNA was assessed as described above.

\section{Method 4: Freeze- thaw method}

The scrapped cells were suspended in $100 \mu \mathrm{l}$ of $10 \mathrm{mM}$ Tris-HC1 (pH 8.1) in a sterile $2 \mathrm{ml}$ tube and frozen at $-20{ }^{\circ} \mathrm{C}$ and then thawed at room temperature for 1 hour each. The freeze and thaw cycle was repeated a total of 3 times and spun down at $4000 \mathrm{x} g$ for 2 minutes. The yield and quality of the DNA was assessed as described above.

\section{Method 5: Lysis Method}

Two separate types of DNA extraction by lysis with lysozyme or SDS were tested as described below. These methods involved extraction of the DNA from the cells on the slide, prior to scrapping the cell debris and DNA from the microscope slide into a $1.5 \mathrm{ml}$ tube.

(i) A total of $60 \mu 1$ of lysozyme was added to the surface of the slide over an area approximately $1 \mathrm{~cm}^{2}$, and the slides were frozen for 1 hour at $-20{ }^{\circ} \mathrm{C}$. The slides were then thawed for 1 hour at room temperature. The freeze and thaw cycle was repeated a total of 3 times. The cells were scraped from the microscope slide and resuspended in $100 \mu$ of DNase RNase free water. It was centrifuged for 5 minutes at $4000 \mathrm{x}$ g. The yield and quality of the DNA was assessed as described.

(ii) A total of $60 \mu \mathrm{l}$ of SDS added on the slide and the slides were frozen for 1 hour at $-20{ }^{\circ} \mathrm{C}$. The slides were then thawed for 1 hour at room temperature. The freeze and thaw cycle was repeated a total of 3 times. The cells were scraped from the microscope slide and resuspended in 
$100 \mathrm{ul}$ of DNase RNase free water centrifuged for 5 minutes at $4000 \mathrm{x}$ g. The yield and quality of the DNA was assessed as described.

\section{Method 6: Proteinase K/Tween-20 lysis method}

In this method, the scraped cells were suspended in $100 \mathrm{ul}$ of lysis buffer $(0.1 \mathrm{mg} / \mathrm{ml}$ proteinase $\mathrm{K}, 0.1 \%(\mathrm{v} / \mathrm{v})$ Tween 20, $50 \mathrm{mM}$ potassium chloride, $10 \mathrm{mM}$ Tris- $\mathrm{HCl} \mathrm{pH} 8.3$ and $1.5 \mathrm{mM}$ magnesium chloride) in a sterile $1.5 \mathrm{ml}$ tube and incubated overnight at $37{ }^{\circ} \mathrm{C}$ in an incubator. The samples were heated at $96{ }^{\circ} \mathrm{C}$ for 10 minutes to inactivate the proteinase $\mathrm{K}$ enzyme and then centrifuged for 3 minutes at 11,000 x g (de Roda Husman et al., 1995). The yield and quality of the DNA was assessed as described above.

\section{Method 7: DNA extraction using Holmes-Bonner Buffer}

This method was followed as described by Holmes 1973 with slight modifications. The scrapped cells were suspended into $100 \mu \mathrm{l}$ of Holmes-Bonner Buffer (1 M Tris (pH $7.5-8), 5 \mathrm{M} \mathrm{NaCl}$, 0.5 M EDTA, $260.8 \mathrm{~g} / \mathrm{L}$ Urea, 10\% SDS and water to reach volume, stirred over mild heat) and $300 \mu \mathrm{DI}$ water. Then 1 volume of phenol and 1 volume of chloroform (can alternately use phenol: chloroform [1:1] was added and the samples were mixed by inverting the tubes manually for 1-2 minutes and centrifuged at 14,000 x for 5 minutes. The upper layer was transferred to a new tube taking care not to include any part of the interphase. The extraction was repeated one additional time and the upper layer was transferred to another sterile $2 \mathrm{ml}$ tube. One volume of chloroform was added and the mixing and centrifugation described above was repeated. Then 0.1 volume of $3 \mathrm{M}$ sodium acetate ( $\mathrm{pH}$ 5.2) and 2 to 3 volumes of cold, 100\% ethanol was added and stored at $-70{ }^{\circ} \mathrm{C}$ for $1 \mathrm{hr}$. The sample was then centrifuged at maximum for 15 minutes and the ethanol was discarded. Cold $70 \%$ ethanol (approximately $1 \mathrm{ml}$ ) was added and the solution was centrifuged at $14,000 \times \mathrm{g}$ for 15 minutes and the ethanol was carefully removed (Holmes \& Bonner, 1973). The open tube containing the DNA was stored upright on a rack covered with Kim wipe tissue (Kimtech Science brand) and allow it to dry. Then $100 \mu \mathrm{l}$ of $10 \mathrm{mM}$ Tris was

added to the DNA in the tube and it was left to dissolve the DNA at room temperature for 10 minutes. The yield and quality of the DNA was assessed as described above. 


\section{Method 8: Phenol: chloroform extraction and (i) isopropanol clean up method, (ii) ethanol cleanup, or (iii) PCR cleanup kit}

The scraped cell were suspended in $500 \mu 1 \mathrm{TE}$ buffer (Tris $10 \mathrm{mM}, \mathrm{pH}$ 7.4; EDTA $1 \mathrm{mM}$ ) and extracted two times with approximately $500 \mu 1$ of 2:1 (v:v) chloroform: methanol mix. The solution was then vortexed and centrifuged for 3 minutes at 14,000 x g. The upper (aqueous) phase containing the DNA (Supernatant 1) was transferred into a separate $2.0 \mathrm{ml}$ Eppendorf tube and centrifuged at $14,000 \times \mathrm{g}$, for 5 minutes. This extraction was then repeated. Then $50 \mu \mathrm{TE}$ buffer and $50 \mu \mathrm{l}$ of $1 \mathrm{M}$ Tris solution (pH 9) were added. Then $5 \mu \mathrm{l}$ of $20 \mathrm{mg} / \mathrm{ml}$ lysozyme (100 $\mu \mathrm{g} / \mathrm{ml}$ final) and $100 \mu \mathrm{l}$ of RNaseA (50 $\mu \mathrm{g} / \mathrm{ml}$ final) was added to the cell suspension and mixed gently by inverting or reversing the tube several times. It was then incubated overnight at $37{ }^{\circ} \mathrm{C}$ in an incubator. Then $25 \mu \mathrm{l}$ of proteinase $\mathrm{K}(100 \mu \mathrm{g} / \mathrm{ml}$ final $)$ was added, the solution was mixed gently and incubated at $37^{\circ} \mathrm{C}$ for an hour. Then $60 \mu 1$ SDS (10\%) was added and incubated for additional 2 to 3 hours at $55^{\circ} \mathrm{C}$. The DNA was extracted by adding $600 \mu 1$ phenol and $800 \mu 1$ chloroform and mixed by gently reversing the tube a few minutes. The solution was then centrifuged at 14,000 x g for 3 minutes. Supernatant was transferred to another $2 \mathrm{ml}$ tube and then the extraction was repeated. After this process one of the following process used for DNA cleanup on the supernatant.

i. A total of 0.1 volumes of sodium acetate (3 $\mathrm{M} \mathrm{pH}$ 5.2) and one volume of isopropanol was added and mixed by gently inverting the tube several times. It was incubated for 1 hour at $4{ }^{\circ} \mathrm{C}$ and centrifuged at $14,000 \mathrm{xg}$ for 10 minutes. The supernatant was carefully removed by pipette and the pellet was dried to remove all liquid. The pellet was then resuspended by adding $50 \mu 1$ of $10 \mathrm{mM}$ Tris ( $\mathrm{pH}$ 7.4). The yield and quality of the DNA was assessed as described above.

ii. A total of 0.1 volumes of sodium acetate ( $3 \mathrm{M} \mathrm{pH}$ 5.2) and 1 volume of $70 \%$ ethanol was added and incubated for 30 minutes at $-20^{\circ} \mathrm{C}$ and centrifuged $14000 \mathrm{xg}$ for 30 minutes at $4^{\circ} \mathrm{C}$. The supernatant was carefully removed and $100 \mu \mathrm{l}$ of $70 \%$ ethanol was added. The solution was then centrifuged $14000 \mathrm{x} \mathrm{g}$ for 5 minutes at $4{ }^{\circ} \mathrm{C}$ in a refrigerated microcentrifuge. All liquid was then removed. The pellet was resuspended in $50 \mathrm{ul}$ of $10 \mathrm{mM}$ Tris (pH 7.4). The yield and quality of the DNA was assessed as described above.

iii. In this method, the DNA was cleaned by using QIAquick® PCR Purification Kit (Qiagen) following the manufacturer instructions. Briefly, in this method, the samples were mixed with 
Qiagen buffer, filtered with DNeasy spin columns and washed. Then eluted by 25 ul of buffer EB (10 mM Tris, $\mathrm{pH} \mathrm{8.5)} \mathrm{instead} \mathrm{of} 50 \mathrm{ul}$ from manufacture's protocol. The yield and quality of the DNA was assessed as described above.

\section{Method 9: Sonication}

The scrapped cells were resuspended in $1.5 \mathrm{ml}$ tubes containing $100 \mathrm{ul}$ of $10 \mathrm{mM}$ Tris solution. The tube was then sonicated in a water bath sonicator (Fisher) for 1 hour and was centrifuged at $10,000 \mathrm{x} \mathrm{g}$ for 1 minute. The supernatant was transferred and cleaned up by the ethanol precipitation cleanup method as described in Method 8 (ii). The DNA was dissolved in $100 \mu 1$ of Tris ( $\mathrm{pH}$ 7.4). The yield and quality of the DNA was assessed as described above. For PCR and qPCR purposes $5 \mu \mathrm{l}$ aliquots were used from each DNA extraction method described above.

\subsection{PCR}

PCR amplification was performed in a total volume of $25 \mu$ l. The PCR reaction mixture contained 1X PCR master mix (Thermo Scientific), $0.2 \mu \mathrm{M}$ of each universal bacteria $8 \mathrm{~F}$ and 1492R primers (Table 3.1), template DNA (5ul), $0.5 \mathrm{mg} / \mathrm{ml}$ of Ultrapure ${ }^{\mathrm{TM}}$ BSA (Ambion®) and enough PCR grade water (DNase, RNase free) to make up a $25 \mu 1$ solution. PCR was conducted on an Eppendorf thermocycler (Eppendorf version 1.628) and the thermocycler program was95 ${ }^{\circ} \mathrm{C}$ for 15 minutes; 40 cycles of: $95{ }^{\circ} \mathrm{C}$ for 60 seconds, $53.5^{\circ} \mathrm{C}$ for 60 seconds, $72^{\circ} \mathrm{C}$ for 90 seconds, extension at $72{ }^{\circ} \mathrm{C}$ for 7 minutes. PCR-amplified DNA was detected by using $1 \%$ (wt/vol) agarose (electrophoresis grade) gel electrophoresis run in 1X TAE buffer at 100 volts for 30 minutes. The gel was stained by adding $2 \mu 1$ of $10 \mathrm{mg} / \mathrm{ml}$ solution of ethidium bromide prior to loading. A total volume of $4 \mu \mathrm{l}$ of PCR product with $1 \mu \mathrm{l}$ of loading dye (Agarose gel loading dye 6X, Nalgene) was added to the gel and DNA was detected by UV light using a Gel logic 100 imaging system (molecular imaging software v 4.0.3).

The primers that were used in the PCR and qPCR for amplification of the 16S rRNA and $d s r A$ gene target in the reactors are presented in Table 3.1. 
Table 3.1. Specific PCR/qPCR primers and probes

\begin{tabular}{|c|c|c|c|c|}
\hline $\begin{array}{c}\text { Primer/ } \\
\text { probe Name }\end{array}$ & Sequence & Target Gene & $\begin{array}{c}\text { Amplicon } \\
\text { length (bp) }\end{array}$ & References \\
\hline $8 \mathrm{~F}$ & 5'-AGA GTT TGA TCC TGG CTC AG-3' & Bacteria 16S rRNA & 1502 & Hendrickson et al. (2002) \\
\hline $1492 \mathrm{R}$ & 5'-GGT TAC CTT GTT ACG ACT T-3' & Bacteria $16 \mathrm{~S}$ rRNA & & Hendrickson et al. (2002) \\
\hline $\mathrm{DHC}-\mathrm{F}$ & 5'-GGT AAT ACG TAG GGA AGC AAG CG-3' & Dehalococcoides sp. 16S rRNA & 98 & Holmes et al. (2006), He et al. (2007) \\
\hline DHC-R & 5'-CCG GTT AAG CCG GGA AAT T-3' & Dehalococcoides sp. 16S rRNA & & $\begin{array}{l}\text { Freeborn et al. (2005), He et al. } \\
\text { (2006), Holmes et al. }(2006)\end{array}$ \\
\hline $\begin{array}{l}16 \mathrm{~S} \text { DHC } \\
\text { Probe }\end{array}$ & $\begin{array}{l}\text { FAM-ACA TCC AAC TTG AAA GAC CAC } \\
\text { CTA CGC TCA CT-BHQ-1 }\end{array}$ & Dehalococcoides sp. 16S rRNA & & $\begin{array}{l}\text { Freeborn et al. (2005), He et al. } \\
\text { (2006), Holmes et al. }(2006)\end{array}$ \\
\hline Arch 344 F & 5'-ACG GGG YGC AGC AGG CGC GA-3' & Archaea $16 \mathrm{~S}$ rRNA & 462 & (Raskin et al., 1994) \\
\hline Arch 806 R & 5' -GGA CTA CCC GGG TAT CTA AT -3' & Archaea $16 \mathrm{~S}$ rRNA & & (Takai \& Horikoshi, 2000) \\
\hline $\mathrm{DSR} 1 \mathrm{~F}+$ & 5'-ACS CAC TGG AAG CAC GGG GG- 3' & $d s r A$ functional gene & 221 & (Kondo et al., 2006) \\
\hline DSR-R & 5'GTG GMR CCG TGC AKR TTG G- 3' & $d s r A$ functional gene & & (Kondo et al., 2006) \\
\hline MBAC-F & 5'-CGW AGG GAA GCT GTT AAG T-3' & Methanobacteriales sp. 16S rRNA & 343 & (Yu et al., 2005) \\
\hline MBAC-R & 5'-TAC CGT CGT CCA CTC CTT-3' & Methanobacteriales sp. 16S rRNA & & (Yu et al., 2005) \\
\hline MCOC-F & 5'-TAA GGG CTG GGC AAG T-3' & Methanococcales sp. 16S rRNA & 337 & (Yu et al., 2005) \\
\hline MCOC-R & 5'-CAC CTA GTY CGC ARA GTT TA-3' & Methanococcales sp. 16S rRNA & & (Yu et al., 2005) \\
\hline MMIC-F & 5'-ATC GRT ACG GGT TGT GGG-3' & Methanomicrobiales sp. 16S rRNA & 506 & (Yu et al., 2005) \\
\hline MMIC-R & 5'-CAC CTA ACG CRC ATH GTT TA C-3' & Methanomicrobiales sp. 16S rRNA & & (Yu et al., 2005) \\
\hline MSAR2-F & 5’-GTA AAC GAT RYT CGC TAG GT-‘3 & Methanosarcinales sp. 16S rRNA & 354 & (Yu et al., 2005) \\
\hline MSAR2-R & 5'-GGT CCC CAC AGW GTA CC-3' & Methanosarcinales sp. $16 \mathrm{~S}$ rRNA & & (Yu et al., 2005) \\
\hline
\end{tabular}




\subsection{1 qPCR}

qPCR was conducted in an Applied Biosystem (Singapore) 7300 Real Time PCR system with SDS software (version 1.3.1) to determine the distribution of the 16S rRNA gene of Dehalococcoides sp. and Archaea and the $d s r A$ functional gene of sulfate reducing bacteria. For DHC, to each qPCR tube a final concentration of $1 \mathrm{X}$ of Maxima® Probe/ROX qPCR master mix (Fermentas Life Sciences Inc.), $0.7 \mu \mathrm{M}$ each of the 16S rRNA DHC forward and reverse primers (Table 3.1), $0.2 \mu \mathrm{M}$ of the DHC 16S rRNA gene probe was added, $5 \mu \mathrm{l}$ of DNA and enough water to make up $25 \mu \mathrm{l}$ of reaction mixture. The qPCR thermocycler conditions was set as $50^{\circ} \mathrm{C}$ for 2 minutes, $95^{\circ} \mathrm{C}$ for 15 minutes, 40 cycles of $95^{\circ} \mathrm{C}$ for 30 seconds, $58^{\circ} \mathrm{C}$ for 60 seconds. For Archaea, to each qPCR tube a final concentration of $1 X$ of Power SYBR®Green PCR master mix (Applied Biosystem), 0.7 $\mu \mathrm{M}$ each of the reverse and forward primers (Arch 344F and Arch 806R (Table 3.1), $0.5 \mathrm{mg} / \mathrm{ml}$ of Ultrapure ${ }^{\mathrm{TM}} \mathrm{BSA}$ (Ambion®), $5 \mu \mathrm{l}$ of DNA and enough PCR grade water to make $25 \mu \mathrm{l}$ reaction mixture. The thermocycler conditions were: $50^{\circ} \mathrm{C}$ for 2 minutes; $95^{\circ} \mathrm{C}$ for 15 minutes; 40 cycles of $95^{\circ} \mathrm{C}$ for 30 seconds, $60^{\circ} \mathrm{C}$ for 30 seconds; and $72^{\circ} \mathrm{C}$ for 30 seconds; followed by $50^{\circ} \mathrm{C}$ for 5 minutes and a dissociation stage. For sulfate reducing bacteria, to each qPCR tube a final concentration of $1 X$ of Power SYBR®Green PCR master mix (Applied Biosystem), $0.5 \mu \mathrm{M}$ each of the reverse and forward primers (DSR1F+ and DSR-R (Table 3.1), $0.5 \mathrm{mg} / \mathrm{ml}$ of Ultrapure ${ }^{\mathrm{TM}} \mathrm{BSA}$ (Ambion®), $5 \mu \mathrm{l}$ of DNA and enough water to make a $25 \mu \mathrm{l}$ reaction mixture. The thermocycler conditions were: $50^{\circ} \mathrm{C}$ for 2 minutes; $94^{\circ} \mathrm{C}$ for 15 minutes; 40 cycles of $94^{\circ} \mathrm{C}$ for 30 seconds, $60^{\circ} \mathrm{C}$ for 30 seconds, and $72^{\circ} \mathrm{C}$ for 1 minute; followed by extension of $72^{\circ} \mathrm{C}$ for 7 minutes and a dissociation stage. Since SYBR green might also bind to nonspecific DNA, a melting curve was performed to assure the specificity of the PCR by analysis of the dissociation curve. For Methanobacteriales sp., Methanococcales sp., Methanomicrobiales sp., and Methanosarcinales sp., the SYBR reaction mixture and thermocyclic conditions were same as the Archaea.

\subsection{Clone library and qPCR standard curve construction}

Plasmids containing the target genes (i.e., 16S rRNA genes of DHC, Archaea and the $d s r A$ gene of SRB) were used for qPCR. The plasmid clones were constructed with the TOPO TA cloning ${ }^{\circledR}$ 
kit (Invitrogen) according to the manufacturer's instructions. PCR products of DNA extracted from the seed reactor were used to generate plasimds with the cloning kit. Plasmids were extracted from the E. coli cells using the TOPO TA® cloning kit (Invitrogen) and Pure Link ${ }^{\mathrm{TM}}$ Quick Pasmid Miniprep Kit (Invitrogen).

These plasmids were used to generate standard curves for $\mathrm{qPCR}$ by serially diluting the plasmids from $10^{11}$ to $10^{2}$ gene copies/ul PCR reaction. Duplicate qPCR was performed for each sample and triplicate qPCR for the serially diluted plasmid standard (Figure 3.5). The efficiency of the assay and the coefficient of determination $\left(\mathrm{R}^{2}\right)$ of the standard curve were calculated based on the linear regression of the standard curve. Perfect amplification must double the starting DNA in every cycle. In a 10-fold dilution of the standards the number of cycles to increase the DNA 10 times must be about 3.32. Consequently, amplification curves for all standards samples should be evenly separated by 3.32 cycles in order to obtain an efficiency of $100 \%$. The amplification efficiency $(\boldsymbol{E})$ was calculated from the slope of the standard curve using the formula in Equation 12.

Efficiency $=-1+10^{-1 / \text { slope }}$

Equation 12

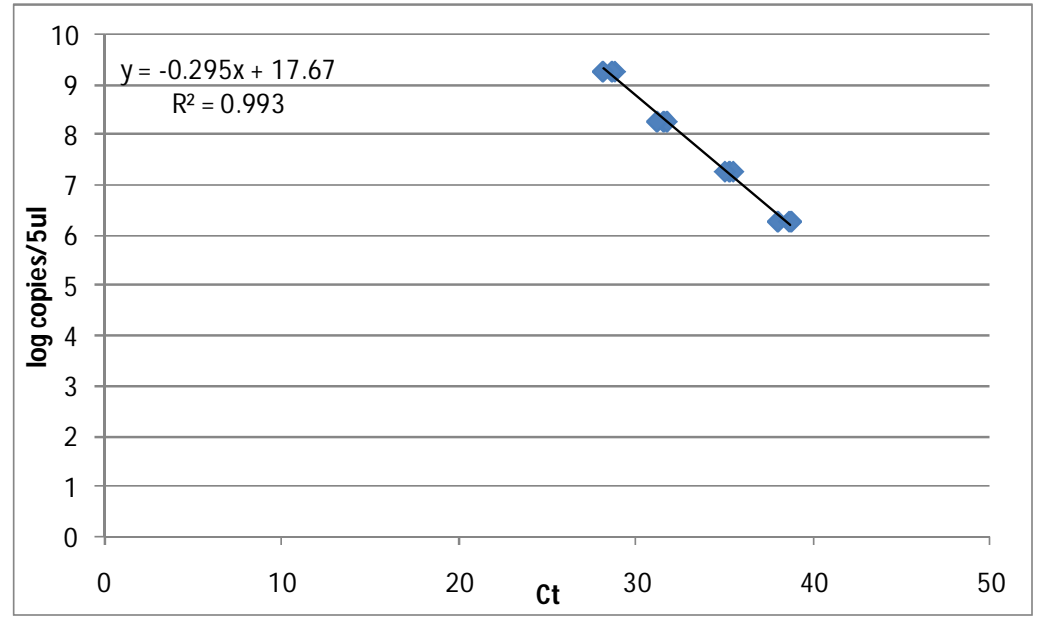

A 


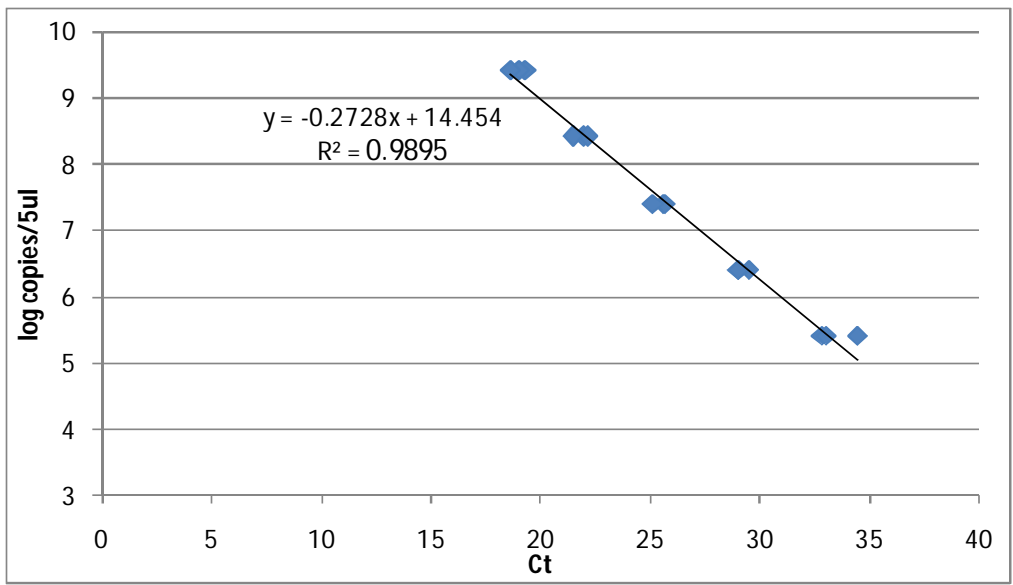

B

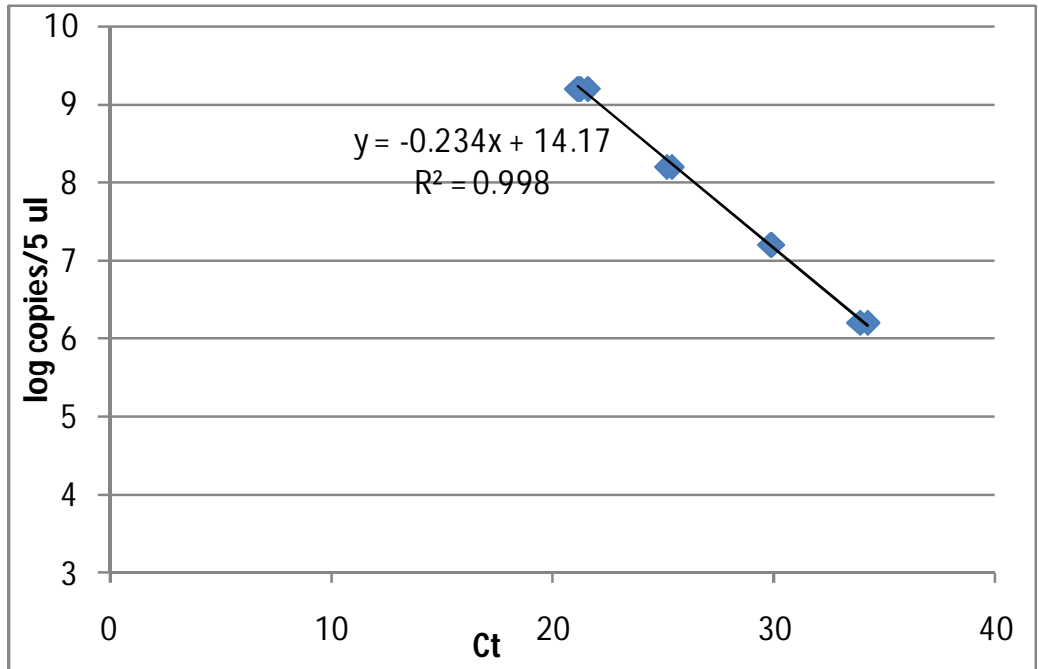

C

Figure 3.5. Standard curve for DHC (A), SRB (B) and Archaea (C).

The estimated efficiency for the qPCR reactions were $98.5 \%$ for DHC 16S rRNA genes, 88.6\% for SRB dsrA genes, and 71.5\% for Archaea 16S rRNA genes.

\subsection{Data analysis}

DNA (copy/ $\mu \mathrm{L})$ was calculated from the following linear Equations (13, 14 and 15) of standard curve with $\mathrm{Ct}$ value analyzed from qPCR:

$\log 16 \mathrm{~S}$ rRNA gene copies of $\mathrm{DHC} / \mathrm{ul}=-0.295 * \mathrm{Ct}+17.67$

Equation 13 
$\log d s r A$ gene copies of SRB/ul $=-0.272 * \mathrm{Ct}+14.45$

Equation 14

$\log 16 \mathrm{~S}$ rRNA gene copies of Archaea/ul $=-0.234 * \mathrm{Ct}+14.17$

Equation 15

Then by using the following equation (16) DNA concentration in the original area of the microscope slide of different species was calculated. All gene concentrations from qPCR were calculated as $\log 10$.

DNA copy $/ \mathrm{cm}^{2}=\frac{\left\{10^{\left.\log \text { gene } \frac{\text { copies }}{u l}\right\} * \text { Vol of DNA extraction }(u l) * \text { dilution factor }}\right.}{\text { Area scrapped } \mathrm{cm}^{2}} \quad$ Equation 16

\section{Statistical Analysis}

All statistical analyses (i.e., linear regressions, Student's t-test) were conducted with Sigma Plot version 11.0 (Systat Software, Inc.). 


\section{CHAPTER 4 RESULTS}

\subsection{Analysis of chemical degradation and culture in seed reactor}

The $\mathrm{pH}$ in the seed reactor was measured every week and ranged from $\mathrm{pH} 6$ to 6.5. Sulfate reduction was found after a 15 day incubation period (Figure 4.1). The average redox potential of the seed reactor was measured as $-56.5 \mathrm{mV}$ (S.D. \pm 45.5 ) with the range of -20 to $-167 \mathrm{mv}$ suggesting that anaerobic reductive dechlorination in the seed reactor occured in the range of iron reduction to sulfate reduction (Figure 2.4).

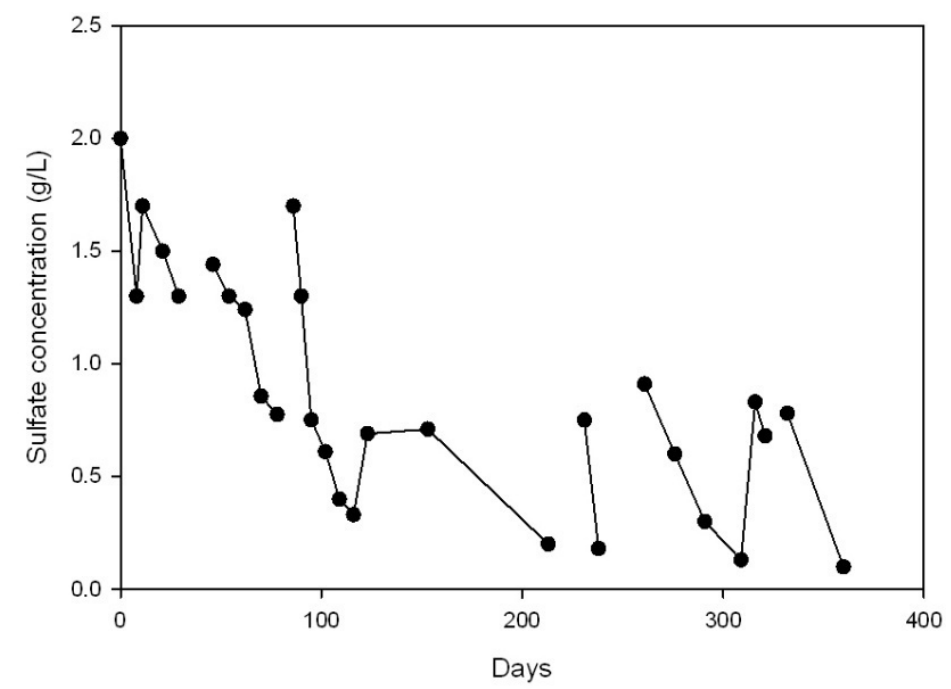

Figure 4.1. Sulfate concentrations in the seed reactors over the operational period

The recommended sulfate concentration for enhanced bioremediation is 500 to $1000 \mathrm{mg} / \mathrm{L}$ (Henry 2010) although 500 to $5000 \mathrm{mg} / \mathrm{L}$ sulfate is the maximum range suitable for reductive dechlorination (Henry 2010). USEPA (1998) indicated that if sulfate exceeds $20 \mathrm{mg} / \mathrm{L}$ reductive dechlorination is reduced. High sulfate levels are problematic because of high electron demand (Henry 2010) and may lower the efficiency of anaerobic dechlorination (USEPA 1998). In this study, initial sulfate concentration was $2 \mathrm{~g} / \mathrm{L}$ and was reduced to $0.3 \mathrm{~g} / \mathrm{L}$ within 15 days after sulfate addition to the seed reactor. 
The culture characteristics of Dehalococcoides mccartyi and other microorganism in the seed reactor was analyzed by staining an aliquot of cells on microscope slides with DAPI (Figure 4.2) and comparing the culture characteristics to those published by others. DAPI stains all DNA present in all cells and therefore is an indicator of both live and dead microorganisms in a sample. Additionally, FISH using the Dhe1259t probe specific to DHC was used to verify the presence of DHC in the seed reactor and DHC cells were visualized by epifluorescence microscope (Figure 4.3) and compared to all cells in the culture stained by DAPI. The cells viewed under the microscope were coccoid and small, specifically, 0.1 to $0.5 \mu \mathrm{m}$ in diameter similar to other published Dehalococcoides sp. culture descriptions (Figure 4.2 and Figure 4.3).

DHC was found to be abundant in the reactor based on qPCR analysis in the seed reactor, specifically greater than $1 * 10^{8}$ to $1 * 10^{10}$ DHC $16 \mathrm{~S}$ rRNA gene copies/ml of reactor and the population was sustained over 255 days of operation. The recommended DHC concentration for natural attenuation in groundwater remediation is near or greater than $1 * 10^{7}$ gene cells/L (Lu et al 2006a) and in lab scale reactors is greater than $1 * 10^{4}$ gene cells $/ \mathrm{ml}$ (Lee et al., 2008, Loeffler 2012). Specifically, concentrations of DHC were measured on 100, 146 and 255 days and were $8.2 * 10^{14}, 6.7 * 10^{17}$ and $2.7 * 10^{19}$ DHC $16 \mathrm{~S}$ rRNA gene copies/ml of reactor, respectively. So it was assumed TCE degradation occurred in the large seed reactors when there were plenty of DHC as many previous studies have shown that DHC only uses organohalogens as energy sources and thus in presence of active DHC, TCE degradation occurs. Additionally, COD analysis in the seed reactors showed degradation of COD from $3 \mathrm{~g} / \mathrm{L}$ to $1.6 \mathrm{~g} / \mathrm{L}$ over 5 days and in type 1 reactor from 671 to $245.4 \mathrm{mg} / \mathrm{L}$ over 5 days after addition of sodium lactate and TCE. Theoretical oxygen demand for the amount of sodium lactate added to the reactors was 857 $\mathrm{mg} / \mathrm{L}$. 

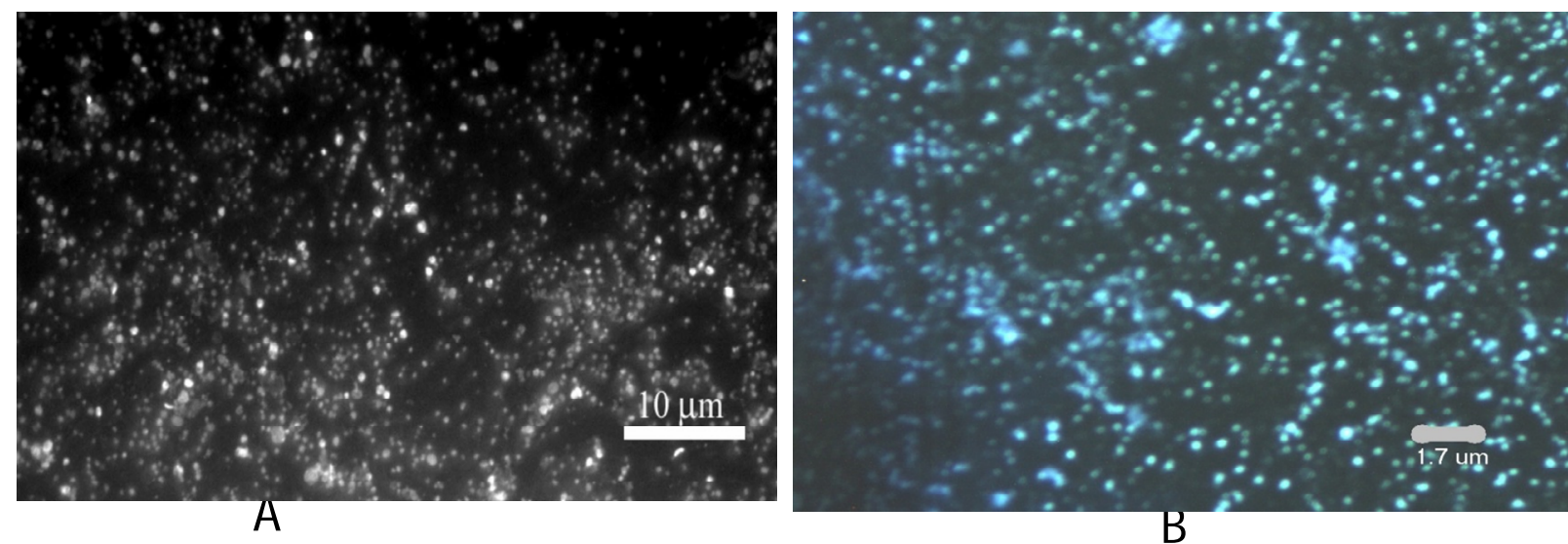

Figure 4.2. Comparison of culture characteristics of DAPI stained DHC in (A) The KB$1 / \mathrm{VC}-\mathrm{H}_{2}$ culture from literature at $1000 \mathrm{X}$ magnification (Duhamel, 2004) and (B) from this study at 100X magnification observed with epifluorescence microscope with emission wavelength of $450-500 \mathrm{~nm}$.
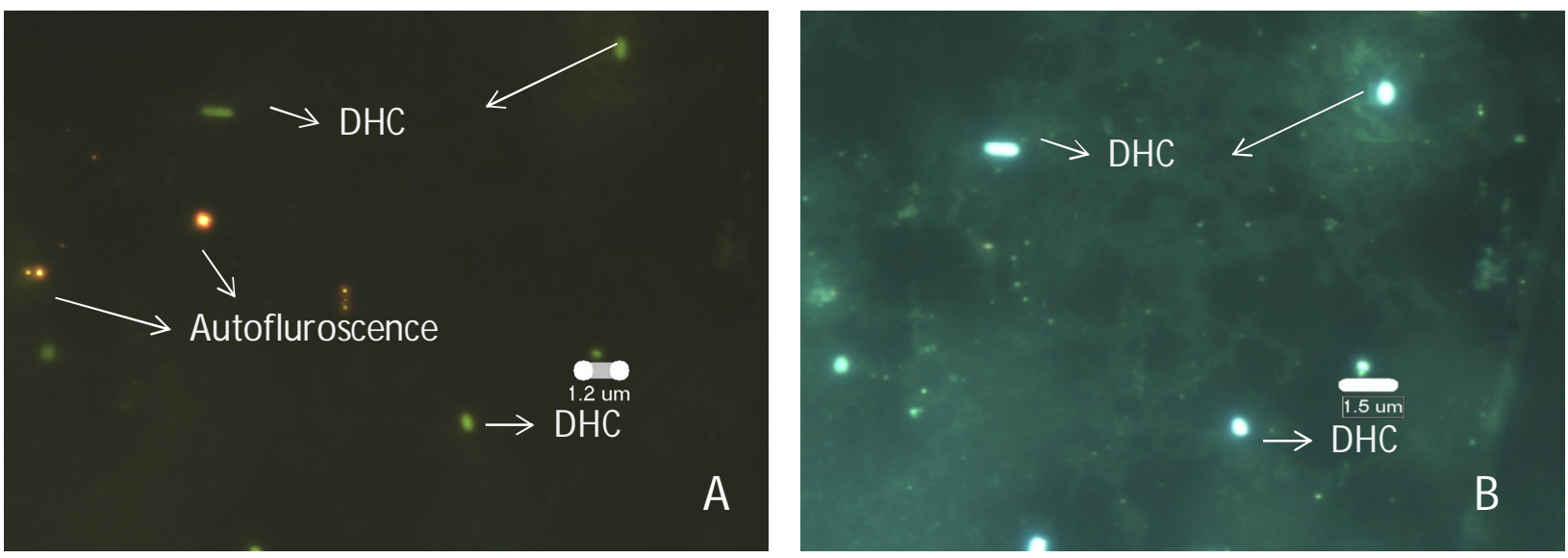

Figure 4.3. FISH microscopic images of culture from seed reactor (A) DHC only at magnification of 100X and wavelength 500-570 nm (green) (B) all cells stained with DAPI in same field as $A$ at $450-500 \mathrm{~nm}$ wavelength (blue).

\subsection{Evaluation of DNA extraction methods by PCR}

DNA was extracted from microscope slides by different protocols as discussed in Section 3.8 and amplified by PCR using universal bacterial primers. The most fast and efficient method for DNA extraction was found to be method $3 \mathrm{ii}$, in which samples were scrapped and cells were resuspended in Tris, then frozen, thawed, boiled and cooled. The resulting DNA concentration, DNA purity and PCR amplification results from the different methods are shown in Table 4.1. 
Table 4.1. DNA concentration, purity and amplification results of various DNA extraction methods

\begin{tabular}{lccc}
\hline \multicolumn{1}{c}{ DNA extraction method } & & \multicolumn{2}{c}{ Bacterial } \\
& & & 16S rRNA \\
& DNA & A260/ & $\begin{array}{c}\text { PCR } \\
\text { amplified? }\end{array}$ \\
& ng/ul & $\mathbf{2 8 0}$ & No \\
\hline 1: Boil & 4.6 & 2.38 & No \\
2: Phenol:chloroform:isoamyl alcohol treatment & 114.4 & 1.55 & Yes \\
3i: Freeze-Thaw and Boil-Cool & 47.7 & 1.73 & Yes \\
3ii: Freeze-Thaw and Boil-Cool & 34.4 & 1.47 & No \\
4: Freeze- thaw method & NA & NA & No \\
5 (i): Lysis Method with lysozyme & 1063 & 0.98 & No \\
5 (ii): Lysis Method with SDS & NA & NA & No \\
6: Proteinase K/Tween-20 lysis method & NA & NA & No \\
7: DNA extraction using Holmes-Bonner Buffer & 6.4 & 1.12 & No \\
8(i): Phenol chloroform extraction , isopropanol clean up & 128.1 & 1.48 & Yes \\
8(ii): Phenol chloroform extraction and ethanol cleanup & 311.1 & 1.64 & Yes \\
8(iii): Phenol chloroform extraction and PCR cleanup kit & 6.6 & 1.99 & No \\
9: Sonication & 194.6 & 1.24 & \\
\hline NA = data not available & & & \\
\hline
\end{tabular}

DNA concentration from method 3 ii as measured by nanodrop quantification is shown in Figure 4.4. The concentration and purity of DNA is estimated by measuring the amount of ultraviolet radiation absorbed. In the figure, absorbance at the wavelength $260 \mathrm{~nm}$ is assumed to be by DNA and the absorbance at $280 \mathrm{~nm}$ is assumed to be by proteins. Optimal ratio of absorbance at 260 versus $280 \mathrm{~nm}$ is 1.8 . In this study the ratio of absorbance at $260 \mathrm{~nm}$ to absorbance at $280 \mathrm{~nm}$ is 1.8 in type 1 and 2 reactors. Only the DNA extracted from the type 3 reactor had DNA purity below 1.8, however the DNA quality at 1.2 A260/280 still represents DNA of high enough purity not to significantly interfere with the PCR reaction (e.g., Table 4.1). The method 3ii was selected for DNA extraction for qPCR analysis to detect Archaea, DHC and SRB because of higher DNA yields, reduced sample handling requirements, faster overall extractions and lower cost. 


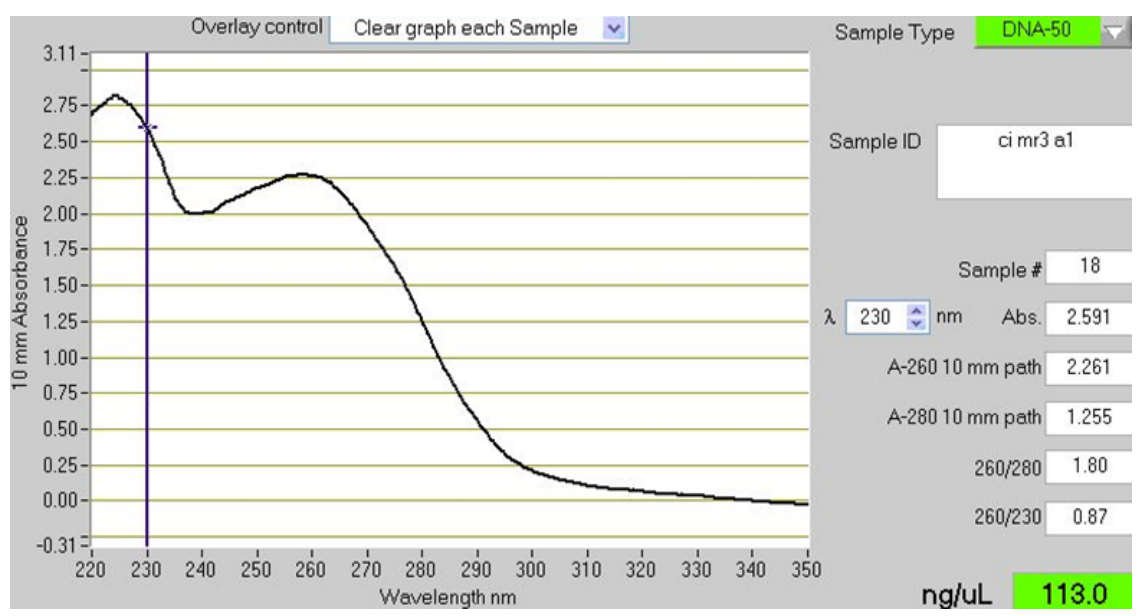

A
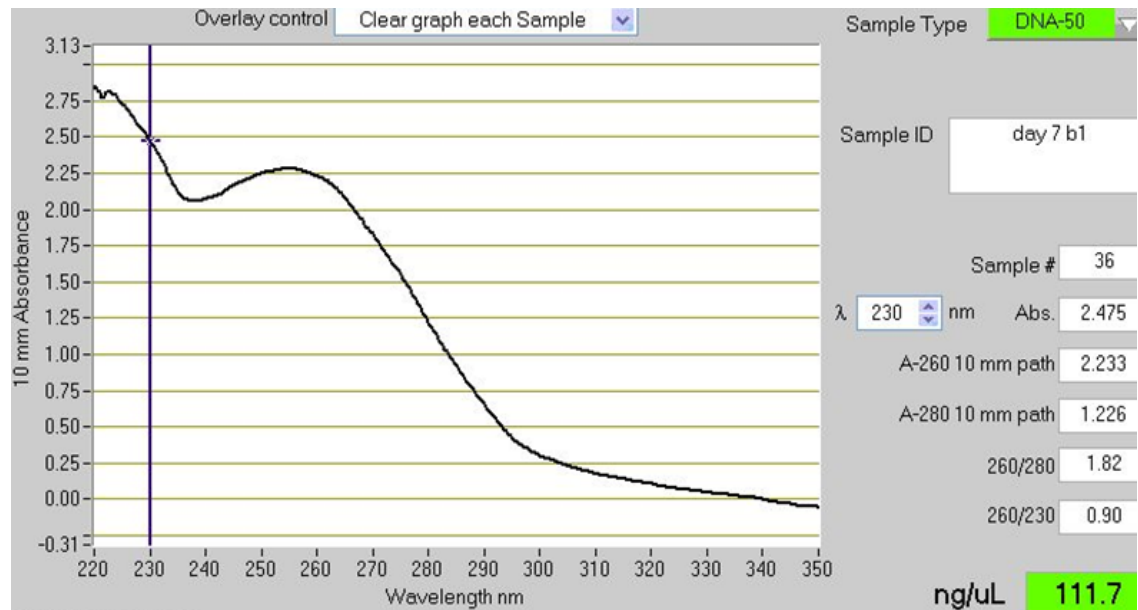

B

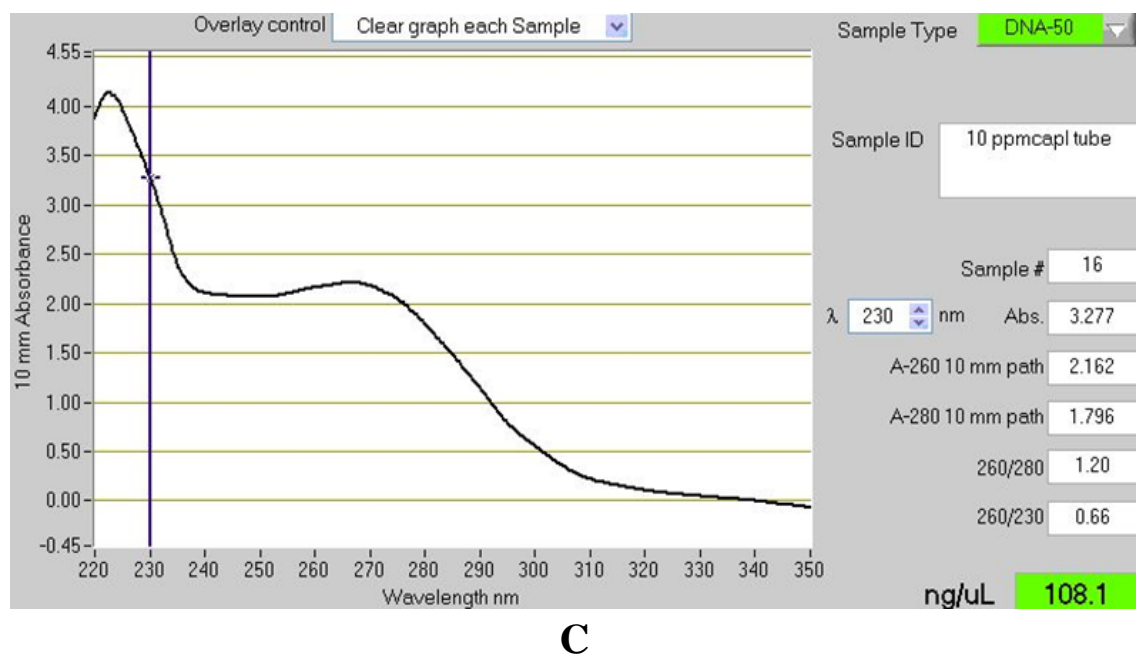

Figure 4.4. Nanodrop DNA quantification of: (A) Type 1 reactor (B) Type 2 reactor and (C) Type 3 reactor for method 3 ii. 
Amplification of DNA from PCR analysis using different primers is shown in Figure 4.5. The amplification without BSA was not as good as with the addition of BSA (data not shown), thus, BSA was added as an adjuvant during the PCR assay.
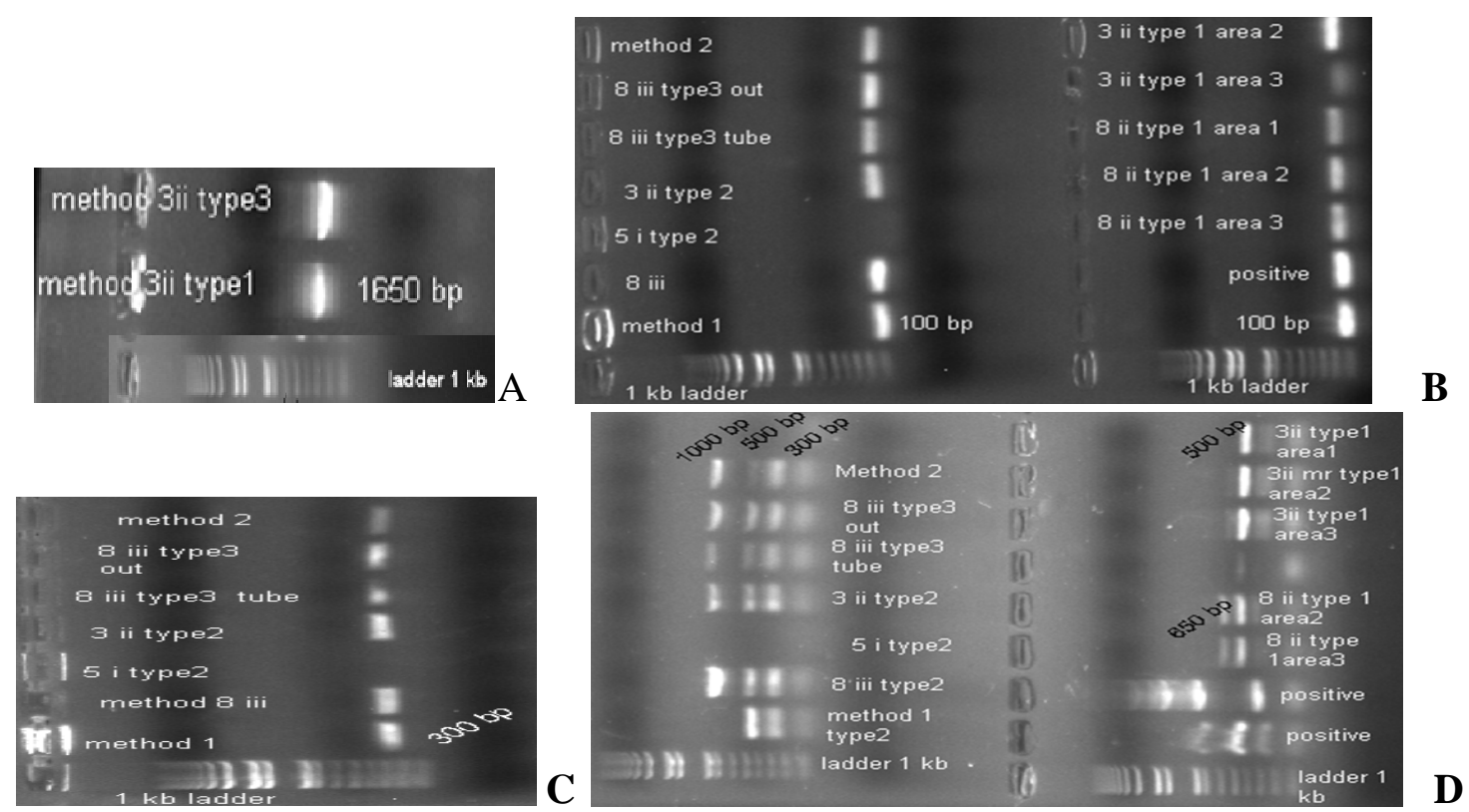

Figure 4.5. Detection of (A) bacterial 16S rRNA, (B) Dehalococcoides 16S rRNA, (C) dsrA genes of sulfate reducers and (D) Archaea 16S rRNA.

As shown in Figure 4.5, amplicons of the expected size targeting the universal bacteria (1502bp), Dehalococcoides group (98bp), SRBs (221bp) and Archaea 16S rRNA (462 bp) were obtained in direct PCR with primers. The lengths in the gel of Archaea group is variable which might be due to non specific amplification as the primers were originially developed in 1994 and don't account for current knowledge on 16S rRNA sequences (e.g., NCBI database updates).

\section{3 qPCR results}

Method 3ii was used for DNA extraction from the microcosms studies conducted to address the main hypotheses in this research. The microorganisms were not found in controls like (i) no cells and (ii) and some DNA were found in growth inhibited control containing sodium azide (Table 4.2). All data is tabulated in the Appendix Table A3. 
Table 4.2. Detection of DHC, SRB and Archaea in the type 1, 2 and 3 control reactors

\begin{tabular}{lccccccccc}
\hline Control Study & \multicolumn{3}{c}{ Type 1 reactor } & \multicolumn{3}{c}{ Type 2 reactor } & \multicolumn{3}{c}{ Type 3 reactor } \\
& DHC & SRB & Archaea & DHC & SRB & Archaea & DHC & SRB & Archaea \\
\hline Growth inhibited & - & ND & ND & - & ND & ND & - & ND & ND \\
(sodium azide) & & & & & & & & & \\
No cells added & - & ND & ND & - & ND & ND & - & ND & ND \\
No TCE added & + & + & + & + & + & + & + & + & + \\
\hline
\end{tabular}

- =cells not present or below detection limits, $+=$ cells present, $\mathrm{ND}=$ no data, samples were not analyzed as DHC was not detected by qPCR .

To investigate the relative concentrations of methanogens as compared to the total Archaea population, a subset of samples were tested to determine the relative abundance of methanogens and total Archaea from the seed reactors (Table 4.3). In general Methanobacteriales was the most abundant methanogen (i.e., smaller $\mathrm{Ct}$ values indicate a larger overall abundance of the particular gene or organism). This Methanobacteriales uses $\mathrm{H}_{2}$ as a substrate (Balch et al., 1979, Zeikus, 1977) and therefore is more likely to compete with $\mathrm{DHC}$ for $\mathrm{H}_{2}$ reducing equivalents generated during degradation of sodium lactate. Methanococcales was also abundant in the reactors and primarily uses $\mathrm{H}_{2}$ as a substrate. The data in Table 4.3 also support the argument that total Archaea 16S rRNA detected by qPCR can be used as a surrogate for methanogens in this study.

Table 4.3. Detection of the different orders of methanogens and total Archaea in the seed

\begin{tabular}{ll}
\multicolumn{2}{c}{ reactor } \\
\hline Methanogenic Archaea & $\mathbf{C t}$ \\
\hline Methanobacteriales & 24.2 \\
Methanococcales & 24.9 \\
Methanomicrobiales & 33 \\
Archaea & 24.1 \\
\hline
\end{tabular}

The treatments in the various aquifer model reactors were analysed when compared with control. The relative microbial population as a fraction of the initial concentration for the 6 treatments is presented in Table 4.4. In analyzing these data, it was found that microorganism concentration increased in most of the treatments. However, for some treatments the degradation extent was not statistically significant relative to the control (Appendix Table A3). 
Table 4.4. Comparison of the average concentration of microorganisms in all areas after 7 days of incubation with different initial nutrient conditions and TCE concentrations

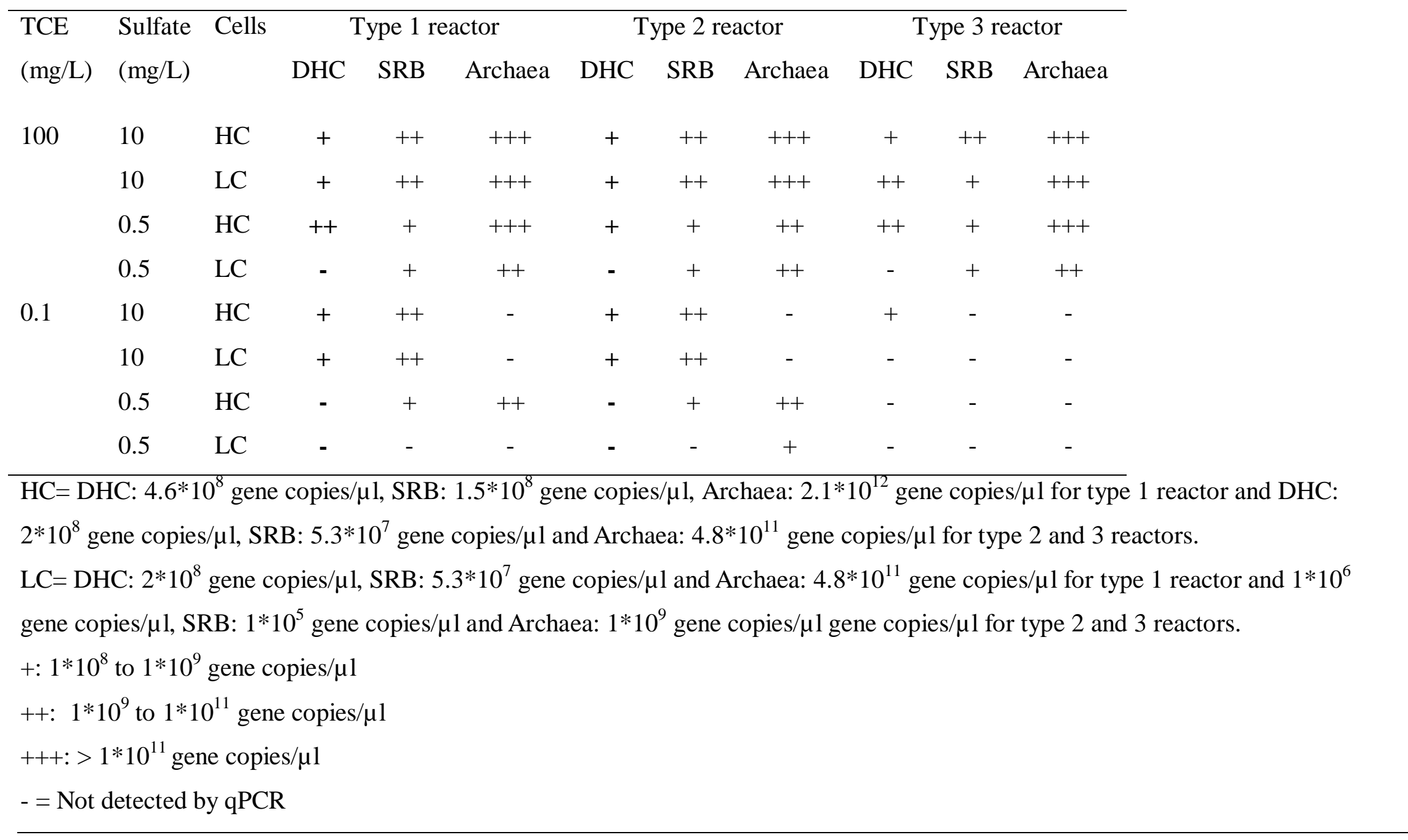




\subsubsection{Specific objective 1: To test the hypothesis that increasing TCE concentrations influence the concentration of DHC, SRB and Archaea.}

The concentration of DHC, SRBs and Archaea were analyzed in three types of reactors after addition of different concentrations of TCE as an electron acceptor and sodium lactate (which can be degraded to hydrogen) as electron donor, in an agar plug. The three different types of reactors were prepared with different concentrations of TCE $(0,10,50,100 \mathrm{mg} / \mathrm{L})$ and incubated for several days. The cells were scrapped after 1 week from three different locations in the reactor and the 16S rRNA gene of DHC and Archaea (a surrogate for methanogens) and $d s r A$ gene of SRB were measured by qPCR. Initial concentrations of DHC, SRB and Archaea added to the reactor, were estimated based on the density of cells in the seed reactor and volumes added at each step of the reactor construction. Therefore these initial concentrations of cells may underestimate the total number of cells added to the reactors due to losses during culture handling and washing prior to reactor innoculation.

Concentrations of Archaea were higher in all reactors than the other microorganisms under study and SRBs were always observed to have the lowest concentration (Figure 4.6A, B and C). The average concentration of Archaea in the type 1 reactors ranged from $2.12 * 10^{12}$ to $1.33 * 10^{13} 16 \mathrm{~S}$ rRNA gene copies $/ \mathrm{cm}^{2}$, while the DHC concentrations were lower ranging from an averge of $4.69 * 10^{10}$ to $3.19 * 10^{11} 16 \mathrm{~S}$ rRNA gene copies $/ \mathrm{cm}^{2}$ and SRB concentrations were the lowest ranging from an average of $3.02 * 10^{8}$ to $3.82 * 10^{9} d s r A$ gene copies $/ \mathrm{cm}^{2}$. This trend was similar in the type 2 and 3 reactors. In the type 2 reactor; Archaea average concentration ranged from $2.42 * 10^{13}$ to $1.37 * 10^{15}$; DHC ranged from $4.3^{*} 10^{9}$ to $9.7 * 10^{9}$ and SRB from $6.6^{*} 10^{7}$ to $7.6^{*} 10^{8}$ $d s r A$ gene copies $/ \mathrm{cm}^{2}$. In the type 3 reactor, Archaea average concentration ranged from $1.89 * 10^{12}$ to $5.44 * 10^{14}$; DHC ranged from $2.66 * 10^{11}$ to $1.45^{*} 10^{12}$ and SRB from $7.8^{*} 10^{8}$ to $1.6^{*} 10^{10} d s r A$ gene copies $/ \mathrm{cm}^{2}$.

In type 1 reactor, the percent increase in average DHC concentration was $25.7 \%$ for all TCE concentrations. There was $21.8 \%, 26 \%, 24.7 \%, 28.7 \%$ and $30.2 \%$ increase in concentration of DHC after seven days in the reactor in the $0.1,1,10,50$ and $100 \mathrm{mg} / \mathrm{L}$ of TCE treatments, respectively. Hence increasing concentration of TCE increased DHC concentration. In contrast 
to the DHC results, with increasing TCE concentration there were no significant changes observed in mean concentrations of Archaea in the type 1 . In the type 2 reactor, the percent increase in average DHC was $18 \%$ over 7 days, however there was no consistent trend in DHC and TCE concentrations. Specifically, at $10 \mathrm{mg} / \mathrm{L}$ TCE the DHC increase was $20 \%$, at $50 \mathrm{mg} / \mathrm{L}$ TCE the DHC increase was $13.4 \%$ and the DHC increase was $19.58 \%$ in the $100 \mathrm{mg} / \mathrm{L}$ TCE treatment. There were no significant changes observed in the mean concentration of SRB and Archaea in reactors with different concentrations of TCE. In the type 3 reactor, there was increase of 33 to $42 \%$ of DHC over 7 days but the trend was not linear. There was not significant change in concentration of SRB and Archaea population with changes in initial concentrations of TCE.

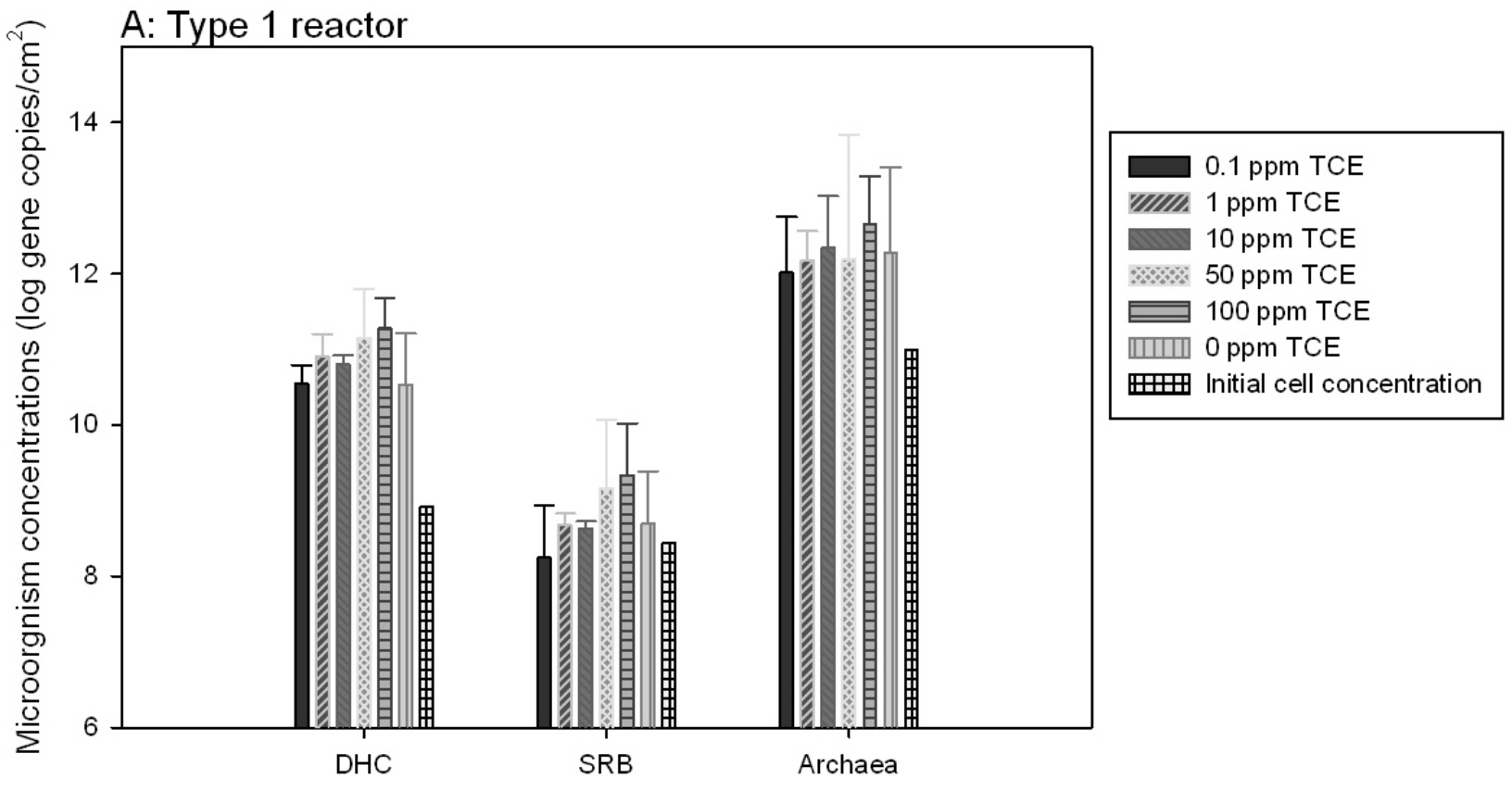




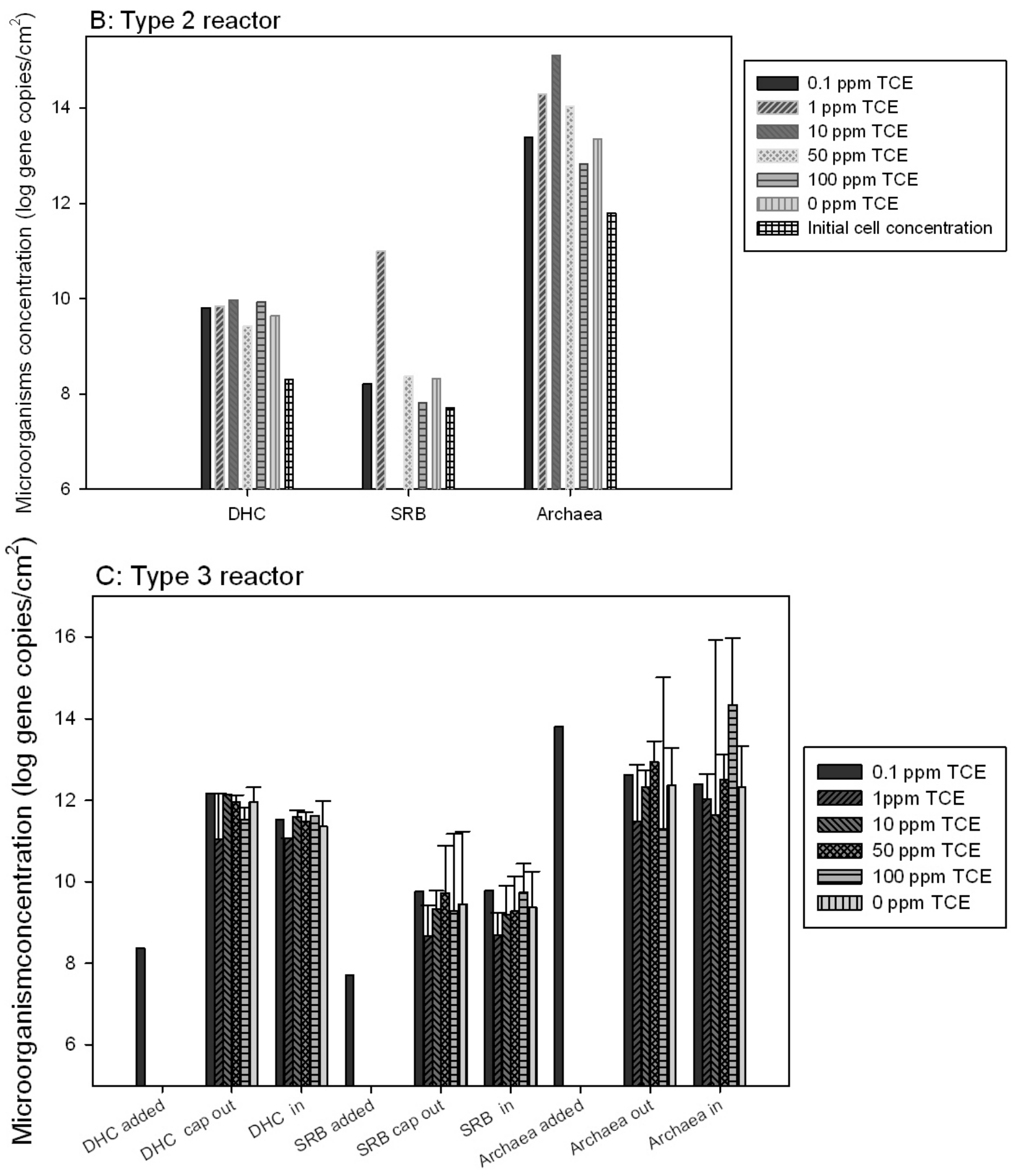

Figure 4.6. DHC, SRB and Archaea gene concentrations with varying TCE concentrations after $\mathbf{7}$ days in type 1 reactor (average and standard deviation of duplicates in all areas of reactor), type 2 reactor and type 3 reactor. 
The effect of increasing TCE concentrations on the average concentration of DHC, SRB and Archaea in all areas of the reactors, after 7 days of incubation is presented in Figure 4.6. In the type 1 reactor (Figure 4.7A), there was a linear correlation between increasing concentrations of TCE and DHC concentrations (Regression, $\mathrm{F}=12.265, \mathrm{P}=0.025$ ) and concentrations of TCE and SRB (Regression, $\mathrm{F}=14.757, \mathrm{P}=0.018$ ). The results suggest a trending relationship between TCE and the concentration of Archaea but at a non significant level (Regression, $\mathrm{F}=5.820, \mathrm{P}=0.073$ ).

In type 2 reactor, there was no observed correlation between initial concentration of TCE and the concentration of DHC (Regression, $\mathrm{F}=0.000201, \mathrm{P}=0.989$ ); concentration of TCE and the concentration of Archaea (Regression, $\mathrm{F}=1.105, \mathrm{P}=0.353$ ) and between concentration of TCE and $\mathrm{SRB}$ concentration (Regression, $\mathrm{F}=0.0175, \mathrm{P}=0.901$ ) (Figure 4.7 B).

Similarly in type 3 reactor, there was not a correlation between the concentration of TCE and the concentration of DHC (Regression, $\mathrm{F}=0.0284, \mathrm{P}=0.869$ ); the concentration of Archaea (Regression, $\mathrm{F}=0.142, \mathrm{P}=0.714$ ) and concentration of TCE and SRB concentration (Regression, $\mathrm{F}=8.258, \mathrm{P}=0.017$ ) (Figure $4.7 \mathrm{C}$ ). However, as shown in Figure 4.7C, there is a trending relationship between the DHC, SRB and Archaea with initial TCE concentration.

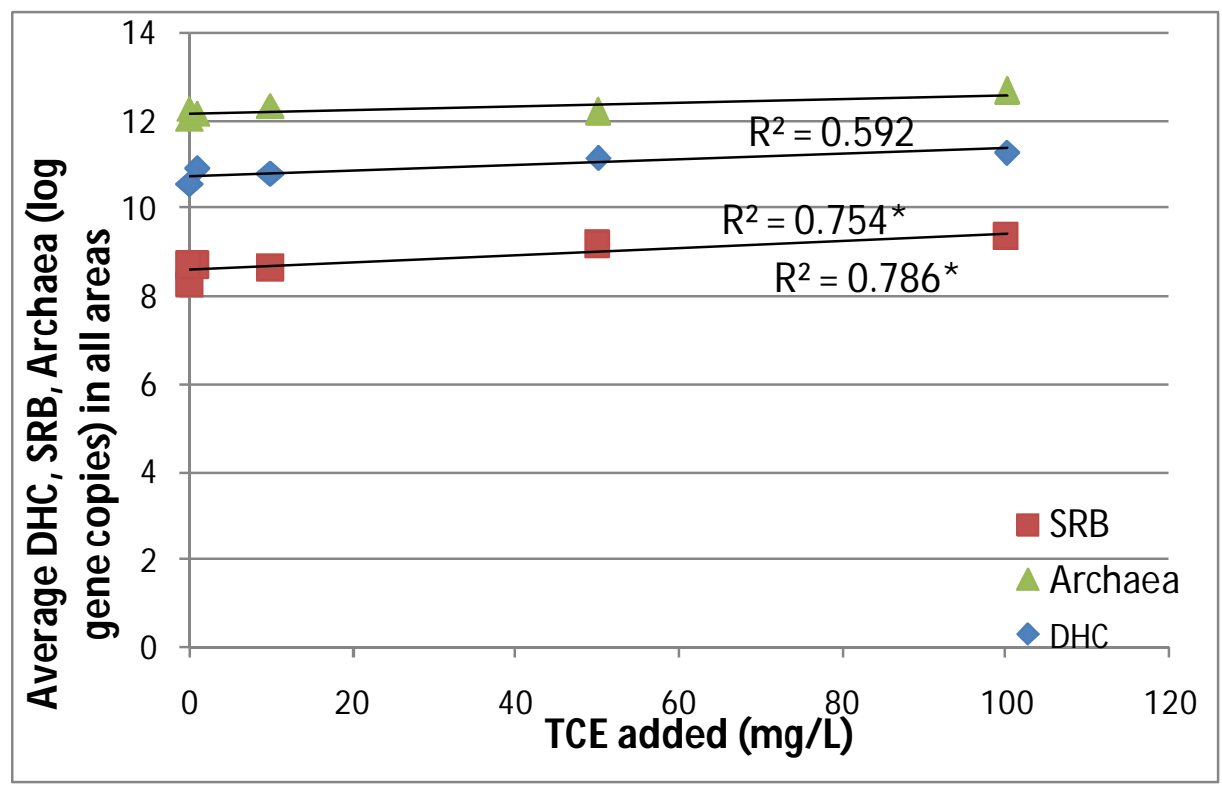




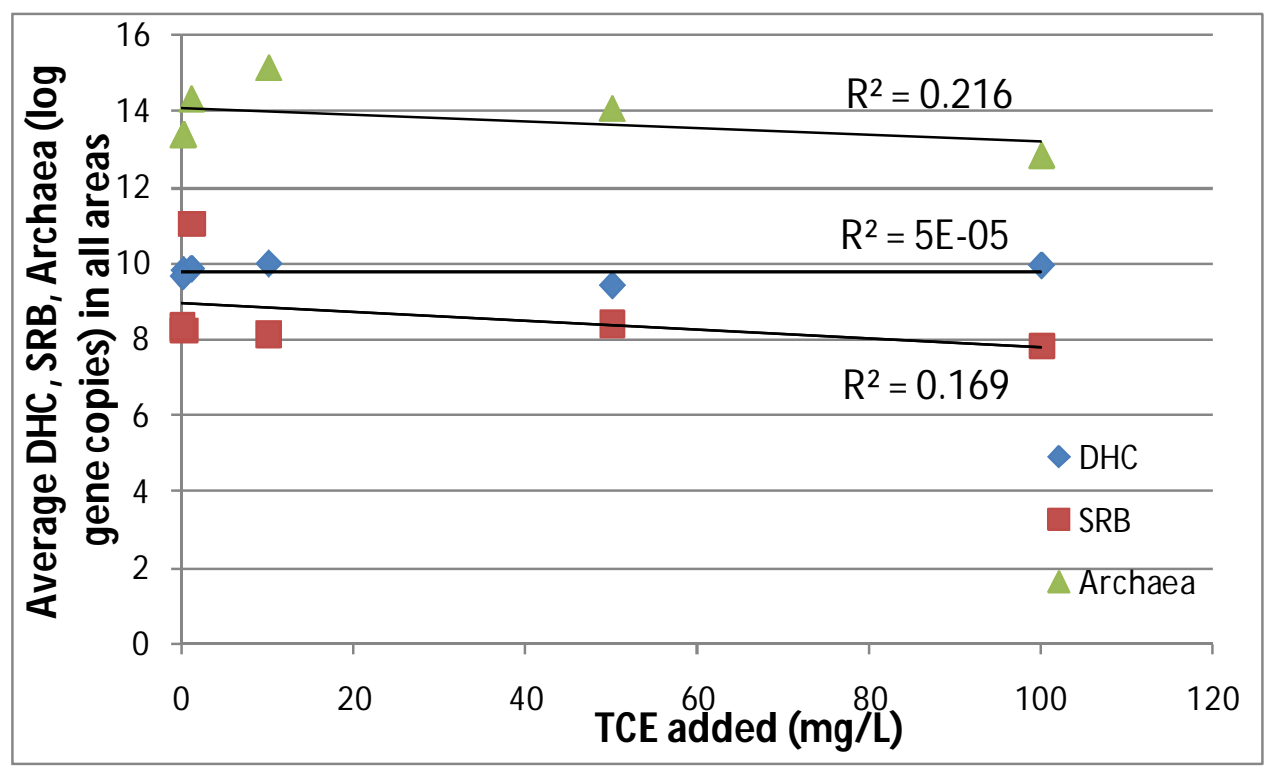

B

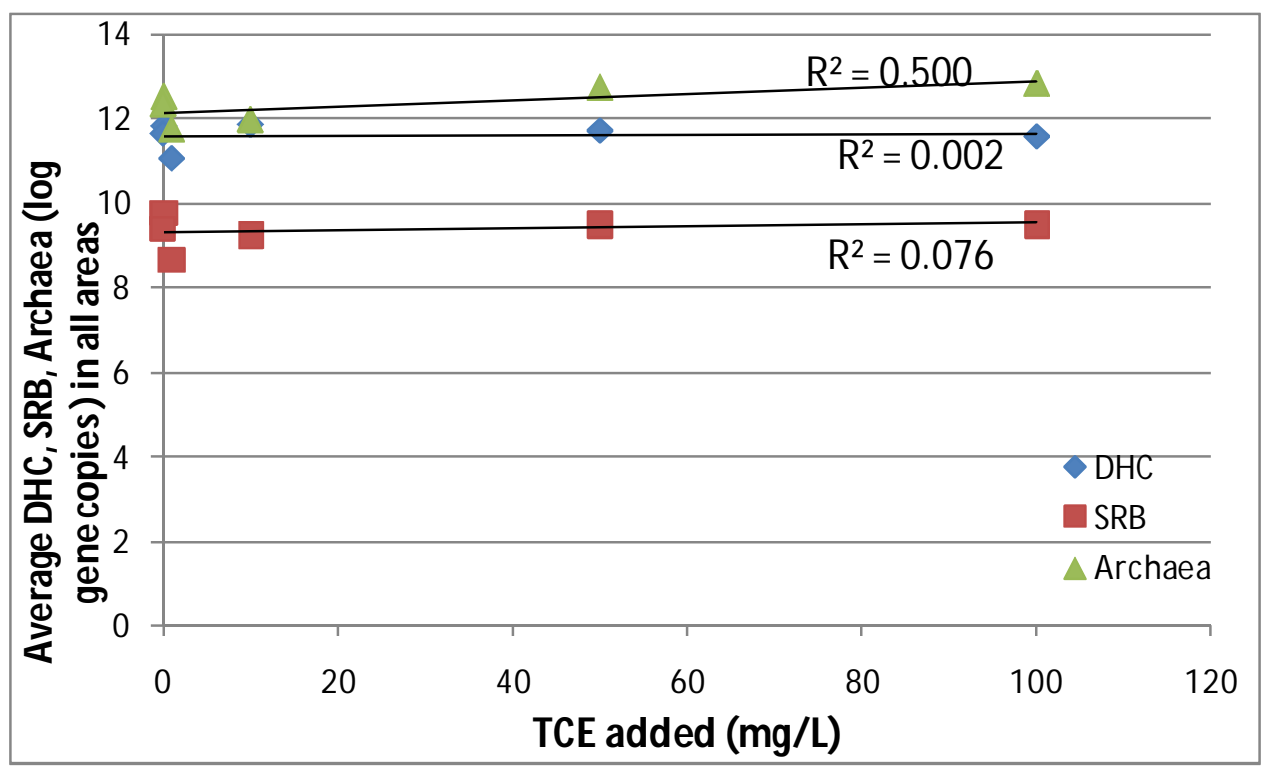

C

Figure 4.7. Relationship between DHC, SRB and Archaea gene concentration with respect to different TCE concentration in different reactor types after 7 days; A: type 1 reactor (average of all areas), B: type 2 reactor (average of all areas) and C: type 3 reactor (average of all inside and outside capillary tube). Regression with * is statistically significant $(\mathbf{P}<\mathbf{0 . 0 5})$. 


\subsubsection{Specific objective 2: To test the hypothesis that the concentration of DHC, SRB and Archaea decrease with increasing distance from the source of reducing equivalents (i.e., food)}

Spatial variability in the distribution of TCE and the distribution of microorganisms with distance from food source in different reactor types compared to different types of natural aquifers was analyzed. Concentration of DHC, SRB and Archaea were quantified in three areas with increasing distance from the location of food and TCE. The concentration of the microorganisms with distance from the food (e.g., agar plug and TCE) source is presented in Figure 4.8, Figure 4.9 and Figure 4.10 below for the type 1, 2 and 3 reactors respectively. Additionally, tests for significant differences between the mean concentrations of microorganisms in all TCE treatment levels in the three areas observed are presented in the Appendix (Appendix Table A4).

In the type 1 reactor (Figure 4.8), there was no statistically significant difference in the mean concentration of DHC, SRB and Archaea observed with distance from the agar plug containing TCE and food. Although DHC concentrations in area 3 in the higher concentration TCE treatments (e.g., 50 and $100 \mathrm{mg} / \mathrm{L} \mathrm{TCE}$ ) did seem to be lower than in areas 1 and 2, these results suggest that DHC concentrations may decline with distance from a TCE source, even in sandy aquifers where significant diffusion of the TCE may occur (i.e., there is less of a concentration gradient). DHC was higher in all areas than control with no TCE or low TCE $(0.1 \mathrm{mg} / \mathrm{L})$. 


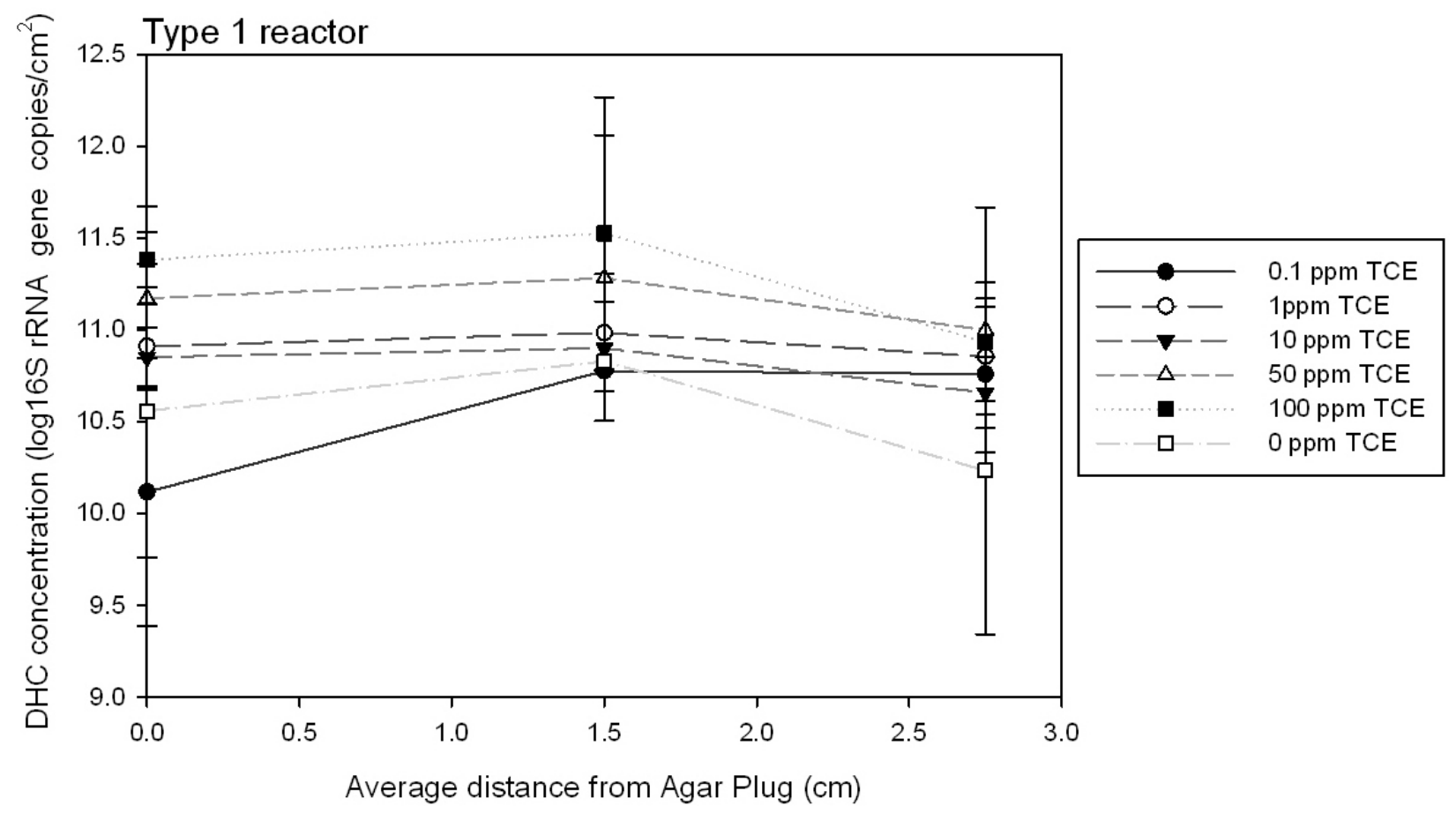

A

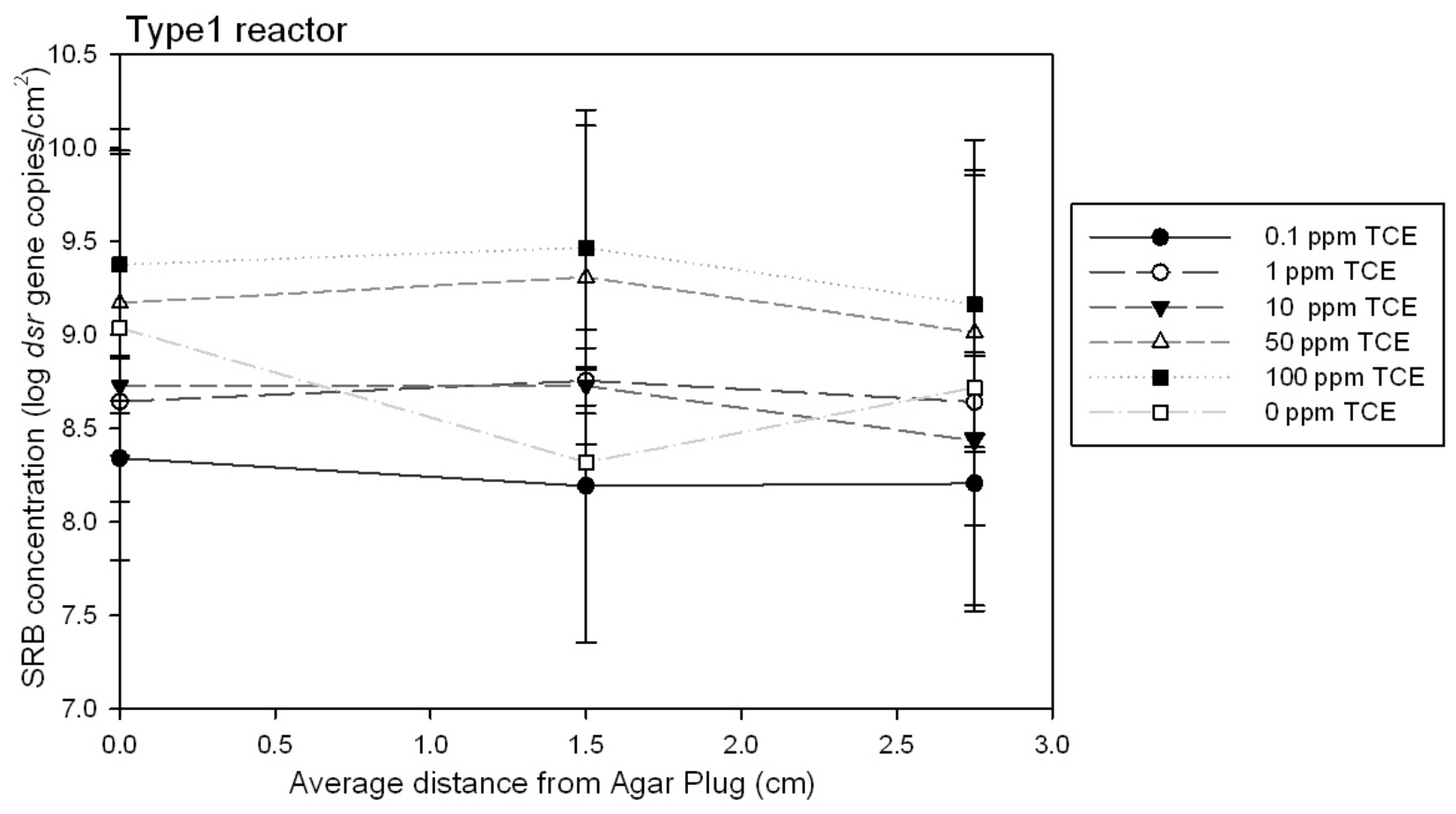

B 


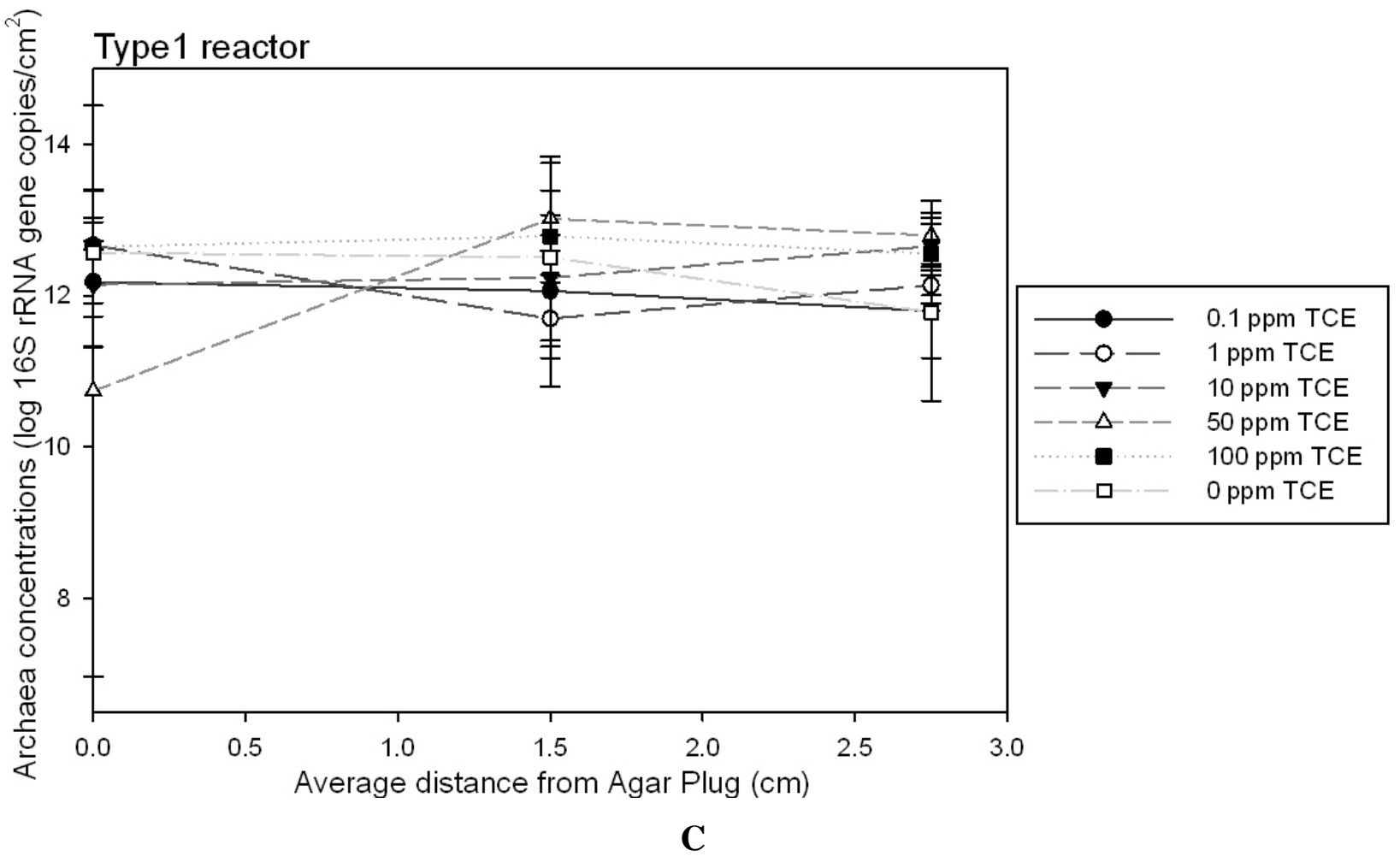

Figure 4.8. DHC (A), SRB (B) and Archaea (C) gene concentrations with distance from the agar plug and with different TCE concentrations after 7 days in Type 1 reactor (average and standard deviation of duplicates in three different areas of reactor).

In the type 2 reactor, there were strong trends observed in the mean concentration of DHC, SRB and Archaea with distance from the agar plug containing TCE and food. The mean concentration of the DHC in all TCE treatment levels in area 1 compared to area 2 (Student's t-test, $\mathrm{t}=2.446$, $\mathrm{P}=0.031$ ) and between area 1 and 3 (Mann Whitney Rank sum $\mathrm{T}=135, \mathrm{P}=0.029$ ) differ significantly but no significant difference between area 2 and 3. Similarly for Archaea, there was no significant difference between area 1 and 2 but was significant difference between area 2 and 3 (Mann Whitney Rank sum $\mathrm{T}=498, \mathrm{P}=0.018$ ) and between area 1 and 3 (Mann Whitney Rank sum $\mathrm{T}=390, \mathrm{P}<0.001)$ observed in the mean concentration with distance from the agar plug containing TCE and food. There was no statistically significant difference observed in the mean concentration of SRB with distance from the agar plug containing TCE and food. The detailed data are provided in Appendix Table A4. 


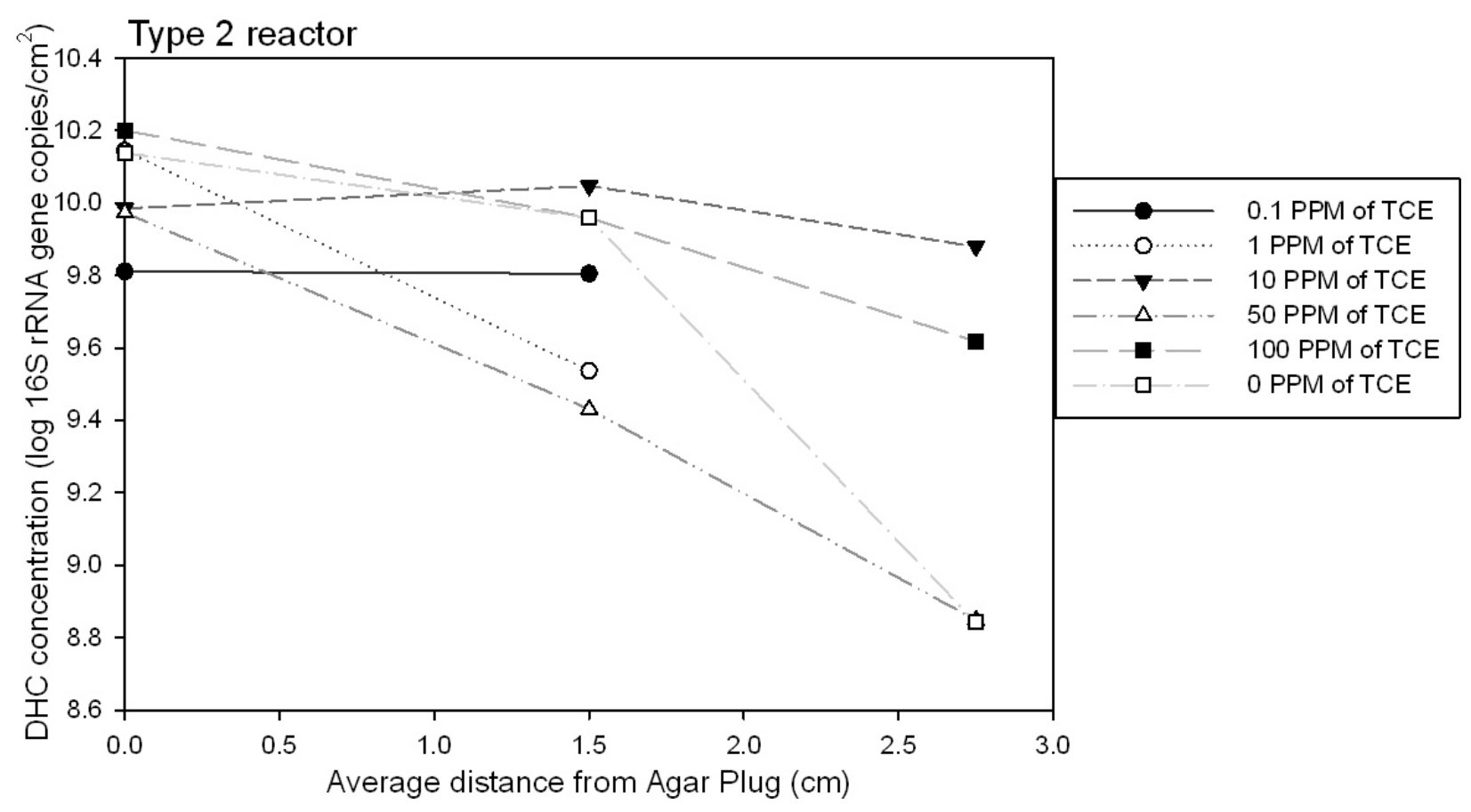

A

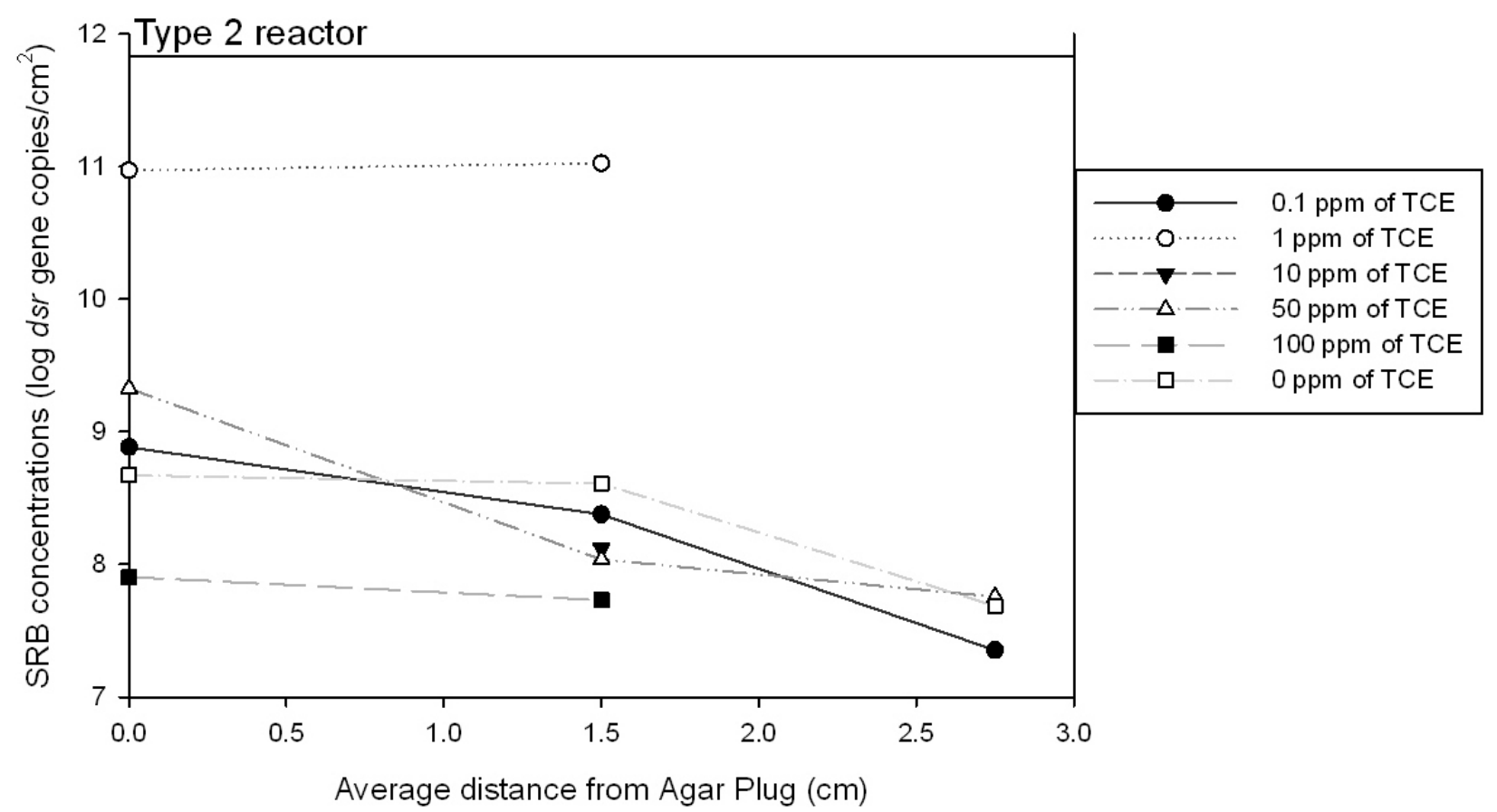

B 


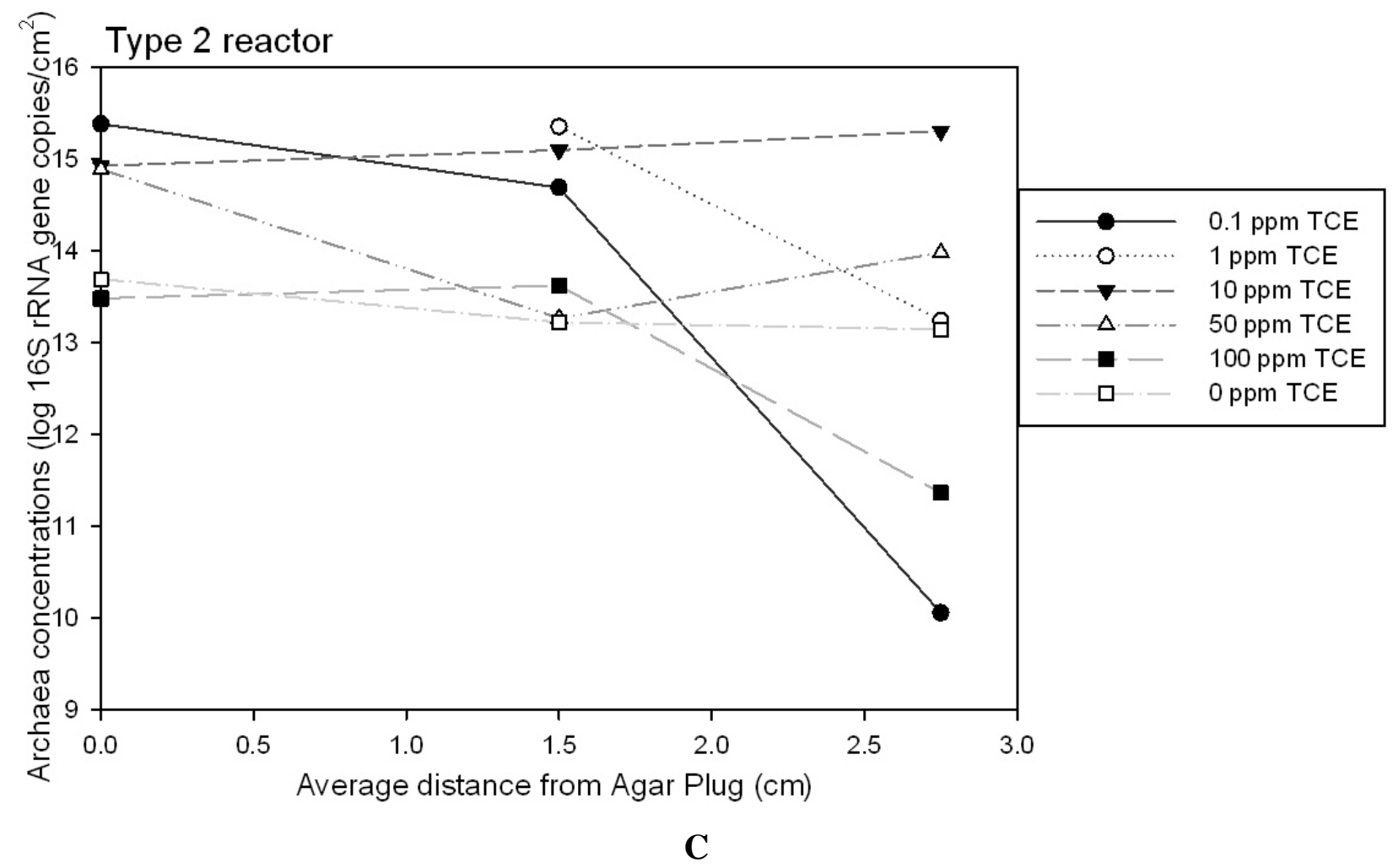

Figure 4.9. Concentration of microorganisms with distance from the agar plug and with differing TCE concentrations after 7 days in the type 2 reactor. DHC (A), SRB (B) and Archaea (C).

In type 3 reactors, at higher concentration at 50 and $100 \mathrm{mg} / \mathrm{L}$, DHC growth inside capillary has increased while outside capillary has decreased (Figure 4.10). In presence of trapped TCE in a fracture, the concentration of the DHC, SRB and Archaea between outside and inside tube (i.e., fracture) did not differ significantly (Appendix Table A4). The mean DHC percentage changed inside the tube was $42 \%$ and outside was $37.7 \%$; mean SRB percentage changed inside the tube was $20.88 \%$ and outside was $21.3 \%$; mean Archaea percentage changed inside the tube was $7.2 \%$ and outside was $4.14 \%$. 


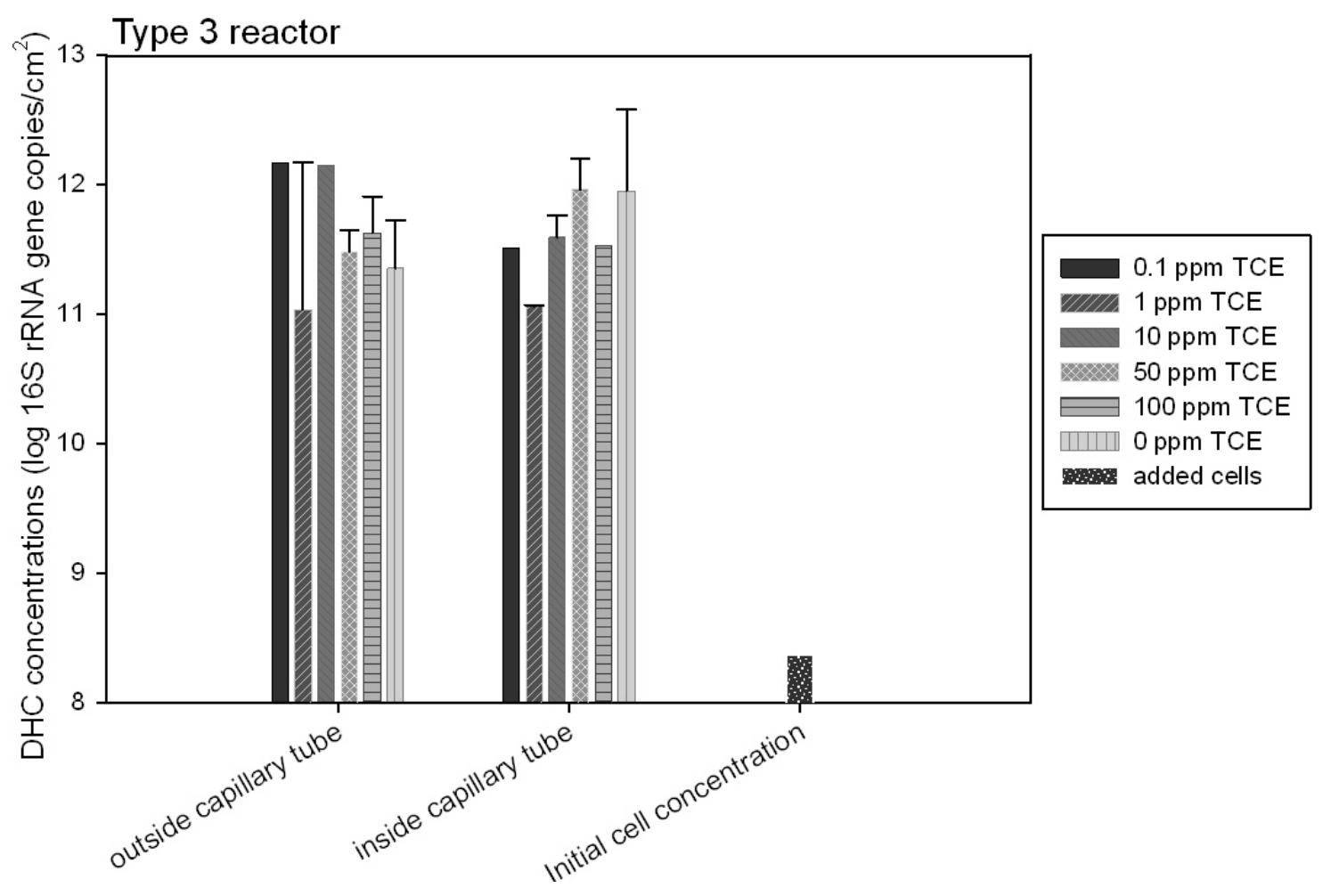

A

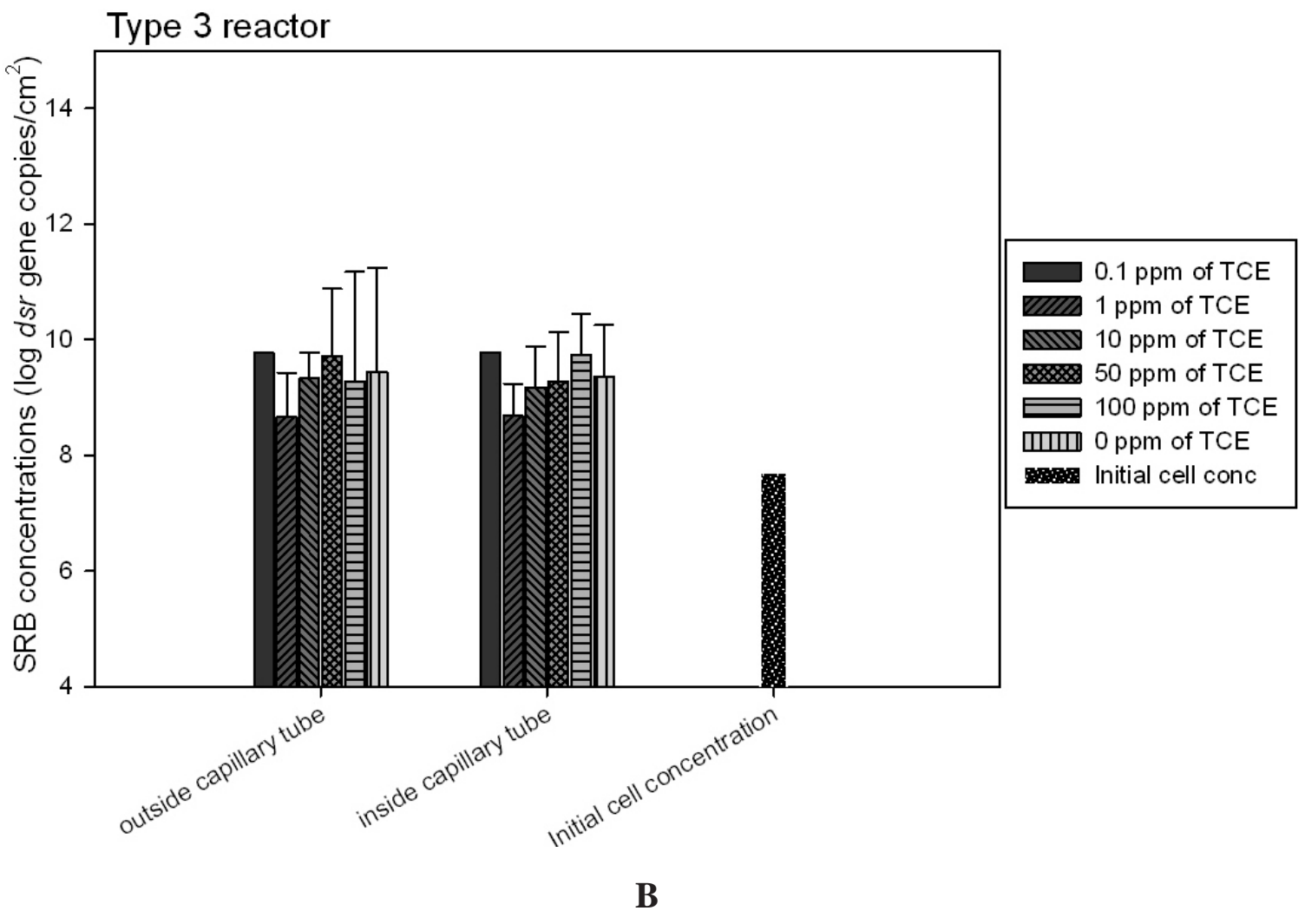




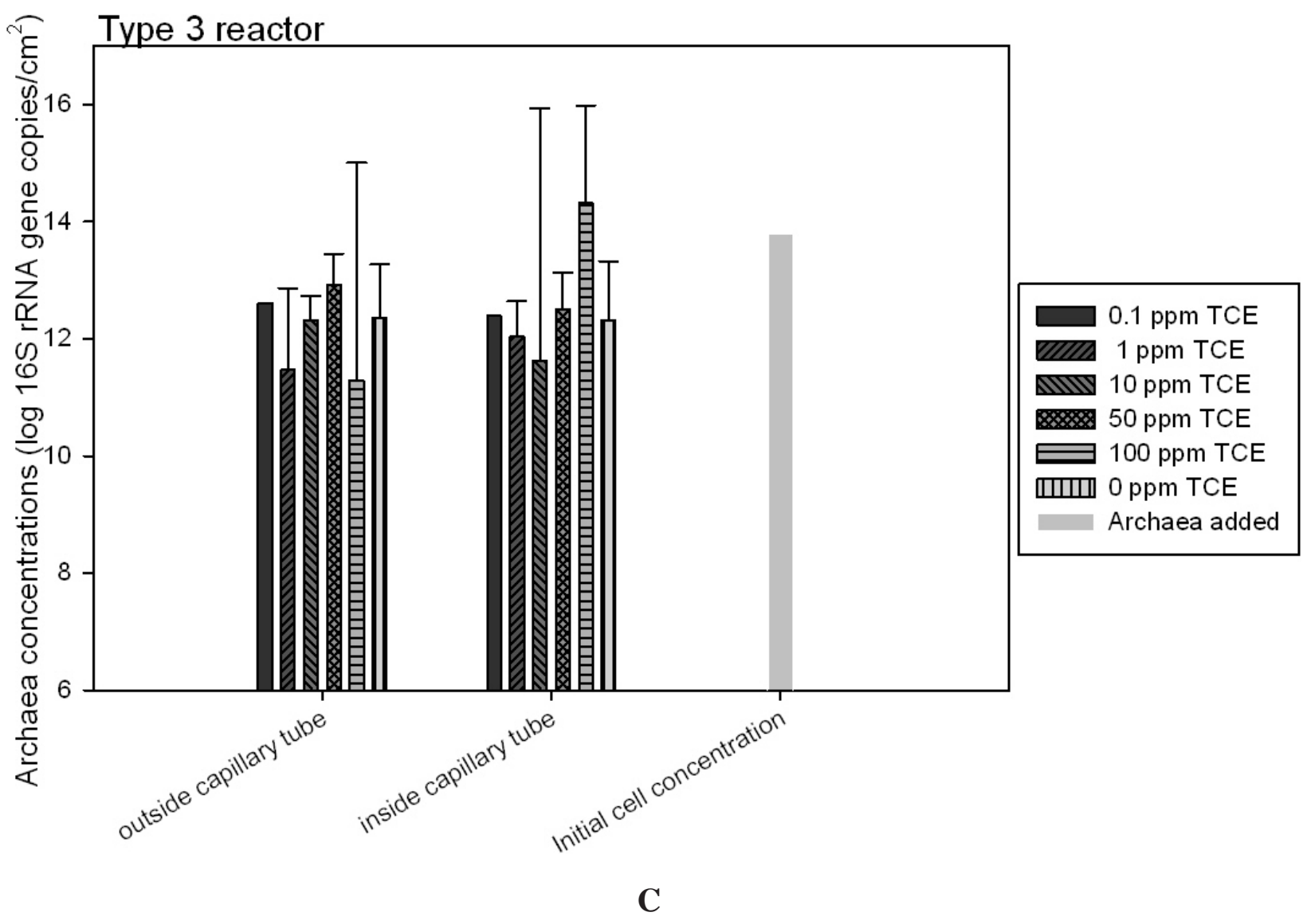

Figure 4.10. Mean and standard deviations of the log gene concentrations of DHC (A), SRB (B) and Archaea (C) with different concentration of TCE after 7 days in the type 3 reactor.

There is a strongly trending correlation between the initial concentration of TCE added and the concentration of $\mathrm{DHC}$ in area 1 (Regression, $\mathrm{F}=6.604, \mathrm{P}=0.062$ ) and area 2 (Regression, $\mathrm{F}=55.47, \mathrm{P}=0.002$ ) (Figure 4.11 ) but not in area 3 in type 1 reactor. There is a correlation between the initial concentration of TCE added and the concentration of SRB in area 2 (Regression, $\mathrm{F}=14.341, \mathrm{P}=0.019$ ) and in area 3 (Regression, $\mathrm{F}=8.736, \mathrm{P}=0.042$ ) but not in area 1 (Regression, $\mathrm{F}=7.060, \mathrm{P}=0.057$ ). There is no relationship between the initial concentration of TCE added and the concentration of Archaea in area 1, in area 2 and area 3. In type 2 reactor, there is no linear correlation between the initial concentration of TCE added and the concentration of DHC in area 1, in area 2 and area 3. Also SRB has no correlation to TCE in area 1, area 2 and area 3. Similarly there is no relationship between the initial concentration of TCE added and the concentration of Archaea in area 1, in area 2 and area 3. In type 3 reactor, there is no correlation between TCE concentration and growth of DHC inside the tube and also outside 
the tube. Similarly, the SRB has also no correlation with TCE concentration inside and outside of the tube. There is a correlation of Archaea inside the tube (Regression, $\mathrm{F}=14.77, \mathrm{P}=0.018$ ) with different concentration of TCE but not outside the tube with different concentration of TCE. The detail data is provided in Appendix Table A4.

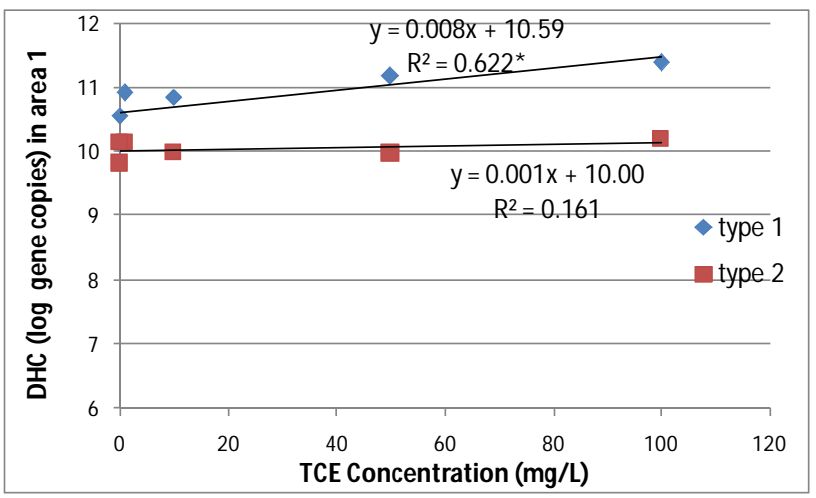

A

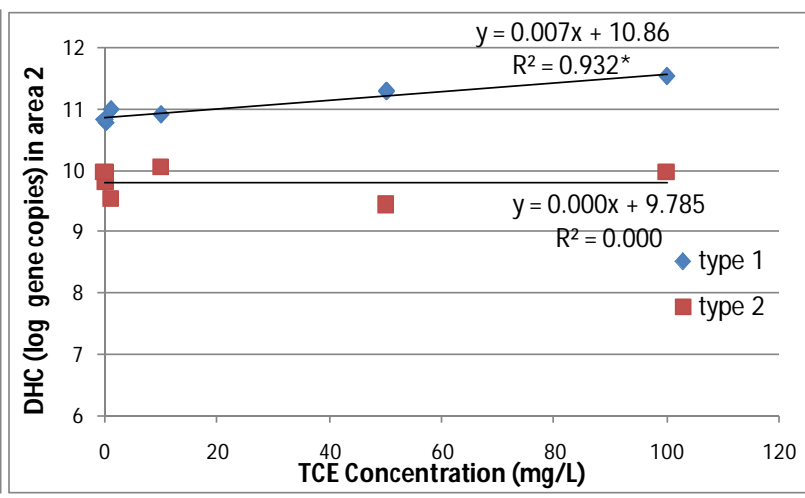

B

Figure 4.11. Relationship between DHC gene concentration with respect to different TCE concentration in type 1 and type 2 reactors after 7 days; A: area 1, B: area 2. Regression with * is statistically significant $(\mathbf{P}<0.05)$.

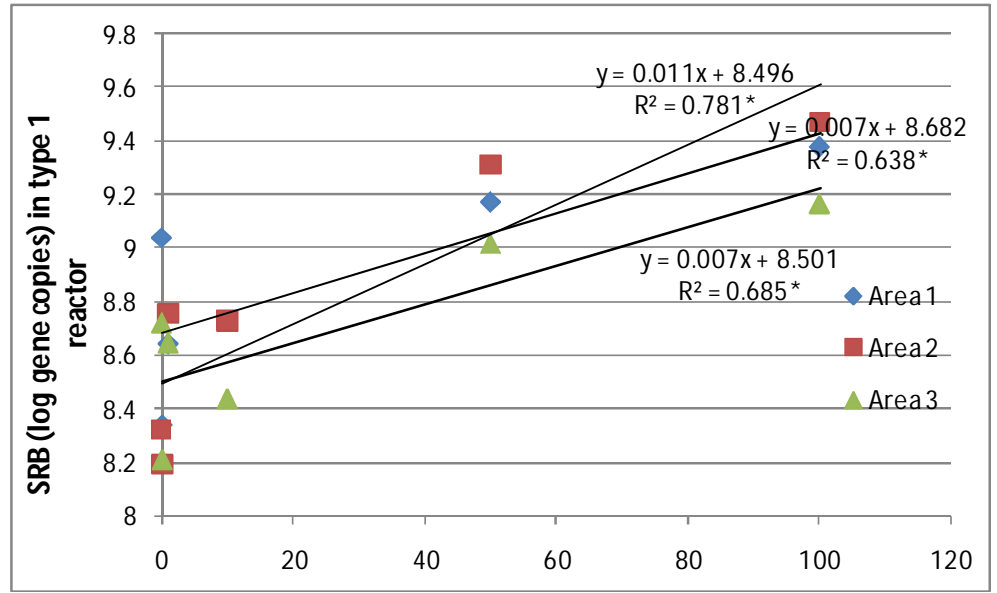

Figure 4.12. Relationship between SRB gene concentration in three different areas with respect to different TCE concentration in type 1 reactor after 7 days. Regression with * is statistically significant $(\mathbf{P}<0.05)$. 


\subsubsection{Specific objective 3: To test the hypothesis that after bioaugmentation DHC, SRB and Archaea concentrations increase due to microbial growth.}

Microorganisms were grown in different types of reactor as described as earlier. A total of 10 $\mathrm{mg} / \mathrm{L}$ of TCE and $0.5 \mathrm{mg} / \mathrm{L}$ of sulfate along with sodium lactate and yeast extract was added in the agar to make the food plug. The reactors were incubated over different period of time ( 0 day to 7 days) and concentration of DHC, SRB and Archaea were quantified by qPCR to observe microbial growth over time.

The concentration of TCE initially added to the reactor affected the observed concentration of micorganisms, but the result was different in each reactor. The microbial populations increased during the 7 days with some exceptions but this was not a constant trend. In type 1 and type 2 reactors, Archaea have increased and SRB may have increased. There was no change of DHC because the growth or doubling time of DHC is 0.8-3 days (Loeffler 2012) and there was no more growth observed after 3 days (Figure 4.13). Dehalococcoides are known to be strict anaerobes (Maymo et al., 1997; He et al., 2003a) and while the microcosms were initially slightly aerobic (as evidenced by the resazurin, DHC did survive in these reactors even though oxygen was present. There was an increase in DHC inside the capillary tube in the type 3 reactors, perhaps due to the more anaerobic conditions expected inside the tubes.

In contrast to the data in Figure 4.13 in the studies for hypothesis 1 there was a significant increase in DHC over the 7 days of study. There was $25.7 \%$ and 18\% change in DHC (Figure 4.8) for type 1 reactor and type 2 reactors respectively. This may be due to the higher concentration of DHC used in the previous studies (e.g., 50 and $100 \mathrm{mg} / \mathrm{L}$ ). 

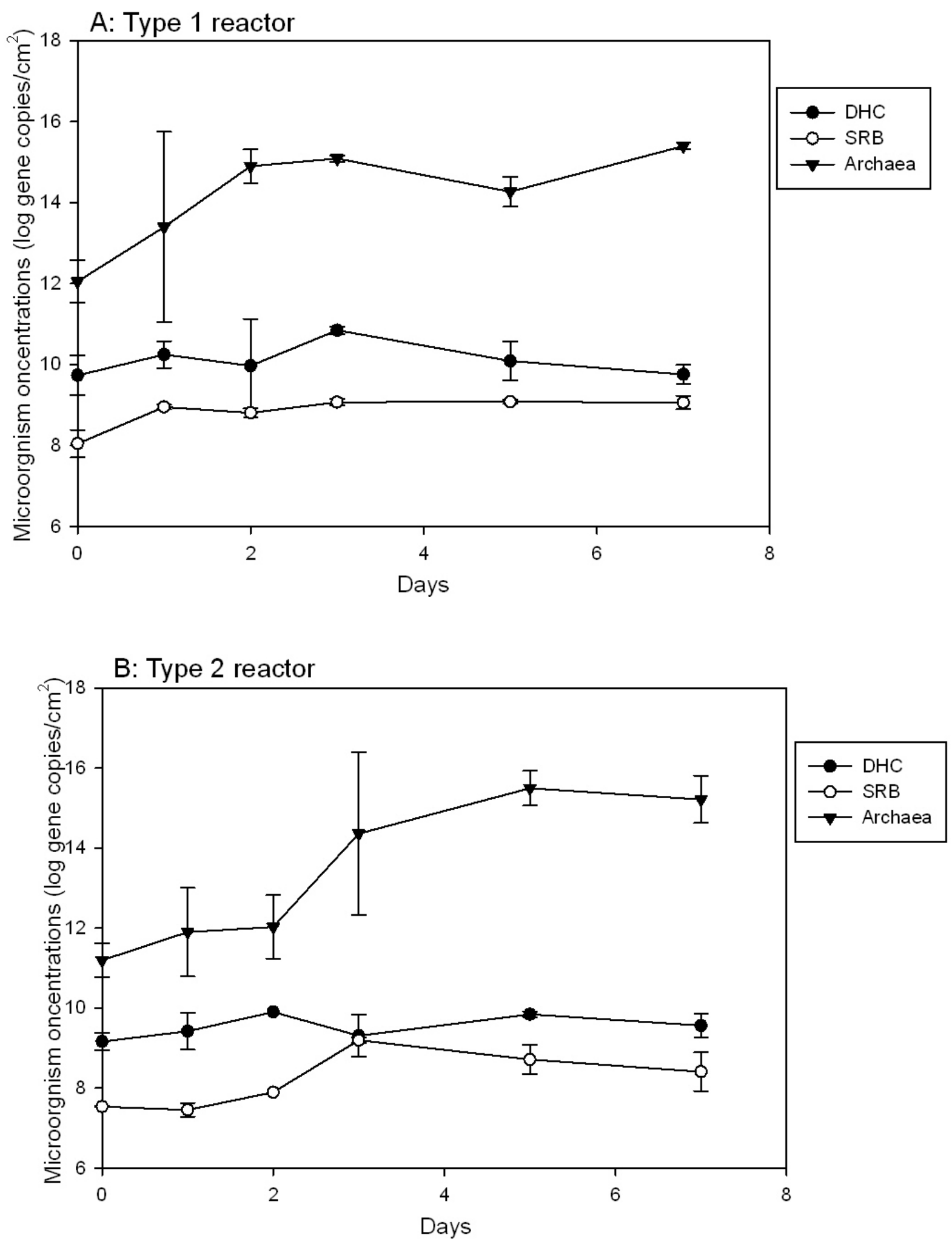


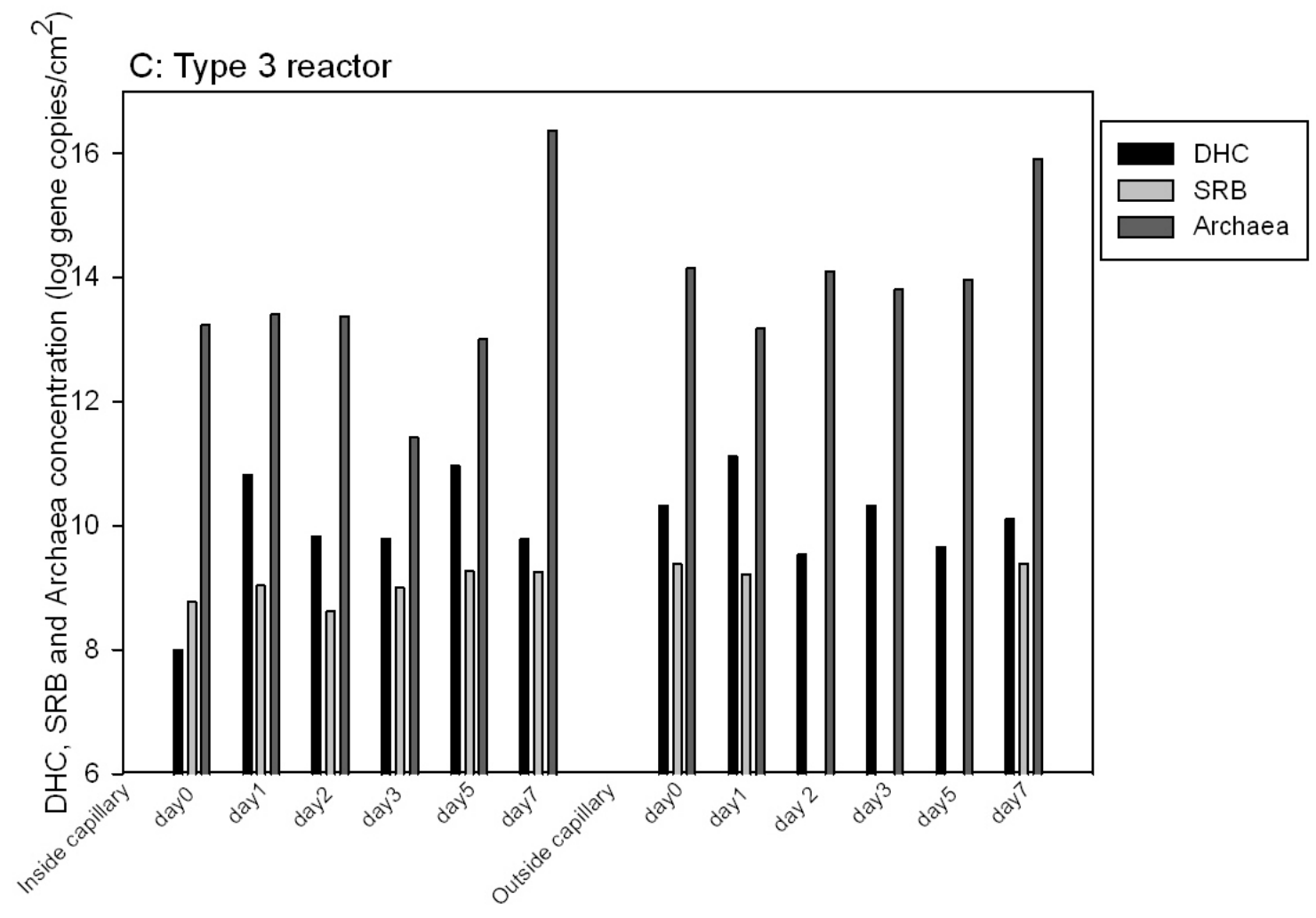

Figure 4.13. Average and standard deviations of the log concentrations of DHC, SRB and Archaea gene copies $/ \mathrm{cm}^{2}$ in type 1 reactor (A), type 2 reactor (B) and type 3 reactor (C)over time 


\section{CHAPTER 5 DISCUSSION}

Remediation of chlorinated solvent sites are complex, controversial, expensive and time consuming (Stroo \& Ward, 2010) because of DNAPL's likelihood to migrate a large distance and create large dissolved phase groundwater plumes. In situ remediation has a wide range of challenges and problems. The major problems associated with the biostimulation and bioremediation studied in this reasearch are:

1. Cometabolic mechanism: Physical, chemical and biological processes that occur during remediation.

2. Spatial variability: The spatial variability in the distribution of microorganisms (DHC, SRB and Archaea) and limited amount of spatial information on the relationship between TCE and microorganisms with distance from food source.

3. Fractured clay or bedrock: The dispersion of TCE over large volume and diffusion of TCE in the inaccessible or low permeability zones such as fractured clay or bedrock where TCE can become trapped posing a difficulty for treatment.

To address the above problems three hypothesis were tested: (1) increasing TCE concentrations influence the concentration of DHC, SRB and Archaea; (2) increasing distance from the source of reducing equivalents decrease the concentration of DHC, SRB and Archaea and (3) DHC, $\mathrm{SRB}$ and Archaea concentrations increase due to microbial growth after bioaugmentation.

Three different types of reactors were constructed to model three different types of aquifers. Type 1 reactor was constructed in such a way where dispersion of TCE is the major mechanism of TCE distribution. If it is compared to permeable aquifer which consists of highly permeable layers (sandy soil), bounded by an impermeable clay lens on the bottom of the aquifer and free water surface (Ritzema, 1994). In this type of aquifer DNAPL will tend to pool on the bottom of the aquifer and one major mechanism of distribution of the DNAPL is through diffusion and advection. The type 2 reactor constructed in this study can be compared to silt aquifer types, a poorly or semi-permeable layer (Ritzema, 1994), in which movement of DNAPL is trapped inside the silt soil and migration is possible within some distance through diffusion and less due to advection. The type 3 reactors was constructed with capillary tube with food compacted inside 
it. If it is compared to relatively impermeable aquifer such as fractured clay or bedrock, TCE might be trapped in pore space due to geological structures which restricts the free movement of water through it (Ritzema, 1994).

\subsection{Cometabolic mechanism}

In situ bioremediation challenges include the absence or low concentrations of specific microbes, and toxic or inhibitory conditions which restrict the biological, chemical and physical activities (Simkin \& Norris 2010). In nature, anaerobic dechlorination is typically carried out by mixed cultures of dechlorinators (Bradley, 2003). Three different species of anaerobic microcosms were studied in this research and modeled the mixed culture of dechlorinators and other microorganisms found in natural aquifers. In general, in this research the Archaea population was the most abundant and SRBs were the least abundant. The dechlorinator DHC competed successfully with these two types of microbes in the studies presented herein. Reductive dechlorination is favored under sulfate and methanogenic conditions (Chapelle 1996, Vogel et al. 1987) because Dehalococcoides coexist with sulfate reducing bacteria and methanogens by getting necessary micronutrients (Duhamel et al 2007, Yager 1997). In the type 1 reactor, there was a linear correlation between increasing concentrations of TCE and DHC and SRB concentrations. In type 2 and 3 reactors, there was no observed correlation between initial concentration of TCE with the average concentration of DHC, SRB and Archaea in all areas. The microbial populations increased during the 7 days with some exceptions but this was not a constant trend.

\subsection{Spatial variability}

One of the problems associated in remediation of chlorinated solvent is the spatial variability and limited amount of spatial information on the distribution of TCE and microorganisms (DHC, SRB and Archaea) with distance from food source. In this study, spatial variability in the distribution of TCE (electron acceptor) and the distribution of microorganisms (DHC, SRB and Archaea) with distance from food source in different reactor types compared to different types of natural aquifers was analyzed. Spatially, the highest concentrations of Archaea were present in 
type 1 reactor. DHC was located more near the food source (area 1 and area 2) than the further zones. In type 1 reactor type, TCE might diffuse throughout the reactor and the TCE concentration would probably be the same everywhere because TCE concentration gradient is lower. DHC was found less in area 3 than area 1 and 2 which might be due to less availability of food. However, these organisms still obtain diffused TCE and they attach where the substrate is located (area 1 and 2). Though area 2 has higher growth than area 1, it can be assumed that DHC attached to the food might get poisoned from high concentration of food itself or accumulation of toxic byproducts and pose problems or inhibit microbial growth (Simkin \& Norris, 2010). For example, high concentrations of some chemicals such as TCE, are toxic to microbes and have been shown to result in decrease of microbial population (Talley 2006) which might be due to sudden changes in the $\mathrm{pH}$ or geochemical conditions or degradation byproducts (Simkin \&Norris 2010).

The spatial variability in type 1 reactor representing sandy aquifer is presented Figure 5.1 in which TCE from the DNAPL is diffused throughout the reactor. TCE is present over a large distance. From the study it was observed that in a permeable (sandy) type of aquifer, type 1, DHC, SRB and Archaea concentration did not change significantly with the increasing distance from the food source as shown in Figures 4.8. Movement or flow of groundwater might carry DHC along with it to the zone farther away from the food amendment and there is still possibility of the growth of these microbes in presence of less substrate also. Hence, the spatial distribution of these microorganisms suggests that significant savings are possible with this bioaugmentation approach. In natural environment, bioaugmentation and biostimulation of substrate or reagents can be performed only at a certain point by measuring necessary distances which saves money on reagents as well as on culture. It also helps in designing of injection wells spacing, screen interval and location thus potentially presenting cost savings. 


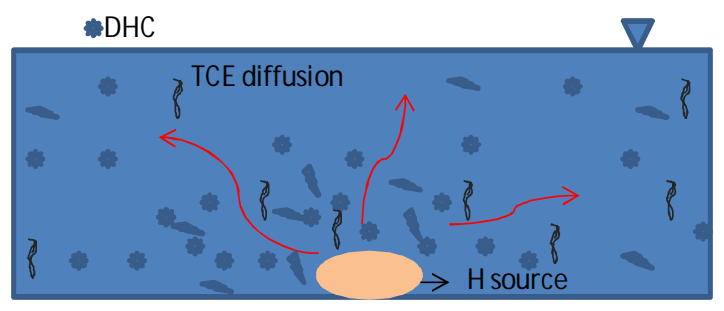

\section{A. X-section of type 1 reactor}
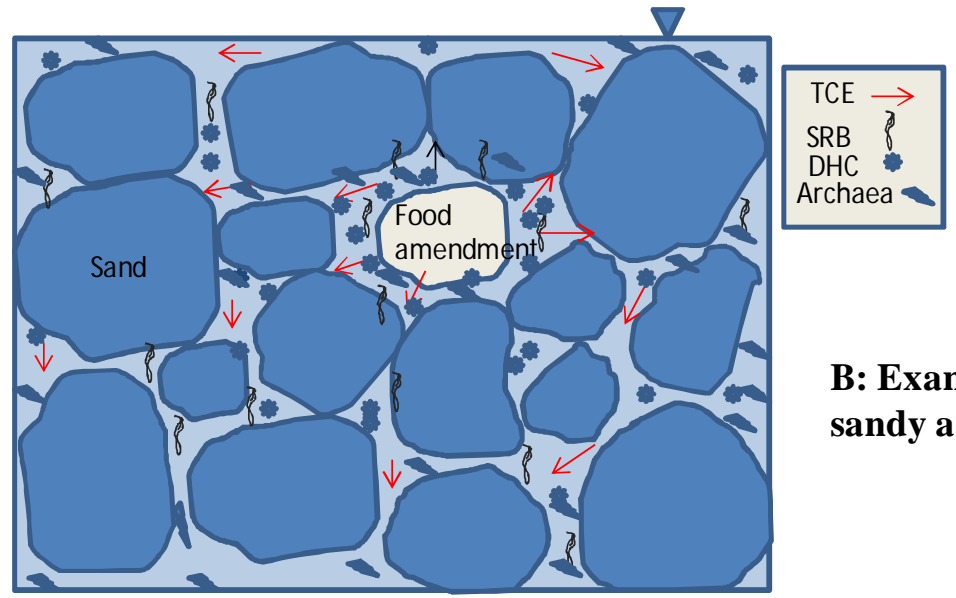

B: Example of sandy aquifer

Figure 5.1. Possible location of microorganisms in type 1 reactor in which most microbes are grown near the food amendment competing for electron donors while they still grow farther from food amendment where TCE is present due to diffusion.

In the type 2 reactor, TCE concentration gradients are more significant, thus, there may be lower concentrations of TCE at farther distances from the DNAPL. These types of reactors can be compared to semi-permeable silt aquifers. In this case, the TCE and food amendments gradient decrease together with distance from say a groundwater well injection point and the microbes more directly compete for food than in the type 1 reactor where these components are more diffuse. The possible distribution of microorganisms and food amendment is presented in Figure 5.2. In type 2 reactors, there were decreasing concentrations of these microorganisms or even no microorganisms detected in area 3 or in zones far from the food. It was observed very less and/or no microorganisms at further zones from the food. Hence, in lower permeability aquifers, the maximum concentration of microorganisms is located near the food and TCE source. 


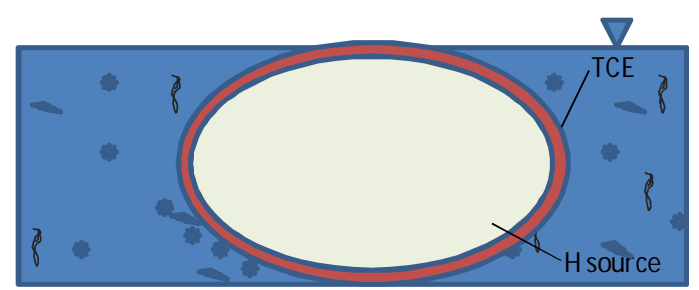

\section{A. X-section of type} 2 reactor
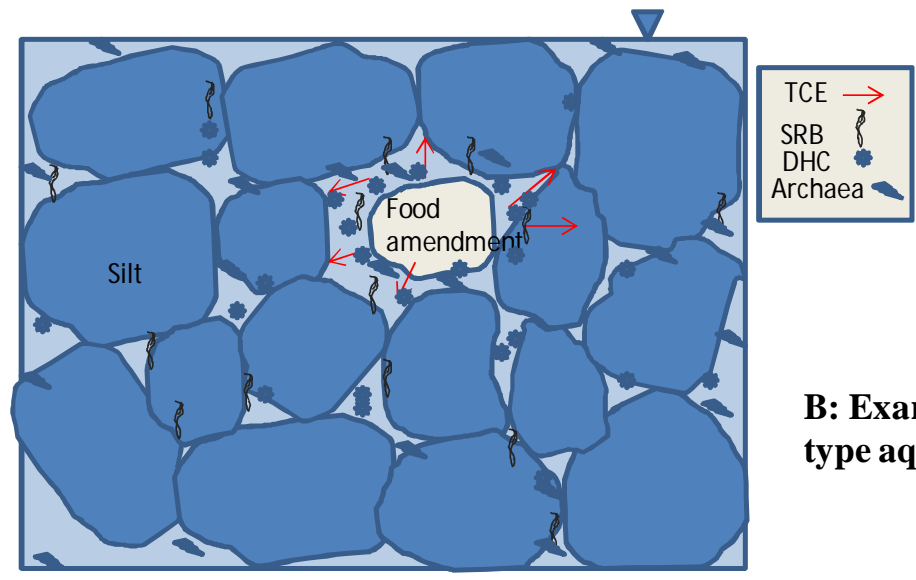

B: Example of silt type aquifer

Figure 5.2. Possible location of microorganisms in type 2 reactor in which TCE and food amendment are together and the microbes compete for them. At farther zone from food there is less and no growth of those microorganisms.

\subsection{Fractured clay or bedrock}

Another problem associated in groundwater remediation of TCE is the migration of contamination to the fractured clay or bedrock. The chlorinated solvents present in the fractured clay or bedrock sites are difficult to treat effectively. Due to complex hydro-geologic conditions, remediation is challenging (Simpkin \& Norris, 2010). There is difficulty in distributing bioremediation amendments or food in these types of aquifers. Pfiffner et al. (2000) found microbial counts decreased with higher clay content in the sediments. They concluded that the microbial communities can be dependent on the spatial distribution of key physical and chemical properties of the soil matrix. Low permeability or a high degree of heterogeneity limits the distributing of the bioremediation substrate effectively throughout the aquifer (Henry, 2010). The type 3 reactor can be compared to fractures in impermeable layers such as bedrock or lower permeability clay. For effective bioremediation, electron donor and microorganism contact with contaminants is essential. In this study, lower concentrations of microorganisms inside the tube were observed in type 3 reactor (Figure 4.10). Microorgansims might have migrated into the 
capillary tube modeling a fracture contaminant DNAPL in a real aquifer due to migration of microorganisms towards the food. Microorganisms added outside the fracture might migrate towards the food present inside the fracture hence competing for TCE and food. In Figure 5.3, the food amendment is inside the fracture or fissure where DNAPL migration took place and the microorganisms were injected outside the capillary tube or fracture. Outside the capillary tube has higher concentrations of these microorganisms and also there was growth observed inside the tube. The microorganisms might get contact with food through small pore volumes or fracture volumes and suspended successfully inside the fractures. Therefore, this study might be important in evaluating site conditions and cost-effective delivery of amendments.
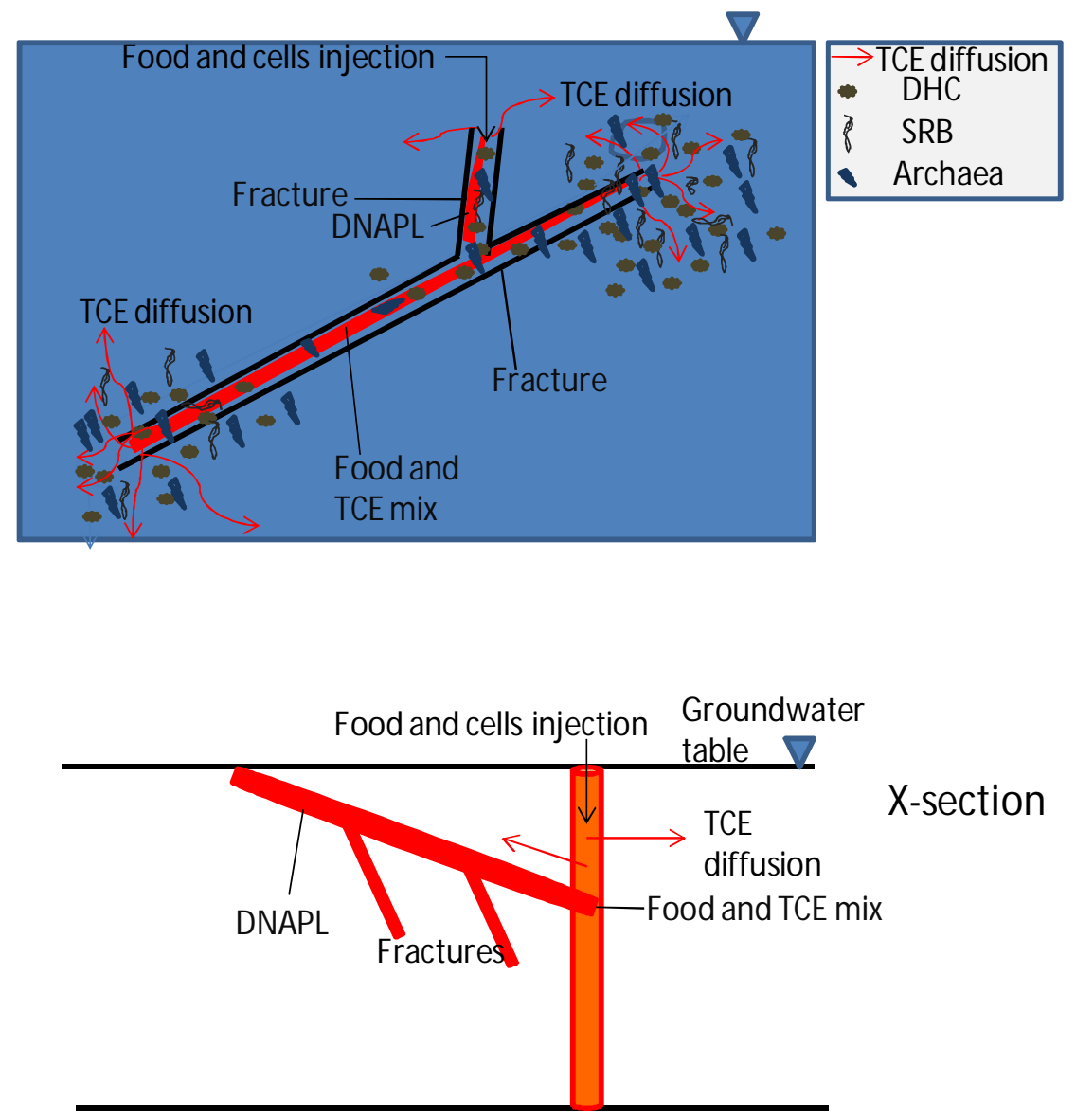

Figure 5.3. Fracture flow microorganisms in type 3 reactor in which TCE and food amendment are together but the space to migrate towards the food is very low. Microbes compete for the TCE located inside the clay as well as water, due to compact structure of clay particle those microbes try to find food. 


\section{CHAPTER 6 CONCLUSIONS AND RECOMMENDED FUTURE RESEARCH}

\subsection{Conclusions}

In this research the Archaea population was the most abundant and SRBs were the least abundant. The dechlorinator DHC competed successfully with these two types of microbes in the studies presented herein. Spatially, the highest concentrations of Archaea were present in type 1 reactor. In type 1 reactor, increasing concentration of TCE increased DHC concentration. There was a linear correlation between increasing concentrations of TCE and DHC concentrations and concentrations of TCE and SRB and a trending relationship between TCE and the concentration of Archaea. The percentage change in average DHC was $25.7 \%$. In type 2 reactors, no observed correlation between initial concentration of TCE and the average concentration of DHC, concentration of TCE and between average concentration of SRB and the average concentration of Archaea. The percentage change in average DHC was 18\%. In type 3 reactor, there was increase of 33 to $42 \%$. There was not a correlation between the concentration of TCE and the average concentration of DHC, Archaea and SRB.

DHC was more likely to be located near the food source (area 1 and area 2) than farther from the food. In a permeable (sandy) type of aquifer, type 1, DHC, SRB and Archaea concentration did not change significantly with increasing distance from the food source. In type 2 reactors in this study, there were decreasing concentrations of these microorganisms or even no microorganisms detected in area 3 or in zones far from the food. Hence, in lower permeability aquifers, the distribution of the maximum microorganisms is near the food and TCE source. The type 3 reactor used in this study modeled fractures in impermeable layers such as bedrock or lower permeability clay. Lower concentrations of microorganisms inside the tube were observed in type 3 reactor. Outside the capillary tube were higher concentrations of microorganisms, however growth was observed inside the tube. Growth of microorganisms inside the tube suggests that microorganisms might grow successfully inside the fractures even with very high TCE concentrations. 
Hence, it is concluded that various concentrations of TCE and the location of food source affects the population and distribution of DHC, SRB and Archaea. In sandy and silty aquifers, DHC concentrations may decline with distance from a TCE source. In thetype 3 reactor (fractured rock), the concentration of the DHC, SRB and Archaea between outside and inside tube did not differ significantly.

\subsection{Recommendations for Future Research}

Because the set-up of this experiment did not emulate a natural environment, it is thought that the application of these products in the field should be tested before any decision is made but it is believed that this test provides a database for further evaluations. The distance from food source in cms is not practical in the field study. The population of microorganism according to food distance provides useful information to help estimate the amounts of sodium lactate for augmentation in order to obtain removal of TCE and thus it is an important cost component of the treatment system. The concentration of sulfate, TCE and sodium lactate and density of culture are the main factors which help to understand the distribution of DHC, SRB and Archaea. The data found in the laboratory should be matched with field observations or injections of cultures in bench scale soil microcosms. Since primary substrate (electron-donor) injection are among the major cost components of an in situ treatment system, methods to grow DHC, SRB and Archaea coexistance are important. The laboratory study suggests that the addition of low sulfate if necessary may help by providing necessary energy without inhibiting TCE degradation. 


\section{REFERENCES}

Adrian L, Szewzyk U, Wecke J \& Görisch H (2000) Bacterial dehalorespiration with chlorinated benzenes Nature 408: 580-583.

Aggarwal V, Li H, Boyd SA \& Teppen BJ (2006) Enhanced sorption of trichloroethene by smectite clay exchanged with Cs Environ Sci Technol 40: 894-899.

Alvarez-Cohen L \& Speitel GE (2001) Kinetics of aerobic cometabolism of chlorinated solvents Biodegradation 12: 105-126.

Amann R \& Fuchs BM (2008) Single-cell identification in microbial communities by improved fluorescence in situ hybridization techniques Nature Reviews Microbiology 6: 339-348.

Amann R, Glöckner FO \& Neef A (2006) Modern methods in subsurface microbiology: in situ identification of microorganisms with nucleic acid probes FEMS Microbiol Rev 20: 191-200.

Amann R, Snaidr J, Wagner M, Ludwig W \& Schleifer KH (1996) In situ visualization of high genetic diversity in a natural microbial community. J Bacteriol 178: 3496-3500.

Arcangeli JP \& Arvin E (1997) Modeling of the cometabolic biodegradation of trichloroethylene by toluene-oxidizing bacteria in a biofilm system Environ Sci Technol 31: 3044-3052.

Arnold WA \& Roberts AL (2000) Pathways and kinetics of chlorinated ethylene and chlorinated acetylene reaction with Fe (0) particles Environ Sci Technol 34: 1794-1805.

Arp DJ, Yeager CM \& Hyman MR (2001) Molecular and cellular fundamentals of aerobic cometabolism of trichloroethylene Biodegradation 12: 81-103.

Arya M, Shergill IS, Williamson M, Gommersall L, Arya N \& Patel HRH (2005) Basic principles of real-time quantitative PCR Expert review of molecular diagnostics 5: 209-219.

ASTM (2012), Standard Test Methods for Chemical Oxygen Demand (Dichromate Oxygen Demand) of Water, ASTM D1252 - 06 http://enterprise.astm.org/filtrexx40.cgi?+REDLINE PAGES/D1252.htm 
ATSDR (1997) Toxicological Profile for Trichloroethylene (updated) Agency for Toxic Substances Disease Registry, Atlanta.

ATSDR (2004) ToxFAQs for 1,1,2-trichloroethane Agency for Toxic Substances and Disease Registry; http://www.atsdr.cdc.gov.www.libproxy.wvu.edu/tfacts148.html.

ATSDR (2007) ATSDR CEP site count report Agency for Toxic Substances and Disease Registry http://www.atsdr.cdc.gov/cep/07cep.html.

Bagley DM \& Gossett JM (1989) Tetrachloroethene transformation to trichloroethene and cis1,2-dichloroethene by sulfate-reducing enrichment culture Appl Environ Microbiol 56: 25112516.

Balch WE, Fox GE, Magrum LJ, Woese CR \& Wolfe RS (1979) Methanogens: Reevaluation of a unique biological group Microbiological Reviews 43: 260-296.

Ballapragada BS, Stensel HD, Puhakka J \& Ferguson JF (1997) Effect of hydrogen on reductive dechlorination of chlorinated ethenes Environ Sci Technol 31: 1728-1734.

Barton LL \& Hamilton WA (2007) Sulphate-reducing bacteria: Environmental and engineered systems Cambridge University Press.

Bouwer EJ \& McCarty PL (1983) Transformations of 1-and 2-carbon halogenated aliphatic organic compounds under methanogenic conditions Appl Environ Microbiol 45: 1286-1294.

Bouwer EJ, Norris R, Hinchee R, Brown R, McCarty P, Semprini L, Wilson J, Kampbell D, Reinhard M \& Borden R (1994) Bioremediation of chlorinated solvents using alternate electron acceptors Handbook of bioremediation 149-175.

Bradley PM \& Chapelle FH (1996) Anaerobic mineralization of vinyl chloride in Fe (III)reducing, aquifer sediments Environ Sci Technol 30: 2084-2086. 
Burris DR, Campbell TJ \& Manoranjan VS (1995) Sorption of trichloroethylene and tetrachloroethylene in a batch reactive metallic iron-water system Environ Sci Technol 29: 28502855.

Butler EC \& Hayes KF (1999) Kinetics of the transformation of trichloroethylene and tetrachloroethylene by iron sulfide Environ Sci Technol 33: 2021-2027.

Castro C \& Belser N (1990) Biodehalogenation: oxidative and reductive metabolism of 1, 1, 2-trichloroethane by Pseudomonas Putida-Biogeneration of vinyl chloride Environmental toxicology and chemistry 9: 707-714.

Chang YJ, Peacock AD, Long PE, Stephen JR, McKinley JP, Macnaughton SJ, Hussain AKMA, Saxton AM \& White DC (2001) Diversity and characterization of sulfate-reducing bacteria in groundwater at a uranium mill tailings site Appl Environ Microbiol 67: 3149-3160.

Chapelle FH, Haack SK, Adriaens P, Henry MA \& Bradley PM (1996) Comparison of Eh and $\mathrm{H}_{2}$ measurements for delineating redox processes in a contaminated aquifer Environ Sci Technol 30: $3565-3569$.

Chapelle FH (1993) Groundwater microbiology and geochemistry JW Sons New York 251- 253.

Chen C, Puhakka JA \& Ferguson JF (1996) Transformations of 1, 1, 2, 2-tetrachloroethane under methanogenic conditions Environ Sci Technol 30: 542-547.

Cheng D \& He J (2009) Isolation and characterization of "Dehalococcoides" sp. strain MB, which dechlorinates tetrachloroethene to trans-1, 2-dichloroethene Appl Environ Microbiol 75: $5910-5918$.

Coleman NV, Mattes TE, Gossett JM \& Spain JC (2002) Phylogenetic and kinetic diversity of aerobic vinyl chloride-assimilating bacteria from contaminated sites Appl Environ Microbiol 68: 6162-6171. 
Cupples AM, Spormann AM \& McCarty PL (2003) Growth of a Dehalococcoides-like microorganism on vinyl chloride and cis-dichloroethene as electron acceptors as determined by competitive PCR Appl Environ Microbiol 69: 953-959.

de Roda Husman A, Snijders P, Stel H, Van Den Brule A, Meijer C \& Walboomers J (1995) Processing of long-stored archival cervical smears for human papillomavirus detection by the polymerase chain reaction. Br J Cancer 72: 412.

DiStefano TD, Gossett J \& Zinder S (1992) Hydrogen as an electron donor for dechlorination of tetrachloroethene by an anaerobic mixed culture Appl Environ Microbiol 58: 3622-3629.

DiStefano TD, Gossett JM \& Zinder SH (1991) Reductive dechlorination of high concentrations of tetrachloroethene to ethene by an anaerobic enrichment culture in the absence of methanogenesis. Appl Environ Microbiol 57: 2287-2292.

Doherty RE (2000) A history of the production and use of carbon tetrachloride, tetrachloroethylene, trichloroethylene and 1, 1, 1-trichloroethane in the United States: Part 1Historical Background; Carbon Tetrachloride and Tetrachloroethylene Environmental forensics 1: $69-81$.

Dolfing J \& Janssen DB (1994) Estimates of Gibbs free energies of formation of chlorinated aliphatic compounds Biodegradation 5: 21-28.

Duhamel M \& Edwards EA (2007) Growth and yields of dechlorinators, acetogens, and methanogens during reductive dechlorination of chlorinated ethenes and dihaloelimination of 1 , 2-dichloroethane Environ Sci Technol 41: 2303-2310.

Duhamel M, Mo K \& Edwards EA (2004) Characterization of a highly enriched Dehalococcoides containing culture that grows on vinyl chloride and trichloroethene Appl Environ Microbiol 70: 5538-5545.

Egli C, Scholtz R, Cook AM \& Leisinger T (1987) Anaerobic dechlorination of tetrachloromethane and 1, 2-dichloroethane to degradable products by pure cultures of Desulfobacterium sp. and Methanobacterium sp. FEMS Microbiol Lett 43: 257-261. 
Egli C, Tschan T, Scholtz R, Cook AM \& Leisinger T (1988) Transformation of tetrachloromethane to dichloromethane and carbon dioxide by Acetobacterium woodii. Appl Environ Microbiol 54: 2819-2824.

Ensley BD \& Suflita JM (1995) Melabolism of environmental contaminants by mixed and pure cultures of sulfate-reducing bacteria L. L. Barton (ed.) Sulfate-reducing bacteria Plenum Press New York 11: 293.

EPA consumer factsheet (2006) Consumer Factsheet on: Trichloroethylene, Environmental Protection Agency; http://www.epa.gov/safewater/dwh/c-voc/trichlor.html.

Fathepure BZ \& Boyd SA (1988) Dependence of tetrachloroethylene dechlorination on methanogenic substrate consumption by Methanosarcina sp. strain DCM Appl Environ Microbiol 54: 2976-2980.

Fathepure BZ, Nengu J \& Boyd SA (1987) Anaerobic bacteria that dechlorinate perchloroethene Appl Environ Microbiol 53: 2671-2674.

Fennell DE, Gossett JM \& Zinder SH (1997) Comparison of butyric acid, ethanol, lactic acid, and propionic acid as hydrogen donors for the reductive dechlorination of tetrachloroethene Environ Sci Technol 31: 918-926.

Fennell DE, Nijenhuis I, Wilson SF, Zinder SH, Haggblom MM (2004) Dehalococcoides ethenogenes strain 195 reductively dechlorinates diverse chlorinated aromatic pollutants Environ Sci Technol 38: 2075-2081.

Field J \& Sierra-Alvarez R (2004) Biodegradability of chlorinated solvents and related chlorinated aliphatic compounds Reviews in Environmental Science and Biotechnology 3: 185254.

Fischer AJ, Rowan EA \& Spalding RF (1987) VOCs in ground water influenced by large scale withdrawals Ground Water 25: 407-414. 
Folsom B, Chapman P \& Pritchard P (1990) Phenol and trichloroethylene degradation by Pseudomonas cepacia G4: kinetics and interactions between substrates Appl Environ Microbiol 56: $1279-1285$.

Freeborn RA, West KA, Bhupathiraju VK, Chauhan S, Rahm BG, Richardson RE \& AlvarezCohen L (2005) Phylogenetic analysis of TCE-dechlorinating consortia enriched on a variety of electron donors Environ Sci Technol 39: 8358-8368.

Freedman DL \& Gossett JM (1989) Biological reductive dechlorination of tetrachloroethylene and trichloroethylene to ethylene under methanogenic conditions Appl Environ Microbiol 55: 2144-2151.

Gall K, Pavicić D, Pavelić J, Audy-Jurković S \& Pavelić K (1993) PCR amplification of DNA from stained cytological smears. J Clin Pathol 46: 378-379.

Gantzer CJ \& Wackett LP (1991) Reductive dechlorination catalyzed by bacterial transitionmetal coenzymes Environ Sci Technol 25: 715-722.

Glod G, Brodmann U, Angst W, Holliger C \& Schwarzenbach RP (1997) Cobalamin-mediated reduction of cis-and trans-dichloroethene, 1, 1-dichloroethene, and vinyl chloride in homogeneous aqueous solution: Reaction kinetics and mechanistic considerations Environ Sci Technol 31: 3154-3160.

Grostern A \& Edwards EA (2006) Growth of Dehalobacter and Dehalococcoides spp. during degradation of chlorinated ethanes Appl Environ Microbiol 72: 428-436.

Grostern A, Chan WWM \& Edwards EA (2009) 1, 1, 1-Trichloroethane and 1, 1-dichloroethane reductive dechlorination kinetics and co-contaminant effects in a Dehalobacter-containing mixed culture Environ Sci Technol 43: 6799-6807.

Guerin T, Mondido M, McClenn B \& Peasley B (2001) Application of resazurin for estimating abundance of contaminant-degrading micro-organisms Lett Appl Microbiol 32: 340-345.

Hackstein JHP (2010) (Endo) symbiotic methanogenic archaea. Springer. 
Hamilton W (1985) Sulphate-reducing bacteria and anaerobic corrosion Annual Reviews in Microbiology 39: 195-217.

He J, Ritalahti KM, Aiello MR \& Löffler FE (2003a) Complete detoxification of vinyl chloride by an anaerobic enrichment culture and identification of the reductively dechlorinating population as a Dehalococcoides species Appl Environ Microbiol 69: 996-1003.

He J, Ritalahti KM, Yang Y, Koenigsberg SS \& Löffler (2003b) Detoxification of vinyl chloride to ethene coupled to growth of an anaerobic bacterium.Nature 424:62-65

He J, Sung Y, Krajmalnik-Brown R, Ritalahti KM \& Löffler FE (2005) Isolation and characterization of Dehalococcoides sp. strain FL2, a trichloroethene (TCE)-and 1, 2-dichloroethene-respiring anaerobe Environ Microbiol 7: 1442-1450.

He J， Robrock KR \& Alvarez-Cohen L (2006) Microbial reductive debromination of polybrominated diphenyl ethers (PBDEs) Environ Sci Technol 40: 44294434.

Hendrickson ER, Payne JA, Young RM, Starr MG, Perry MP, Fahnestock S, Ellis DE \& Ebersole RC (2002) Molecular analysis of Dehalococcoides 16S ribosomal DNA from chloroethene-contaminated sites throughout North America and Europe Appl Environ Microbiol 68: $485-495$.

Henry B M (2012) Biostimulation for anaerobic bioremediation of chlorinated solvents In situ Remediation of chlorinated solvent plumes SERDP and ESTCP remediation technology monograph series $357-423$.

Holliger C, Regeard C \& Diekert G (2004) Dehalogenation by anaerobic bacteria Dehalogenation: Microbial processes and environmental applications Kluwer academic publisher 5: $115-157$.

Holliger C, Schraa G, Stams A \& Zehnder A (1993) A highly purified enrichment culture couples the reductive dechlorination of tetrachloroethene to growth Appl Environ Microbiol 59: 2991-2997. 
Holliger C, Wohlfarth G \& Diekert G (2006) Reductive dechlorination in the energy metabolism of anaerobic bacteria FEMS Microbiol Rev 22: 383-398.

Holmes DS \& Bonner J (1973) Preparation, molecular weight, base composition, and secondary structure of giant nuclear ribonucleic acid biochemistry (NY ) 12: 2330-2338.

Holmes VF, He J, Lee PKH \& Alvarez-Cohen L (2006) Discrimination of multiple Dehalococcoides strains in trichloroethene enrichment by quantification of their reductive dehalogenase genes Appl Environ Microbiol 72: 5877-5883.

HSDB (2012) Hazardous Substances Data Bank, Toxnet, National Institutes of Health; http://toxnet.nlm.nih.gov.

Inguva S \& Shreve GS (1999) Biodegradation kinetics of trichloroethylene and1, 2dichloroethane by Burkholderia (Pseudomonas) cepacia PR131 and Xanthobacter autotrophicus GJ10. Int Biodeterior Biodegrad 43: 57-61.

Jayachandran G, Görisch H \& Adrian L (2003) Dehalorespiration with hexachlorobenzene and pentachlorobenzene by Dehalococcoides sp. strain CBDB1 Arch Microbiol 180: 411-416.

Joulian C, Ramsing NB \& Ingvorsen K (2001) Congruent phylogenies of most common smallsubunit rRNA and dissimilatory sulfite reductase gene sequences retrieved from estuarine sediments Appl Environ Microbiol 67: 3314-3318.

Kengen SWM, Breidenbach CG, Felske A, Stams AJM, Schraa G \& De Vos WM (1999) Reductive Dechlorination of Tetrachloroethene tocis-1, 2-Dichloroethene by a Thermophilic Anaerobic Enrichment Culture Appl Environ Microbiol 65: 2312-2316.

Kolmert Å, Wikström P \& Hallberg KB (2000) A fast and simple turbidimetric method for the determination of sulfate in sulfate-reducing bacterial cultures J Microbiol Methods 41: 179-184.

Kondo R, Nedwell DB, Purdy KJ \& Silva SQ (2004) Detection and enumeration of sulphatereducing bacteria in estuarine sediments by competitive PCR Geomicrobiol J 21: 145-157. 
Kondo R, Osawa K, Mochizuki L, Fujioka Y \& Butani J (2006) Abundance and diversity of sulphate-reducing bacterioplankton in Lake Suigetsu, a meromictic lake in Fukui, Japan Plankton and Benthos Research 1: 165-177.

Krone UE, Thauer RK \& Hogenkamp HPC (1989) Reductive dehalogenation of chlorinated C1hydrocarbons mediated by corrinoids Biochemistry (NY) 28: 4908-4914.

Lash LH, Fisher JW, Lipscomb JC \& Parker JC (2000) Metabolism of trichloroethylene. Environ Health Perspect 108: 177.

Lee M, Odom J \& Buchanan Jr R (1998) New perspectives on microbial dehalogenation of chlorinated solvents: insights from the field Annual Reviews in Microbiology 52: 423-452.

Lee W \& Batchelor B (2003) Reductive capacity of natural reductants Environ Sci Technol 37: $535-541$.

Liu Y \& Whitman WB (2008) Metabolic, phylogenetic, and ecological diversity of the methanogenic archaea Ann N Y Acad Sci 1125: 171-189.

Loffler F.E., Yan J., Ritalahti K.M., Adrian L. \& Edwards E.A. (2012) Dehalococcoides mccartyigen. nov., sp. Nov., obligate organohalide-respiring anaerobic bacteria, relevant to halogen cycling and bioremediation, belong to a novel bacterial class, Dehalococcoidetes classis nov., within the phylum Chloroflexi IJSEM papers in Press.

Löffler FE, Cole JR, Ritalahti KM \& Tiedje JM (2004) Diversity of dechlorinating bacteria Dehalogenation 53-87.

Lorah MM \& Voytek MA (2004) Degradation of 1, 1, 2, 2-tetrachloroethane and accumulation of vinyl chloride in wetland sediment microcosms and in situ porewater: biogeochemical controls and associations with microbial communities J Contam Hydrol 70: 117-145.

Lovley DR, \& Klug MJ (1983) Sulfate Reducers Can Outcompete Methanogens at Freshwater Sulfate Concentrations Appl Environ Microbiol 45: 187-192 
Lovley DR, Dwyer DF \& Klug MJ (1982) Kinetic analysis of competition between sulfate reducers and methanogens for hydrogen in sediments Appl Environ Microbiol 43: 1373-1379.

Lu X, J.T. Wilson, D.H. Kampbell ( 2006 a) Relationship between Dehalococcoides DNA in ground water and rates of reductive dechlorination at field scale, Water Res., 40: 3131-3140.

Lu X, J.T. Wilson, D.H. Kampbell (2006 b) Relationship between geochemical parameters and the occurrence of Dehalococcoides DNA in contaminated aquifers, Water resources research, $42: 8$

Macbeth TW, Cummings DE, Spring S, Petzke LM \& Sorenson KS (2004) Molecular characterization of a dechlorinating community resulting from in situ biostimulation in a trichloroethene-contaminated deep, fractured basalt aquifer and comparison to a derivative laboratory culture Appl Environ Microbiol 70: 7329-7341.

Maymó-Gatell X, Anguish T \& Zinder SH (1999) Reductive dechlorination of chlorinated ethenes and 1, 2-dichloroethane by "Dehalococcoides ethenogenes" 195 Appl Environ Microbiol 65: $3108-3113$.

Maymo-Gatell X, Chien Y, Gossett JM \& Zinder SH (1997) Isolation of a bacterium that reductively dechlorinates tetrachloroethene to ethene Science 276: 1568-1571.

Maymó-Gatell X, Nijenhuis I \& Zinder SH (2001) Reductive dechlorination of cis-1, 2dichloroethene and vinyl chloride by "Dehalococcoides ethenogenes" Environ Sci Technol 35: 516-521.

Maymó-Gatell X, Tandoi V, Gossett JM \& Zinder SH (1995) Characterization of an H2-utilizing enrichment culture that reductively dechlorinates tetrachloroethene to vinyl chloride and ethene in the absence of methanogenesis and acetogenesis. Appl Environ Microbiol 61: 3928-3933.

McCarty PL (1997) Breathing with chlorinated solvents Science 276: 1521-1522. 
McCarty PL (2010) Groundwater contamination by chlorinated solvents: Histor, remediation technologies and strategies. In situ Remediation of chlorinated solvent plumes. SERDP and ESTCP remediation technology monograph series. 1-24.

Middeldorp PJM, Luijten MLGC, van de Pas BA, van Eekert MHA, Kengen SWM, Schraa G \& Stams AJM (1999) Anaerobic microbial reductive dehalogenation of chlorinated ethenes Bioremediation J 3: 151-169.

Mohammad OI \& Kibbey TCG (2005) Dissolution-induced contact angle modification in dense nonaqueous phase liquid/water systems Environ Sci Technol 39: 1698-1706.

Mohn WW \& Tiedje JM (1992) Microbial reductive dehalogenation. Microbiol Rev 56: 482507.

Moran MJ, Zogorski JS \& Squillace PJ (2007) Chlorinated solvents in groundwater of the United States Environ Sci Technol 41: 74-81.

Morrill PL, Lacrampe-Couloume G, Slater GF, Sleep BE, Edwards EA, McMaster ML, Major DW \& Sherwood Lollar B (2005) Quantifying chlorinated ethene degradation during reductive dechlorination at Kelly AFB using stable carbon isotopes J Contam Hydrol 76: 279-293.

NCPH (2007) North Carolina public health, Trichloroethylene (TCE) Fact Sheet and FAQs, NC Division of Public Health, Health Assessment, Consultation and Education Program; http://epi.publichealth.nc.gov/oee/hace/pdf/TCEfactsheet.pdf.

Nelson M \& Bourquin AW (1990) Method for stimulating biodegradation of halogenated aliphatic hydrocarbons U.S. Patent 4925802; A.

Nelson M, Montgomery S \& Pritchard P (1988) Trichloroethylene metabolism by microorganisms that degrade aromatic compounds. Appl Environ Microbiol 54: 604-606.

Nelson MJK, Montgomery S, O'neill E \& Pritchard P (1986) Aerobic metabolism of trichloroethylene by a bacterial isolate Appl Environ Microbiol 52: 383-384. 
Neumann A, Wohlfarth G \& Diekert G (1995) Properties of tetrachloroethene and trichloroethene dehalogenase of Dehalospirillum multivorans Arch Microbiol 163: 276-281.

NRC (1993), In Situ bioremediation: When does it work? National Research Council, National Academy Press. Washington, DC.

NRC (2012) Alternatives for Managing the Nation's Complex Contaminated Groundwater Sites Water Science and Technology Board, Prepublication copy, National Research Council, Washington, DC.http://www.nap.edu/catalog.php?record_id=14668

Odom JM, Singleton R \& Postgate JR (1993) The sulfate-reducing bacteria: contemporary perspectives Springer-Verlag (New York).

Oldenhuis R, Vink R, Janssen DB \& Witholt B (1989) Degradation of chlorinated aliphatic hydrocarbons by Methylosinus trichosporium OB3b expressing soluble methane monooxygenase. Appl Environ Microbiol 55: 2819-2826.

O'Loughlin EJ \& Burris DR (1999) Reductive dehalogenation of trichloroethene mediated by wetland DOC- transition metal complexes In: Means J.L. and Hinchee R.E. (eds), Wetlands and Remediation. Battelle Press, Columbus, OH 1-8.

O'Loughlin EJ, Burris DR \& Delcomyn CA (999) Reductive dechlorination of trichloroethene mediated by humic-metal complexes Environ Sci Technol 33: 1145-1147.

Pill KG, Kupillas GE, Picardal FW \& Arnold RG (1991) Estimating the toxicity of chlorinated organic compounds using a multiparameter bacterial bioassay Environ Toxicol Water Qual 6: 271-291.

Poljak M, Barlič J, Seme K, Avšič-Županc T \& Zore A (1995) Isolation of DNA from archival Papanicolaou stained cytological smears using a simple salting-out procedure Clinical molecular pathology 48: M55-M56.

Postgate JR (1979) The sulphate-reducing bacteria 2nd ed. Cambridge University Press, Cambridge, United Kingdom. 
Raskin L, Stromley JM, Rittmann BE \& Stahl DA (1994) Group-specific 16S rRNA hybridization probes to describe natural communities of methanogens. Appl Environ Microbiol 60: $1232-1240$.

Richardson RE, Bhupathiraju VK, Song DL, Goulet TA \& Alvarez-Cohen L (2002) Phylogenetic characterization of microbial communities that reductively dechlorinate TCE based upon a combination of molecular techniques Environ Sci Technol 36: 2652-2662.

Ritzema H (1994) Drainage principles and applications ILRI Publication No. 16 Wageningen The Netherlands.

Rooney-Varga JN, Sharak Genthner BR, Devereux R, Willis SG, Friedman SD \& Hines ME (1998) Phylogenetic and physiological diversity of sulphate-reducing bacteria isolated from a salt marsh sediment Syst Appl Microbiol 21: 557-568.

Rosner BM, McCarty PL \& Spormann AM (1997) In vitro studies on reductive vinyl chloride dehalogenation by an anaerobic mixed culture. Appl Environ Microbiol 63: 4139-4144.

Rudolf K . Thauer (1998) Biochemistry of methanogenesis : a tribute to Marjory Stephenson Microbiology 144 2377-2406

Russell HH, Matthews JE \& Sewell GW (1992) EPA Groundwater Issue: TCE removal from contaminated soil and groundwater US Environmental Protection Agency, USA.

Schaumburg F (1990) Banning trichloroethylene: responsible reaction or overkill? Environ Sci Technol 24: 17-22.

Scholz-Muramatsu H, Neumann A, Meßmer M, Moore E \& Diekert G (1995) Isolation and characterization of Dehalospirillum multivorans gen. nov., sp. nov., a tetrachloroethene-utilizing, strictly anaerobic bacterium Arch Microbiol 163: 48-56.

Schumacher W, Holliger C, Zehnder AJB \& Hagen WR (1997) Redox chemistry of cobalamin and iron-sulfur cofactors in the tetrachloroethene reductase of Dehalobacter restrictus FEBS Lett 409: 421-425. 
Semprini L (1997) Strategies for the aerobic co-metabolism of chlorinated solvents Curr Opin in Biotechnol 8: 296-308.

Sepp R, Szabo I, Uda H \& Sakamoto H (1994) Rapid techniques for DNA extraction from routinely processed archival tissue for use in PCR, Clin Pathol 47: 318-323.

Sharma PK \& McCarty PL (1996) Isolation and characterization of a facultatively aerobic bacterium that reductively dehalogenates tetrachloroethene to cis-1, 2-dichloroethene. Appl Environ Microbiol 62: 761-765.

Shen H \& Wilson JT (2007) Trichloroethylene removal from groundwater in flow-through columns simulating a permeable reactive barrier constructed with plant mulch Environ Sci Technol 41: 4077-4083.

Simkin T.J. and Norris R.D. (2010) Engineering and implementation challenges for chlorinated solvent remediation In situ Remediation of chlorinated solvent plumes SERDP and ESTCP remediation technology monograph series 109-143.

Sipkema E, De Koning W, Van Hylckama Vlieg J, Ganzeveld K, Janssen D \& Beenackers A (1999) Trichloroethene degradation in a two-step system by Methylosinus trichosporium OB3b. Optimization of system performance: Use of formate and methane Biotechnol Bioeng 63: 56-68.

Smatlak CR, Gossett JM \& Zinder SH (1996) Comparative kinetics of hydrogen utilization for reductive dechlorination of tetrachloroethene and methanogenesis in an anaerobic enrichment culture Environ Sci Technol 30: 2850-2858.

Stroo H.F. and Ward C.H. (2010) Future directions and research needs for chlorinated solvent plumes. In situ Remediation of chlorinated solvent plumes SERDP and ESTCP remediation technology monograph series 699-725.

Sun B, Griffin BM, Ayala-del-Río HL, Hashsham SA \& Tiedje JM (2002) Microbial dehalorespiration with 1, 1, 1-trichloroethane Science 298: 1023-1025. 
Sung Y, Ritalahti K \& Apkarian R LöZer (2006) Quantitative PCR confirms purity of strain GT, a novel trichloroethene-toethene-respiring Dehalococcoides isolate Appl Environ Microbiol 72: 1980-1987.

Sung Y, Ritalahti KM, Sanford RA, Urbance JW, Flynn SJ, Tiedje JM \& Löffler FE (2003) Characterization of two tetrachloroethene-reducing, acetate-oxidizing anaerobic bacteria and their description as Desulfuromonas michiganensis sp. nov. Appl Environ Microbiol 69: 29642974.

Takai K \& Horikoshi K (2000) Rapid detection and quantification of members of the archaeal community by quantitative PCR using fluorogenic probes Appl Environ Microbiol 66: 50665072.

Thauer RK, Jungermann K \& Decker K (1977) Energy conservation in chemotrophic anaerobic bacteria. Bacteriol Rev 41: 100.

Tsien HC, Brusseau GA, Hanson RS \& Waclett L (1989) Biodegradation of trichloroethylene by Methylosinus trichosporium OB3b Appl Environ Microbiol 55: 3155-3161.

Twigg R (1945) Oxidation-reduction aspects of resazurin Nature 155: 401-402.

Tyagi M, da Fonseca MMR \& de Carvalho CCCR (2011) Bioaugmentation and biostimulation strategies to improve the effectiveness of bioremediation processes Biodegradation 22: 231-241.

USEPA (1998) Technical Protocol for Evaluating Natural Attenuation of Chlorinated Solvents in Groundwater. Cincinnati, OH: National Risk Management Research Laboratory, Office of Research and Development, USEPA EPA/600/R-98/128.

USEPA (2000) Engineered Approaches to In Situ Bioremediation of Chlorinated Solvents: Fundamentals and Field Applications United States Environmental Protection Agency.

USEPA (2004) 2004 Edition of the Drinking Water Standards and Health Advisories U.S. Environmental Protection Agency Office of Water Washington, DC. 
USEPA (2012) Integrated Risk Information System (IRIS) US Environmental Protection Agency 2012.

Van Agteren MH, Keuning S \& Janssen D (1998) Handbook on biodegradation and biological treatment of hazardous organic compounds Springer.

Vannelli T, Logan M, Arciero DM \& Hooper AB (1990) Degradation of halogenated aliphatic compounds by the ammonia-oxidizing bacterium Nitrosomonas europaea Appl Environ Microbiol 56: 1169-1171.

Vogel T, Norris R, Hinchee R, Brown R, McCarty P, Semprini L, Wilson J, Kampbell D, Reinhard M \& Bouwer E (1994) Natural bioremediation of chlorinated solvents Handbook of bioremediation 201-225.

Vogel TM, Criddle CS \& McCarty PL (1987) ES\&T critical reviews: transformations of halogenated aliphatic compounds Environ Sci Technol 21: 722-736.

Wackett LP \& Gibson DT (1988) Degradation of trichloroethylene by toluene dioxygenase in whole-cell studies with Pseudomonas putida F1 Appl Environ Microbiol 54: 1703-1708.

Wackett LP, Sadowsky MJ, Newman LM, Hur HG \& Li S (1994) Metabolism of polyhalogenated compounds by a genetically engineered bacterium Nature 368: 627-629.

Wagner M, Roger AJ, Flax JL, Brusseau GA \& Stahl DA (1998) Phylogeny of dissimilatory sulfite reductases supports an early origin of sulfate respiration J Bacteriol 180: 2975-2982.

WHO (1984) World Health Organization; Guidelines for drinking-water quality Recommendations, Geneva I: 66.

Wiedemeier TH, Wilson JT, Kampbell D, Jansen J \& Haas P (1996) Technical protocol for evaluating the natural attenuation of chlorinated ethenes in groundwater 425-444.

Wilson JT \& Wilson B (1985) Biotransformation of trichloroethylene in soil. Appl Environ Microbiol 49: 242. 
Wrenn BA \& Rittmann BE (1996) Evaluation of a model for the effects of substrate interactions on the kinetics of reductive dehalogenation Biodegradation 7: 49-64.

Yager RM, Bilotta SE, Mann CL \& Madsen EL (1997) Metabolic adaptation and in situ attenuation of chlorinated ethenes by naturally occurring microorganisms in a fractured dolomite aquifer near Niagara Falls, New York Environ Sci Technol 31: 3138-3147.

Yang Y \& McCarty PL (1998) Competition for hydrogen within a chlorinated solvent dehalogenating anaerobic mixed culture Environ Sci Technol 32: 3591-3597.

Yu Y, Lee C, Kim J \& Hwang S (2005) Group-specific primer and probe sets to detect methanogenic communities using quantitative real-time polymerase chain reaction Biotechnol Bioeng 89: 670-679.

Zeikus J (1977) The biology of methanogenic bacteria. Bacteriol Rev 41: 514.

Zimmer C \& Wähnert U (1986) Nonintercalating DNA-binding ligands: specificity of the interaction and their use as tools in biophysical, biochemical and biological investigations of the genetic material. Prog Biophys Mol Biol 47: 31. 


\section{APPENDIX}

Table A1. Standard Curve for Sulfate Analysis

\begin{tabular}{cc}
\hline $\begin{array}{c}\text { Sulfate } \\
\mathrm{mM}\end{array}$ & $\begin{array}{c}\text { Absorbance } \\
\text { at } 420 \mathrm{~nm}\end{array}$ \\
\hline 1 & 0.275 \\
2 & 0.493 \\
3 & 0.78 \\
4 & 1.06 \\
5 & 1.272
\end{tabular}

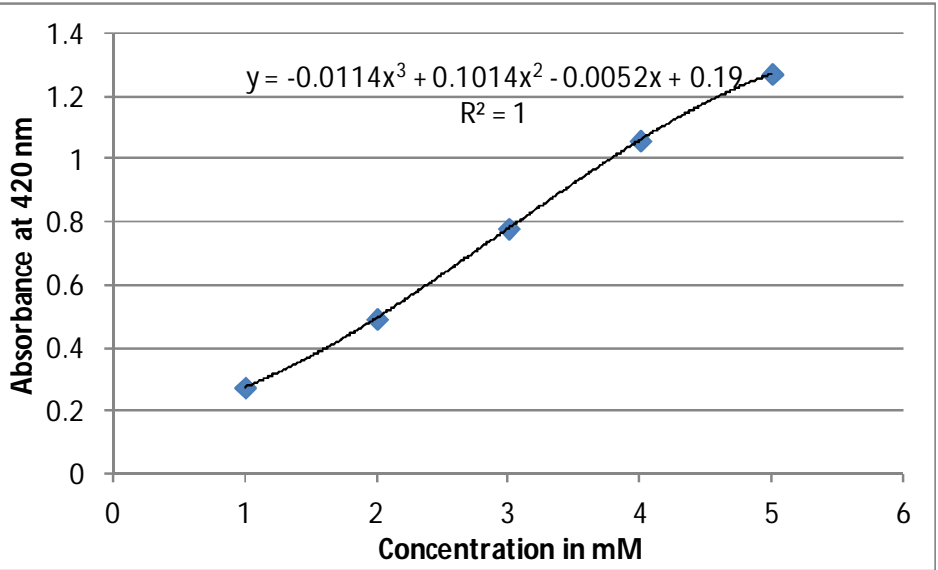

Figure A1. Standard curve for sulfate analysis 
Table A2. Standard Curve for COD Analysis

\begin{tabular}{cc}
\hline Absorbance at $\mathbf{4 2 0} \mathbf{~ n m}$ & $\mathbf{C O D} \mathbf{~ m g} / \mathbf{L}$ \\
\hline 0.379 & 0 \\
0.376 & 0 \\
0.378 & 0 \\
0.363 & 10 \\
0.344 & 20 \\
0.337 & 20 \\
0.314 & 30 \\
0.311 & 30 \\
0.267 & 50 \\
0.207 & 75 \\
0.212 & 75 \\
0.153 & 100 \\
\hline
\end{tabular}

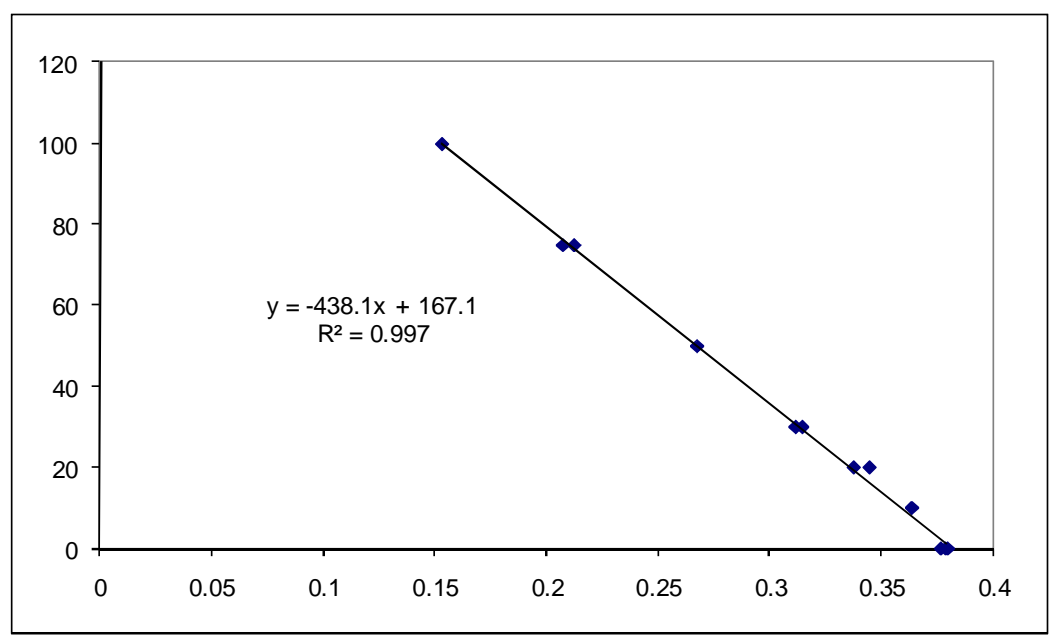

Figure A2. Standard curve for COD analysis 
Table A3. Detailed results for DHC, SRB and Archaea from qPCR analysis in various reactor types and experimental conditions.

\begin{tabular}{|c|c|c|c|c|c|c|c|c|}
\hline $\begin{array}{c}\text { Reactor } \\
\text { type }\end{array}$ & $\begin{array}{c}\mathrm{TCE} \\
\text { concentration } \\
\mathrm{mg} / \mathrm{L} \\
\end{array}$ & $\begin{array}{c}\text { Sulfate } \\
\text { concentration } \\
\mathrm{mg} / \mathrm{L} \\
\end{array}$ & Other & $\begin{array}{c}\text { Cells } \\
\text { added } \\
\mu 1 \\
\end{array}$ & $\begin{array}{c}\text { Area } \\
\text { scrapped }\end{array}$ & $\begin{array}{c}\mathrm{DHC} \\
\left(\text { copies } / \mathrm{cm}^{2}\right)\end{array}$ & $\begin{array}{c}\text { SRB } \\
\left(\text { copies/cm } / \mathrm{cm}^{2}\right)\end{array}$ & $\begin{array}{c}\text { Archaea } \\
\left(\text { copies } / \mathrm{cm}^{2}\right)\end{array}$ \\
\hline 1 & 100 & 10 & & 100 & 1 & NA & $5.24 \times 10^{10}$ & $1.30 \times 10^{15}$ \\
\hline 1 & 100 & 10 & & 100 & 2 & NA & $6.09 \times 10^{10}$ & $1.34 \times 10^{15}$ \\
\hline 1 & 100 & 10 & & 100 & 3 & $2.46 \times 10^{9}$ & $3.22 \times 10^{10}$ & $1.35 \times 10^{15}$ \\
\hline 1 & 100 & 10 & Sod. azide & 100 & 1 & NA & NR & NR \\
\hline 1 & 100 & 10 & Sod. azide & 100 & 2 & NA & NR & NR \\
\hline 1 & 100 & 10 & Sod. azide & 100 & 3 & NA & NR & NR \\
\hline 1 & 100 & 10 & & 10 & 1 & $2.18 \times 10^{10}$ & $2.46 \times 10^{11}$ & $5.07 \times 10^{15}$ \\
\hline 1 & 100 & 10 & & 10 & 2 & $3.25 \times 10^{9}$ & $2.72 \times 10^{11}$ & $6.00 \times 10^{15}$ \\
\hline 1 & 100 & 10 & & 10 & 3 & $7.89 \times 10^{8}$ & $1.49 \times 10^{11}$ & $3.86 \times 10^{15}$ \\
\hline 1 & 100 & 0.5 & & 100 & 1 & $6.95 \times 10^{10}$ & $1.47 \times 10^{9}$ & $1.80 \times 10^{14}$ \\
\hline 1 & 100 & 0.5 & & 100 & 2 & $7.94 \times 10^{10}$ & $6.88 \times 10^{9}$ & $3.87 \times 10^{13}$ \\
\hline 1 & 100 & 0.5 & & 100 & 3 & $1.71 \times 10^{10}$ & $8.27 \times 10^{9}$ & $4.08 \times 10^{13}$ \\
\hline 1 & 100 & 0.5 & & 10 & 1 & NA & NR & NR \\
\hline 1 & 100 & 0.5 & & 10 & 2 & NR & NR & NR \\
\hline 1 & 100 & 0.5 & & 10 & 3 & NR & NR & NR \\
\hline 1 & 100 & 10 & & 0 & 1 & NA & $1.97 \times 10^{10}$ & $7.42 \times 10^{13}$ \\
\hline 1 & 100 & 10 & & 0 & 2 & $\mathrm{NA}$ & $1.04 \times 10^{10}$ & $8.59 \times 10^{13}$ \\
\hline 1 & 100 & 10 & & 0 & 3 & NA & $7.20 \times 10^{9}$ & $4.19 \times 10^{13}$ \\
\hline 1 & 10 & 0.5 & & 100 & 1 & NA & $1.30 \times 10^{10}$ & $3.07 \times 10^{13}$ \\
\hline 1 & 10 & 0.5 & & 100 & 2 & NA & $1.15 \times 10^{10}$ & $2.30 \times 10^{13}$ \\
\hline 1 & 10 & 0.5 & & 100 & 3 & NA & $7.37 \times 10^{8}$ & $2.13 \times 10^{14}$ \\
\hline 1 & 10 & 0.5 & & 10 & 1 & $1.75 \times 10^{11}$ & $1.28 \times 10^{11}$ & $1.46 \times 10^{16}$ \\
\hline 1 & 10 & 0.5 & & 10 & 2 & $1.40 \times 10^{11}$ & $1.66 \times 10^{11}$ & $1.90 \times 10^{16}$ \\
\hline 1 & 10 & 0.5 & & 10 & 3 & $5.17 \times 10^{10}$ & $7.54 \times 10^{10}$ & $3.84 \times 10^{15}$ \\
\hline 1 & 10 & 10 & & 10 & 1 & $5.88 \times 10^{9}$ & $8.59 \times 10^{10}$ & $1.77 \times 10^{16}$ \\
\hline
\end{tabular}




\begin{tabular}{|c|c|c|c|c|c|c|c|c|}
\hline $\begin{array}{c}\text { Reactor } \\
\text { type }\end{array}$ & $\begin{array}{c}\text { TCE } \\
\text { concentration } \\
\mathrm{mg} / \mathrm{L} \\
\end{array}$ & $\begin{array}{c}\text { Sulfate } \\
\text { concentration } \\
\mathrm{mg} / \mathrm{L} \\
\end{array}$ & Other & $\begin{array}{c}\text { Cells } \\
\text { added } \\
\mu 1 \\
\end{array}$ & $\begin{array}{c}\text { Area } \\
\text { scrapped }\end{array}$ & $\begin{array}{c}\mathrm{DHC} \\
\left(\text { copies } / \mathrm{cm}^{2}\right)\end{array}$ & $\begin{array}{c}\mathrm{SRB} \\
\left(\text { copies } / \mathrm{cm}^{2}\right)\end{array}$ & $\begin{array}{c}\text { Archaea } \\
\left(\text { copies } / \mathrm{cm}^{2}\right)\end{array}$ \\
\hline 1 & 10 & 10 & & 10 & 2 & $5.57 \times 10^{7}$ & $1.07 \times 10^{11}$ & $1.32 \times 10^{16}$ \\
\hline 1 & 10 & 10 & & 10 & 3 & NA & NA & NA \\
\hline 1 & 10 & 10 & & 100 & 1 & $4.51 \times 10^{10}$ & $1.21 \times 10^{11}$ & NA \\
\hline 1 & 10 & 10 & & 100 & 2 & $8.73 \times 10^{10}$ & $1.63 \times 10^{11}$ & NA \\
\hline 1 & 10 & 10 & & 100 & 3 & $3.77 \times 10^{9}$ & $5.80 \times 10^{10}$ & NA \\
\hline 1 & 10 & 10 & & 100 & 1 & $1.47 \times 10^{11}$ & $3.16 \times 10^{11}$ & NA \\
\hline 1 & 10 & 10 & & 100 & 2 & $1.36 \times 10^{11}$ & $2.27 \times 10^{11}$ & NA \\
\hline 1 & 10 & 10 & & 100 & 3 & $1.00 \times 10^{11}$ & $1.00 \times 10^{11}$ & NA \\
\hline 1 & 10 & 10 & & 0 & 1 & $2.15 \times 10^{10}$ & $1.94 \times 10^{11}$ & NA \\
\hline 1 & 10 & 10 & & 0 & 2 & NA & $3.20 \times 10^{11}$ & NA \\
\hline 1 & 10 & 10 & & 0 & 3 & NA & $1.39 \times 10^{11}$ & NA \\
\hline 1 & 0.1 & 10 & & 100 & 1 & NA & NR & NR \\
\hline 1 & 0.1 & 10 & & 100 & 2 & NA & NR & NR \\
\hline 1 & 0.1 & 10 & & 100 & 3 & NA & NR & NR \\
\hline 1 & 0.1 & 10 & & 10 & 1 & NA & $5.04 \times 10^{10}$ & $6.64 \times 10^{14}$ \\
\hline 1 & 0.1 & 10 & & 10 & 2 & NA & $7.53 \times 10^{10}$ & $7.10 \times 10^{14}$ \\
\hline 1 & 0.1 & 10 & & 10 & 3 & NA & $5.05 \times 10^{10}$ & $6.52 \times 10^{14}$ \\
\hline 1 & 0.1 & 10 & & 100 & 1 & NA & NR & NA \\
\hline 1 & 0.1 & 10 & & 100 & 2 & NA & NR & NA \\
\hline 1 & 0.1 & 10 & & 100 & 3 & NA & NR & NA \\
\hline 1 & 0.1 & 0.5 & & 10 & 1 & NA & NR & NR \\
\hline 1 & 0.1 & 0.5 & & 10 & 2 & NA & NR & NR \\
\hline 1 & 0.1 & 0.5 & & 10 & 3 & NA & NR & NR \\
\hline 1 & 0.1 & 0.5 & & 100 & 1 & NA & NR & NR \\
\hline 1 & 0.1 & 0.5 & & 100 & 2 & NA & NR & NR \\
\hline 1 & 0.1 & 0.5 & & 100 & 3 & NA & NR & NR \\
\hline 1 & 0.1 & 10 & & 0 & 1 & NA & NR & NR \\
\hline 1 & 0.1 & 10 & & 0 & 2 & NA & NR & NR \\
\hline
\end{tabular}




\begin{tabular}{|c|c|c|c|c|c|c|c|c|}
\hline $\begin{array}{l}\text { Reactor } \\
\text { type }\end{array}$ & $\begin{array}{c}\text { TCE } \\
\text { concentration } \\
\mathrm{mg} / \mathrm{L}\end{array}$ & $\begin{array}{c}\text { Sulfate } \\
\text { concentration } \\
\mathrm{mg} / \mathrm{L}\end{array}$ & Other & $\begin{array}{c}\text { Cells } \\
\text { added } \\
\mu 1\end{array}$ & $\begin{array}{c}\text { Area } \\
\text { scrapped }\end{array}$ & $\begin{array}{c}\mathrm{DHC} \\
\left(\text { copies } / \mathrm{cm}^{2}\right)\end{array}$ & $\begin{array}{c}\mathrm{SRB} \\
\left(\text { copies } / \mathrm{cm}^{2}\right)\end{array}$ & $\begin{array}{c}\text { Archaea } \\
\left(\text { copies } / \mathrm{cm}^{2}\right)\end{array}$ \\
\hline 1 & 0.1 & 10 & & 0 & 3 & NA & NR & NR \\
\hline 2 & 100 & 10 & & 10 & 1 & $5.03 \times 10^{9}$ & $1.20 \times 10^{11}$ & $6.86 \times 10^{15}$ \\
\hline 2 & 100 & 10 & & 10 & 2 & NA & $1.06 \times 10^{11}$ & $6.27 \times 10^{15}$ \\
\hline 2 & 100 & 10 & & 10 & 3 & NA & $3.93 \times 10^{10}$ & $3.89 \times 10^{15}$ \\
\hline 2 & 100 & 10 & Sod. azide & 10 & 1 & $5.06 \times 10^{7}$ & $2.33 \times 10^{9}$ & $3.80 \times 10^{13}$ \\
\hline 2 & 100 & 10 & Sod. azide & 10 & 2 & NA & NR & NR \\
\hline 2 & 100 & 10 & Sod. azide & 10 & 3 & NA & NR & NR \\
\hline 2 & 100 & 10 & & 1 & 1 & $2.47 \times 10^{9}$ & $3.41 \times 10^{11}$ & $7.50 \times 10^{15}$ \\
\hline 2 & 100 & 10 & & 1 & 2 & $1.41 \times 10^{9}$ & $3.08 \times 10^{11}$ & $6.16 \times 10^{15}$ \\
\hline 2 & 100 & 10 & & 1 & 3 & $2.37 \times 10^{9}$ & $2.46 \times 10^{11}$ & $8.52 \times 10^{13}$ \\
\hline 2 & 100 & 0.5 & & 10 & 1 & NA & $9.92 \times 10^{7}$ & $3.20 \times 10^{11}$ \\
\hline 2 & 100 & 0.5 & & 10 & 2 & NA & $2.65 \times 10^{8}$ & $2.36 \times 10^{10}$ \\
\hline 2 & 100 & 0.5 & & 10 & 3 & $2.23 \times 10^{9}$ & $4.40 \times 10^{7}$ & $2.03 \times 10^{11}$ \\
\hline 2 & 100 & 0.5 & & 1 & 1 & NA & $6.41 \times 10^{8}$ & $4.52 \times 10^{13}$ \\
\hline 2 & 100 & 0.5 & & 1 & 2 & NA & NR & NR \\
\hline 2 & 100 & 0.5 & & 1 & 3 & NA & NR & NR \\
\hline 2 & 10 & 0.5 & & 10 & 1 & NA & $3.16 \times 10^{8}$ & $1.10 \times 10^{13}$ \\
\hline 2 & 10 & 0.5 & & 10 & 2 & NA & $1.30 \times 10^{8}$ & $1.14 \times 10^{14}$ \\
\hline 2 & 10 & 0.5 & & 10 & 3 & NA & NA & NA \\
\hline 2 & 10 & 0.5 & & 1 & 1 & NA & $9.94 \times 10^{8}$ & $1.78 \times 10^{12}$ \\
\hline 2 & 10 & 0.5 & & 1 & 2 & NA & NA & NA \\
\hline 2 & 10 & 0.5 & & 1 & 3 & NA & NA & NA \\
\hline 2 & 10 & 10 & & 1 & 1 & $4.55 \times 10^{9}$ & $6.85 \times 10^{10}$ & $2.19 \times 10^{15}$ \\
\hline 2 & 10 & 10 & & 1 & 2 & $7.51 \times 10^{8}$ & $5.40 \times 10^{10}$ & $6.79 \times 10^{14}$ \\
\hline 2 & 10 & 10 & & 1 & 3 & $1.90 \times 10^{8}$ & $3.73 \times 10^{9}$ & $4.37 \times 10^{14}$ \\
\hline 2 & 10 & 10 & Sod Azide & 10 & 1 & NA & NR & NR \\
\hline 2 & 10 & 10 & Sod Azide & 10 & 2 & NA & NR & NR \\
\hline 2 & 10 & 10 & Sod Azide & 10 & 3 & NA & NR & NR \\
\hline
\end{tabular}




\begin{tabular}{|c|c|c|c|c|c|c|c|c|}
\hline $\begin{array}{l}\text { Reactor } \\
\text { type }\end{array}$ & $\begin{array}{c}\text { TCE } \\
\text { concentration } \\
\mathrm{mg} / \mathrm{L}\end{array}$ & $\begin{array}{c}\text { Sulfate } \\
\text { concentration } \\
\mathrm{mg} / \mathrm{L}\end{array}$ & Other & $\begin{array}{c}\text { Cells } \\
\text { added } \\
\mu 1\end{array}$ & $\begin{array}{c}\text { Area } \\
\text { scrapped }\end{array}$ & $\begin{array}{c}\mathrm{DHC} \\
\left(\text { copies } / \mathrm{cm}^{2}\right)\end{array}$ & $\begin{array}{c}\mathrm{SRB} \\
\left(\text { copies } / \mathrm{cm}^{2} \text { ) }\right.\end{array}$ & $\begin{array}{c}\text { Archaea } \\
\left(\text { copies } / \mathrm{cm}^{2}\right)\end{array}$ \\
\hline 2 & 10 & 10 & & 10 & 1 & $3.14 \times 10^{9}$ & $2.59 \times 10^{11}$ & $5.59 \times 10^{15}$ \\
\hline 2 & 10 & 10 & & 10 & 2 & $1.85 \times 10^{9}$ & $1.53 \times 10^{11}$ & $3.50 \times 10^{15}$ \\
\hline 2 & 10 & 10 & & 10 & 3 & $7.41 \times 10^{7}$ & $1.33 \times 10^{11}$ & NA \\
\hline 2 & 0.1 & 10 & & 10 & 1 & $1.42 \times 10^{10}$ & $6.12 \times 10^{10}$ & NA \\
\hline 2 & 0.1 & 10 & & 10 & 2 & $\mathrm{NA}$ & $6.28 \times 10^{10}$ & NA \\
\hline 2 & 0.1 & 10 & & 10 & 3 & $3.11 \times 10^{7}$ & $1.84 \times 10^{10}$ & NA \\
\hline 2 & 0.1 & 10 & & 1 & 1 & NA & $2.35 \times 10^{10}$ & NA \\
\hline 2 & 0.1 & 10 & & 1 & 2 & NA & $4.98 \times 10^{10}$ & NA \\
\hline 2 & 0.1 & 10 & & 1 & 3 & $2.23 \times 10^{9}$ & $2.58 \times 10^{10}$ & NA \\
\hline 2 & 0.1 & 10 & Sod Azide & 10 & 1 & NA & NR & NR \\
\hline 2 & 0.1 & 10 & Sod Azide & 10 & 2 & NA & NR & NR \\
\hline 2 & 0.1 & 10 & Sod Azide & 10 & 3 & NA & NR & NR \\
\hline 2 & 0.1 & 0.5 & & 1 & 1 & NA & $2.37 \times 10^{8}$ & $5.21 \times 10^{11}$ \\
\hline 2 & 0.1 & 0.5 & & 1 & 2 & NA & $4.57 \times 10^{8}$ & $8.36 \times 10^{11}$ \\
\hline 2 & 0.1 & 0.5 & & 1 & 3 & NA & $4.21 \times 10^{10}$ & $1.01 \times 10^{15}$ \\
\hline 2 & 0.1 & 0.5 & & 10 & 1 & NA & NA & $8.62 \times 10^{15}$ \\
\hline 2 & 0.1 & 0.5 & & 10 & 2 & NA & NA & $8.42 \times 10^{14}$ \\
\hline 2 & 0.1 & 0.5 & & 10 & 3 & NA & NR & NR \\
\hline 2 & 100 & 10 & & 0 & 1 & NA & NR & NR \\
\hline 2 & 100 & 10 & & 0 & 2 & NA & NR & NR \\
\hline 2 & 100 & 10 & & 0 & 3 & NA & NR & NR \\
\hline 2 & 10 & 10 & & 0 & 1 & NA & NR & NR \\
\hline 2 & 10 & 10 & & 0 & 2 & NA & NR & NR \\
\hline 2 & 10 & 10 & & 0 & 3 & NA & NR & NR \\
\hline 2 & 0.1 & 10 & & 0 & 1 & NA & NR & NR \\
\hline 2 & 0.1 & 10 & & 0 & 2 & NA & NR & NR \\
\hline 2 & 0.1 & 10 & & 0 & 3 & NA & NR & NR \\
\hline 3 & 100 & 10 & & 10 & out & $2.80 \times 10^{8}$ & $4.07 \times 10^{9}$ & $1.61 \times 10^{16}$ \\
\hline
\end{tabular}




\begin{tabular}{|c|c|c|c|c|c|c|c|c|}
\hline $\begin{array}{c}\text { Reactor } \\
\text { type }\end{array}$ & $\begin{array}{c}\text { TCE } \\
\text { concentration } \\
\mathrm{mg} / \mathrm{L} \\
\end{array}$ & $\begin{array}{c}\text { Sulfate } \\
\text { concentration } \\
\mathrm{mg} / \mathrm{L} \\
\end{array}$ & Other & $\begin{array}{c}\text { Cells } \\
\text { added } \\
\mu 1\end{array}$ & $\begin{array}{c}\text { Area } \\
\text { scrapped }\end{array}$ & $\begin{array}{c}\text { DHC } \\
\left(\text { copies } / \mathrm{cm}^{2}\right)\end{array}$ & $\begin{array}{c}\mathrm{SRB} \\
\left(\text { copies/cm } / \mathrm{cm}^{2}\right)\end{array}$ & $\begin{array}{c}\text { Archaea } \\
\left(\text { copies } / \mathrm{cm}^{2}\right)\end{array}$ \\
\hline 3 & 100 & 10 & & 10 & tube & $3.06 \times 10^{10}$ & $1.61 \times 10^{9}$ & $2.64 \times 10^{12}$ \\
\hline 3 & 100 & 10 & Sod. azide & 10 & out & NA & NR & NR \\
\hline 3 & 100 & 10 & Sod. azide & 10 & tube & NA & NR & NR \\
\hline 3 & 100 & 10 & & 1 & tube & $7.76 \times 10^{9}$ & $6.33 \times 10^{8}$ & $6.08 \times 10^{13}$ \\
\hline 3 & 100 & 10 & & 1 & out & $1.18 \times 10^{10}$ & $4.41 \times 10^{9}$ & $7.50 \times 10^{14}$ \\
\hline 3 & 100 & 0.5 & & 10 & out & $6.06 \times 10^{10}$ & $2.85 \times 10^{9}$ & $1.39 \times 10^{12}$ \\
\hline 3 & 100 & 0.5 & & 10 & tube & $4.92 \times 10^{9}$ & $1.83 \times 10^{8}$ & NA \\
\hline 3 & 100 & 0.5 & & 1 & tube & NA & $4.88 \times 10^{9}$ & $1.29 \times 10^{12}$ \\
\hline 3 & 100 & 0.5 & & 1 & out & NA & $2.76 \times 10^{9}$ & $8.54 \times 10^{11}$ \\
\hline 3 & 10 & 0.5 & & 10 & tube & NA & $2.75 \times 10^{8}$ & $1.73 \times 10^{12}$ \\
\hline 3 & 10 & 0.5 & & 10 & out & NA & $9.33 \times 10^{8}$ & $2.92 \times 10^{11}$ \\
\hline 3 & 10 & 0.5 & & 1 & tube & NA & $2.35 \times 10^{8}$ & $3.36 \times 10^{12}$ \\
\hline 3 & 10 & 0.5 & & 1 & out & NA & $2.92 \times 10^{9}$ & $4.66 \times 10^{11}$ \\
\hline 3 & 10 & 10 & & 1 & out & $8.13 \times 10^{10}$ & $2.91 \times 10^{\wedge}+10$ & $1.40 \times 10^{14}$ \\
\hline 3 & 10 & 10 & & 1 & tube & $7.42 \times 10^{10}$ & $2.07 \times 10^{9}$ & NA \\
\hline 3 & 10 & 10 & Sod Azide & 10 & out & NA & NR & NR \\
\hline 3 & 10 & 10 & Sod Azide & 10 & tube & NA & NR & NR \\
\hline 3 & 10 & 10 & & 10 & out & $8.98 \times 10^{10}$ & $3.25 \times 10^{10}$ & $4.90 \times 10^{12}$ \\
\hline 3 & 10 & 10 & & 10 & tube & $9.09 \times 10^{10}$ & $3.61 \times 10^{9}$ & $1.29 \times 10^{12}$ \\
\hline 3 & 0.1 & 10 & & 10 & out & $2.29 \times 10^{11}$ & NA & NA \\
\hline 3 & 0.1 & 10 & & 10 & tube & NA & NA & NA \\
\hline 3 & 0.1 & 10 & & 1 & out & NA & NA & NA \\
\hline 3 & 0.1 & 10 & & 1 & tube & NA & NA & NA \\
\hline 3 & 0.1 & 10 & Sod Azide & 10 & out & NA & NR & NR \\
\hline 3 & 0.1 & 10 & Sod Azide & 10 & tube & NA & NR & NR \\
\hline 3 & 0.1 & 0.5 & & 1 & out & NA & NA & NA \\
\hline 3 & 0.1 & 0.5 & & 1 & tube & NA & NR & NR \\
\hline 3 & 0.1 & 0.5 & & 10 & out & NA & NR & NA \\
\hline
\end{tabular}




\begin{tabular}{|c|c|c|c|c|c|c|c|c|c|}
\hline $\begin{array}{c}\text { Reactor } \\
\text { type }\end{array}$ & $\begin{array}{c}\mathrm{TCE} \\
\text { concentration } \\
\mathrm{mg} / \mathrm{L}\end{array}$ & $\begin{array}{c}\text { Sulfate } \\
\text { concentration } \\
\mathrm{mg} / \mathrm{L}\end{array}$ & Other & $\begin{array}{c}\text { Cells } \\
\text { added } \\
\mu 1\end{array}$ & $\begin{array}{r}\text { Area } \\
\text { scrappe }\end{array}$ & & $\begin{array}{c}\mathrm{DHC} \\
\left(\text { copies } / \mathrm{cm}^{2}\right)\end{array}$ & $\begin{array}{c}\mathrm{SRB} \\
\left(\text { copies } / \mathrm{cm}^{2}\right)\end{array}$ & $\begin{array}{c}\text { Archaea } \\
\left(\text { copies } / \mathrm{cm}^{2}\right)\end{array}$ \\
\hline 3 & 0.1 & 0.5 & & 10 & tube & & $\mathrm{NA}$ & NR & $\mathrm{NA}$ \\
\hline 3 & 100 & 10 & & 0 & out & & NA & NR & NR \\
\hline 3 & 100 & 10 & & 0 & tube & & NA & NR & NR \\
\hline 3 & 10 & 10 & & 0 & out & & NA & NR & NR \\
\hline 3 & 10 & 10 & & 0 & tube & & NA & NR & NR \\
\hline 3 & 0.1 & 10 & & 0 & out & & NA & NR & NR \\
\hline 3 & 0.1 & 10 & & 0 & tube & & NA & NR & NR \\
\hline 1 & 0 & 10 & & 10 & & 1 & $7.15 \times 10^{10}$ & $2.60 \times 10^{9}$ & $7.77 \times 10^{12}$ \\
\hline 1 & 0 & 10 & & 10 & & 2 & $7.71 \times 10^{10}$ & $2.09 \times 10^{8}$ & $1.43 \times 10^{13}$ \\
\hline 1 & 0 & 10 & & 10 & & 3 & $3.84 \times 10^{10}$ & $1.77 \times 10^{9}$ & $2.08 \times 10^{12}$ \\
\hline 2 & 0 & 10 & & 10 & & 1 & $1.38 \times 10^{10}$ & $4.69 \times 10^{8}$ & $4.92 \times 10^{13}$ \\
\hline 2 & 0 & 10 & & 10 & & 2 & $9.09 \times 10^{9}$ & $4.06 \times 10^{8}$ & $1.67 \times 10^{13}$ \\
\hline 2 & 0 & 10 & & 10 & & 3 & $6.94 \times 10^{8}$ & $4.86 \times 10^{7}$ & $1.40 \times 10^{13}$ \\
\hline 3 & 0 & 10 & & 10 & out & & $1.39 \times 10^{12}$ & $2.59 \times 10^{10}$ & $5.34 \times 10^{12}$ \\
\hline 3 & 0 & 10 & & 10 & tube & & $2.66 \times 10^{11}$ & $5.18 \times 10^{9}$ & $5.53 \times 10^{12}$ \\
\hline \multicolumn{10}{|c|}{$\mathrm{NA}=$ Not Amplified } \\
\hline
\end{tabular}


Table A4. Statistical tests for different reactors and microorganisms

\begin{tabular}{|c|c|c|c|c|c|c|}
\hline Reactor Type & Microorganisms & Area & Statistical test & Coefficient & $\mathrm{P}$ & Remarks \\
\hline \multirow[t]{9}{*}{1} & \multirow[t]{3}{*}{$\mathrm{DHC}$} & 1 vs 2 & Student's t-test & $\mathrm{t}=-0.132$ & 0.896 & Not siginificant \\
\hline & & 2 vs3 & Student's t-test & $\mathrm{t}=1.882$ & 0.089 & Not siginificant \\
\hline & & 1 vs 3 & Student's t-test & $\mathrm{t}=1.434$ & 0.168 & Not siginificant \\
\hline & \multirow[t]{3}{*}{ SRB } & 1 vs 2 & Student's t-test & $\mathrm{t}=1.218$ & 0.238 & Not siginificant \\
\hline & & 2 vs 3 & Student's t-test & $\mathrm{t}=1.313$ & 0.205 & Not siginificant \\
\hline & & 1 vs 3 & MWRS & $\mathrm{T}=231$ & 0.967 & Not siginificant \\
\hline & \multirow[t]{3}{*}{ Archaea } & 1 vs 2 & Student's t-test & $\mathrm{t}=-0.0182$ & 0.986 & Not siginificant \\
\hline & & 2 vs 3 & Student's t-test & $\mathrm{t}=-0.526$ & 0.605 & Not siginificant \\
\hline & & 1 vs 3 & MWRS & $\mathrm{T}=40$ & 0.937 & Not siginificant \\
\hline \multirow[t]{9}{*}{2} & \multirow[t]{3}{*}{ DHC } & 1 vs 2 & Student's t-test & $\mathrm{t}=2.446$ & 0.031 & Siginificant \\
\hline & & 2 vs 3 & MWRS & $\mathrm{T}=137.5$ & 0.827 & Not siginificant \\
\hline & & 1 vs 3 & MWRS & $\mathrm{T}=135$ & 0.029 & Siginificant \\
\hline & \multirow[t]{3}{*}{ SRB } & 1 vs 2 & MWRS & $\mathrm{T}=398$ & 0.1 & Not siginificant \\
\hline & & 2 vs 3 & MWRS & $\mathrm{T}=777$ & 0.427 & Not siginificant \\
\hline & & 1 vs 3 & MWRS & $\mathrm{T}=522$ & 0.302 & Not siginificant \\
\hline & \multirow[t]{3}{*}{ Archaea } & 1 vs 2 & MWRS & $\mathrm{T}=553$ & 0.461 & Not siginificant \\
\hline & & 2 vs 3 & MWRS & $\mathrm{T}=498$ & 0.018 & Siginificant \\
\hline & & 1 vs 3 & MWRS & $\mathrm{T}=390$ & $<0.001$ & Siginificant \\
\hline \multirow[t]{9}{*}{1} & \multirow[t]{3}{*}{ DHC } & $1 \mathrm{vs} \mathrm{T}_{0}$ & Linear Regression & $\mathrm{F}=6.604$ & 0.062 & Linear correlation \\
\hline & & $2 \mathrm{vs} \mathrm{T}_{0}$ & Linear Regression & $\mathrm{F}=55.47$ & 0.002 & Linear correlation \\
\hline & & 3 vs $\mathrm{T}_{0}$ & Linear Regression & $\mathrm{F}=1.860$ & 0.244 & No linear correlation \\
\hline & \multirow[t]{3}{*}{ SRB } & 1 vs $\mathrm{T}_{0}$ & Linear Regression & $\mathrm{F}=7.060$ & 0.057 & Linear correlation \\
\hline & & 2 vs $T_{0}$ & Linear Regression & $\mathrm{F}=14.341$ & 0.019 & Linear correlation \\
\hline & & 3 vs $\mathrm{T}_{0}$ & Linear Regression & $\mathrm{F}=8.736$ & 0.042 & Linear correlation \\
\hline & \multirow[t]{3}{*}{ Archaea } & $1 \mathrm{vs} \mathrm{T}_{0}$ & Linear Regression & $\mathrm{F}=0.0903$ & 0.772 & No linear correlation \\
\hline & & 2 vs $\mathrm{T}_{0}$ & Linear Regression & $\mathrm{F}=3.969$ & 0.117 & No linear correlation \\
\hline & & 3 vs $\mathrm{T}_{0}$ & Linear Regression & $\mathrm{F}=2.459$ & 0.192 & No linear correlation \\
\hline \multirow[t]{3}{*}{2} & \multirow[t]{3}{*}{ DHC } & $1 \mathrm{vs} \mathrm{T}_{0}$ & Linear Regression & $\mathrm{F}=0.775$ & 0.410 & No linear correlation \\
\hline & & 2 vs $\mathrm{T}_{0}$ & Linear Regression & $\mathrm{F}=0.264$ & 0.611 & No linear correlation \\
\hline & & 3 vs $\mathrm{T}_{0}$ & Linear Regression & $\mathrm{F}=0.00255$ & 0.962 & No linear correlation \\
\hline
\end{tabular}




\begin{tabular}{|c|c|c|c|c|c|c|}
\hline Reactor Type & Microorganisms & Area & Statistical test & Coefficient & $\mathrm{P}$ & Remarks \\
\hline \multirow{12}{*}{3} & SRB & 1 vs $\mathrm{T}_{0}$ & Linear Regression & $\mathrm{F}=0.338$ & 0.570 & No linear correlation \\
\hline & & 2 vs $\mathrm{T}_{0}$ & Linear Regression & $\mathrm{F}=1.433$ & 0.297 & No linear correlation \\
\hline & & 3 vs $\mathrm{T}_{0}$ & Linear Regression & $\mathrm{F}=0.299$ & 0.673 & No linear correlation \\
\hline & Archaea & $1 \mathrm{vs} \mathrm{T}_{0}$ & Linear Regression & $\mathrm{F}=0.262$ & 0.630 & No linear correlation \\
\hline & & 2 vs $\mathrm{T}_{0}$ & Linear Regression & $\mathrm{F}=1.292$ & 0.319 & No linear correlation \\
\hline & & $3 \mathrm{vs} \mathrm{T}_{0}$ & Linear Regression & $\mathrm{F}=0.129$ & 0.738 & No linear correlation \\
\hline & $\mathrm{DHC}$ & In vs $T_{0}$ & Linear Regression & $\mathrm{F}=0.126$ & 0.777 & No linear correlation \\
\hline & & Out vs $\mathrm{T}_{0}$ & Linear Regression & $\mathrm{F}=1.502$ & 0.288 & No linear correlation \\
\hline & SRB & In vs $\mathrm{T}_{0}$ & Linear Regression & $\mathrm{F}=0.857$ & 0.407 & No linear correlation \\
\hline & & Out vs $\mathrm{T}_{0}$ & Linear Regression & $\mathrm{F}=0.0357$ & 0.859 & No linear correlation \\
\hline & Archaea & In vs $\mathrm{T}_{0}$ & Linear Regression & $\mathrm{F}=14.77$ & 0.018 & Linear correlation \\
\hline & & Out vs $\mathrm{T}_{0}$ & Linear Regression & $\mathrm{F}=0.611$ & 0.478 & No linear correlation \\
\hline \multirow[t]{3}{*}{1} & $\mathrm{DHC}$ & Avg area vs $T_{0}$ & Linear Regression & $\mathrm{F}=12.265$ & 0.025 & Linear correlation \\
\hline & SRB & Avg area vs $T_{0}$ & Linear Regression & $\mathrm{F}=14.756$ & 0.018 & Linear correlation \\
\hline & Archaea & Avg area vs $T_{0}$ & Linear Regression & $\mathrm{F}=5.820$ & 0.073 & Linear correlation \\
\hline \multirow[t]{3}{*}{2} & DHC & Avg area vs $T_{0}$ & Linear Regression & $\mathrm{F}=0.000201$ & 0.989 & No linear correlation \\
\hline & SRB & Avg area vs $T_{0}$ & Linear Regression & $\mathrm{F}=0.0175$ & 0.901 & No linear correlation \\
\hline & Archaea & Avg area vs $T_{0}$ & Linear Regression & $\mathrm{F}=1.105$ & 0.353 & No linear correlation \\
\hline \multirow[t]{3}{*}{3} & $\mathrm{DHC}$ & Avg area vs $\mathrm{T}_{0}$ & Linear Regression & $\mathrm{F}=0.0284$ & 0.869 & No linear correlation \\
\hline & SRB & Avg area vs $T_{0}$ & Linear Regression & $\mathrm{F}=8.258$ & 0.017 & Linear correlation \\
\hline & Archaea & Avg area vs $T_{0}$ & Linear Regression & $\mathrm{F}=0.142$ & 0.714 & No linear correlation \\
\hline \multirow[t]{3}{*}{3} & DHC & In vs Out & MWRS & $\mathrm{T}=172$ & 0.214 & Not siginificant \\
\hline & SRB & In vs Out & Student's t-test & $\mathrm{t}=-0.140$ & 0.892 & Not siginificant \\
\hline & Archaea & In vs Out & Student's t-test & $\mathrm{T}=0.447$ & 0.447 & Not siginificant \\
\hline \multirow[t]{3}{*}{1} & $\mathrm{DHC}$ & Over 7 days & Linear Regression & $\mathrm{F}=0.104$ & 0.753 & No linear correlation \\
\hline & SRB & Over 7 days & Linear Regression & $\mathrm{F}=5.755$ & 0.037 & Linear correlation \\
\hline & Archaea & Over 7 days & Linear Regression & $\mathrm{F}=0.304$ & 0.594 & No linear correlation \\
\hline
\end{tabular}




\begin{tabular}{lllllll}
\hline Reactor Type & Microorganisms & Area & Statistical test & Coefficient & P & Remarks \\
\hline 2 & DHC & Over 7 days & Linear Regression & $\mathrm{F}=0.990$ & 0.376 & No linear correlation \\
& SRB & Over 7 days & Linear Regression & $\mathrm{F}=2.585$ & 0.183 & No linear correlation \\
& Archaea & Over 7 days & Linear Regression & $\mathrm{F}=21.253$ & 0.010 & Linear correlation \\
\hline
\end{tabular}

MWRS = Mann Whitney Rank sum

$\mathrm{T}_{0}=$ Initial concentration of TCE 

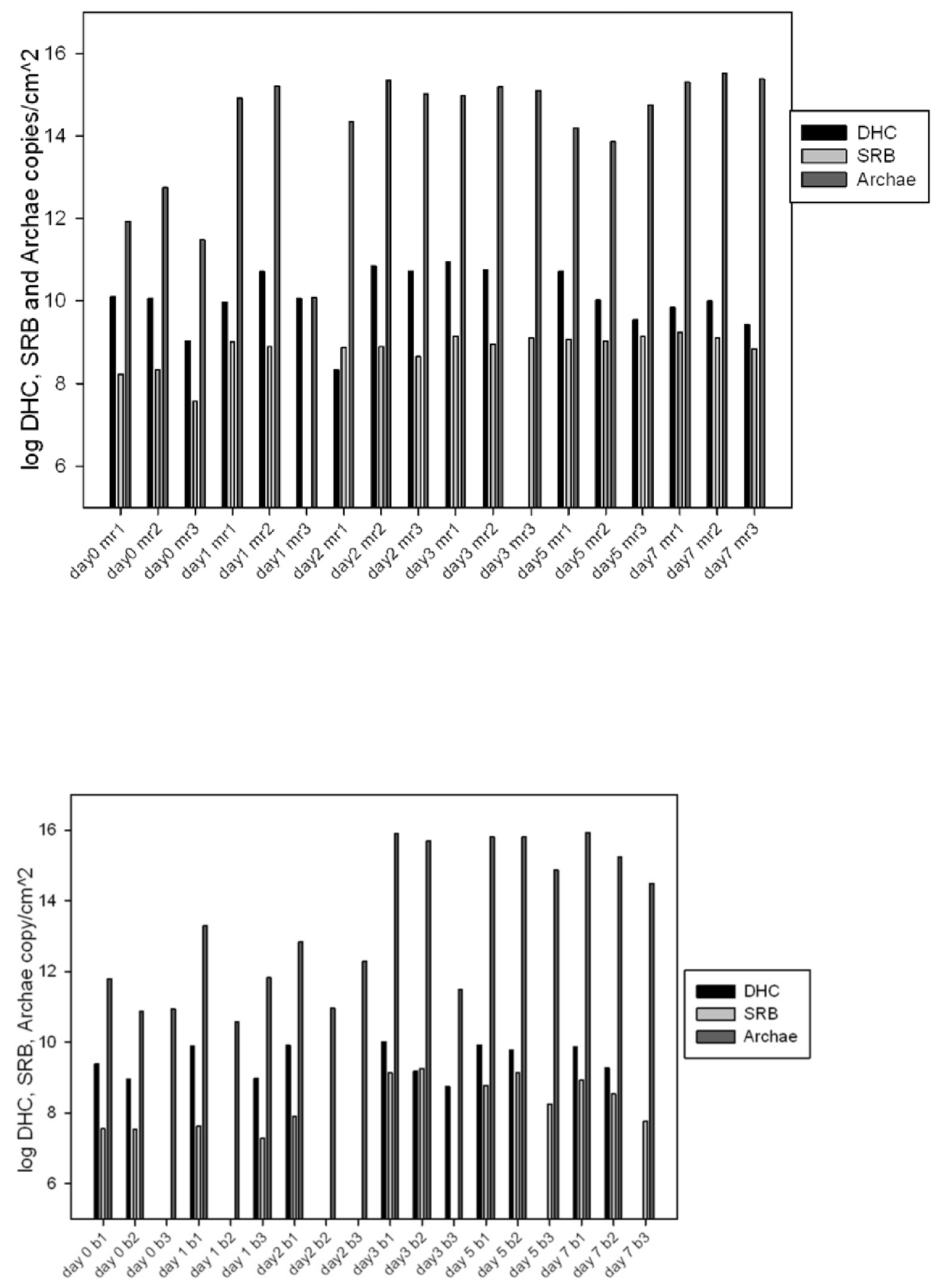

Figure A3. The log concentrations of DHC, SRB and archaea in type 1 and 2 reactor with all distances. 


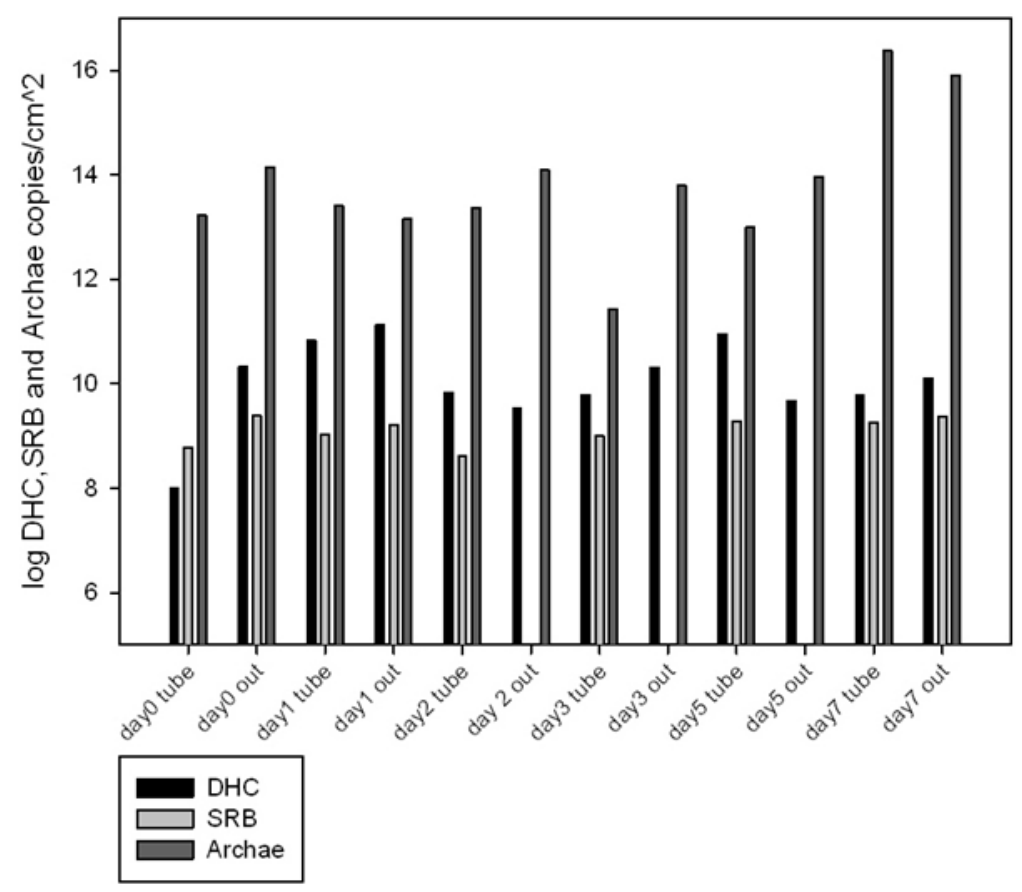

Figure A4. Relative abundance of dechlorinators maintained over the course of 7 days (type 3) reactor. Relative abundance was calculated from qPCR data with genus-specific primer sets.

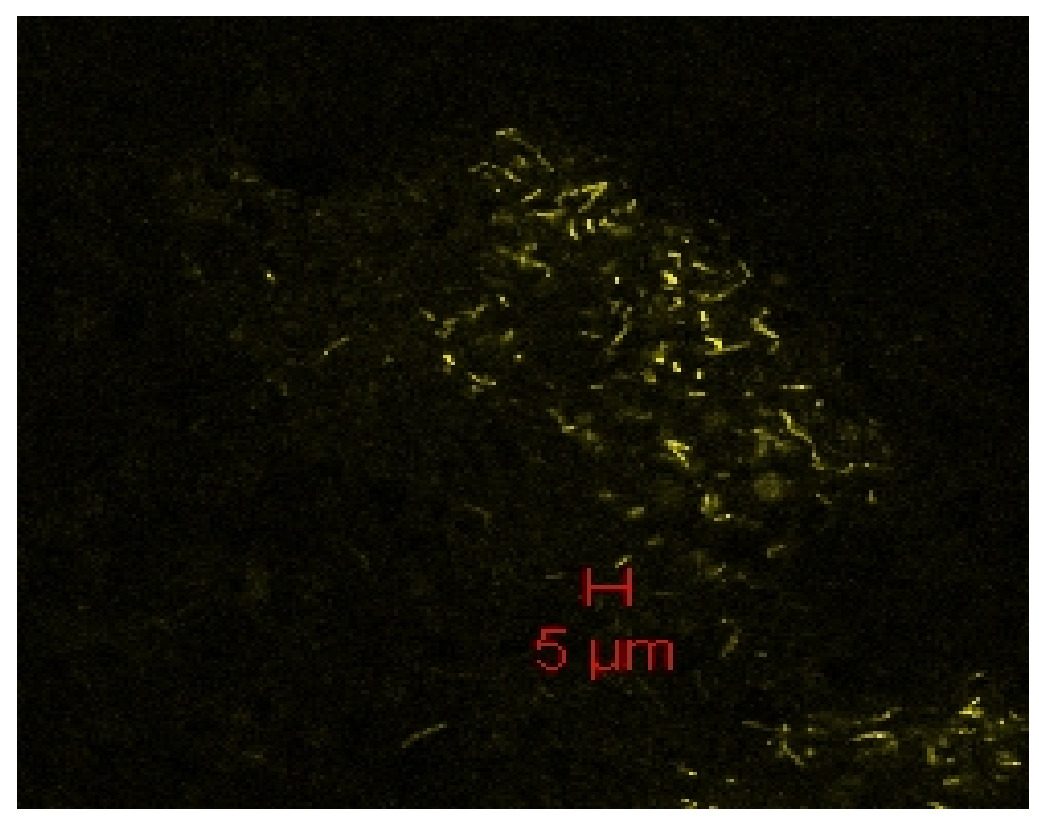

Figure A5. Archaea cells observed on confocal microscope after FISH stained with DAPI and Arch-647 Alexa probe from the seed reactor 


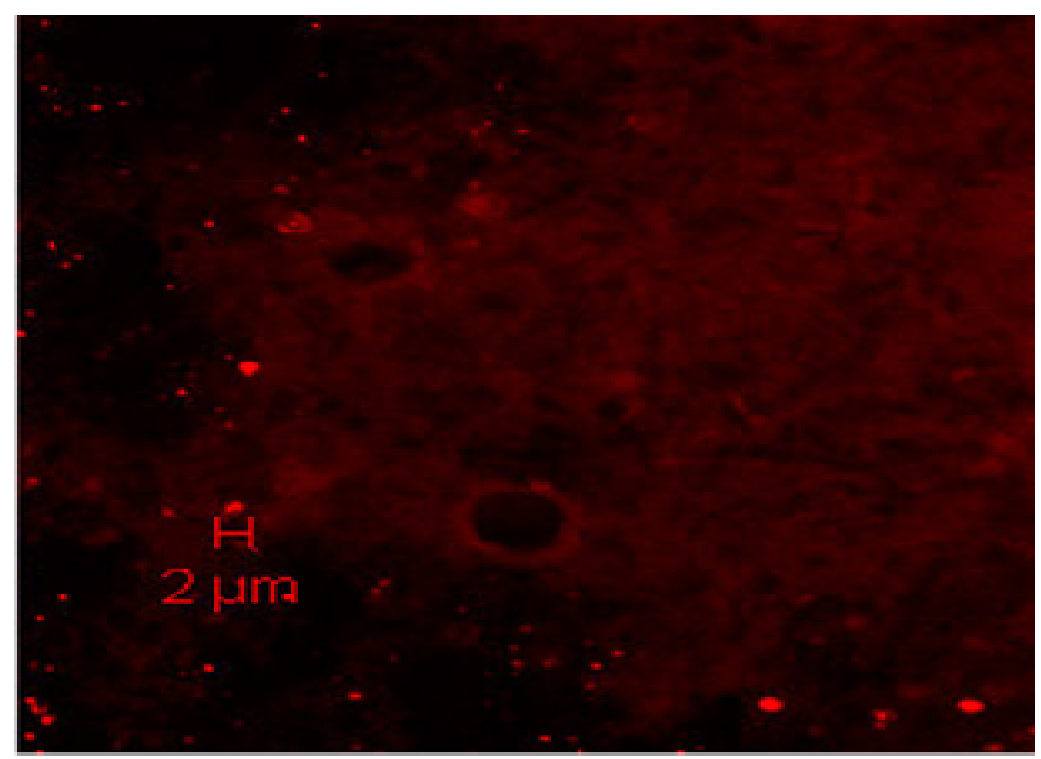

Figure A6. Sulfate reucing bacteria observed on confocal microscope after FISH stained with DAPI and SRB-555 Alexa probe from the seed reactor 


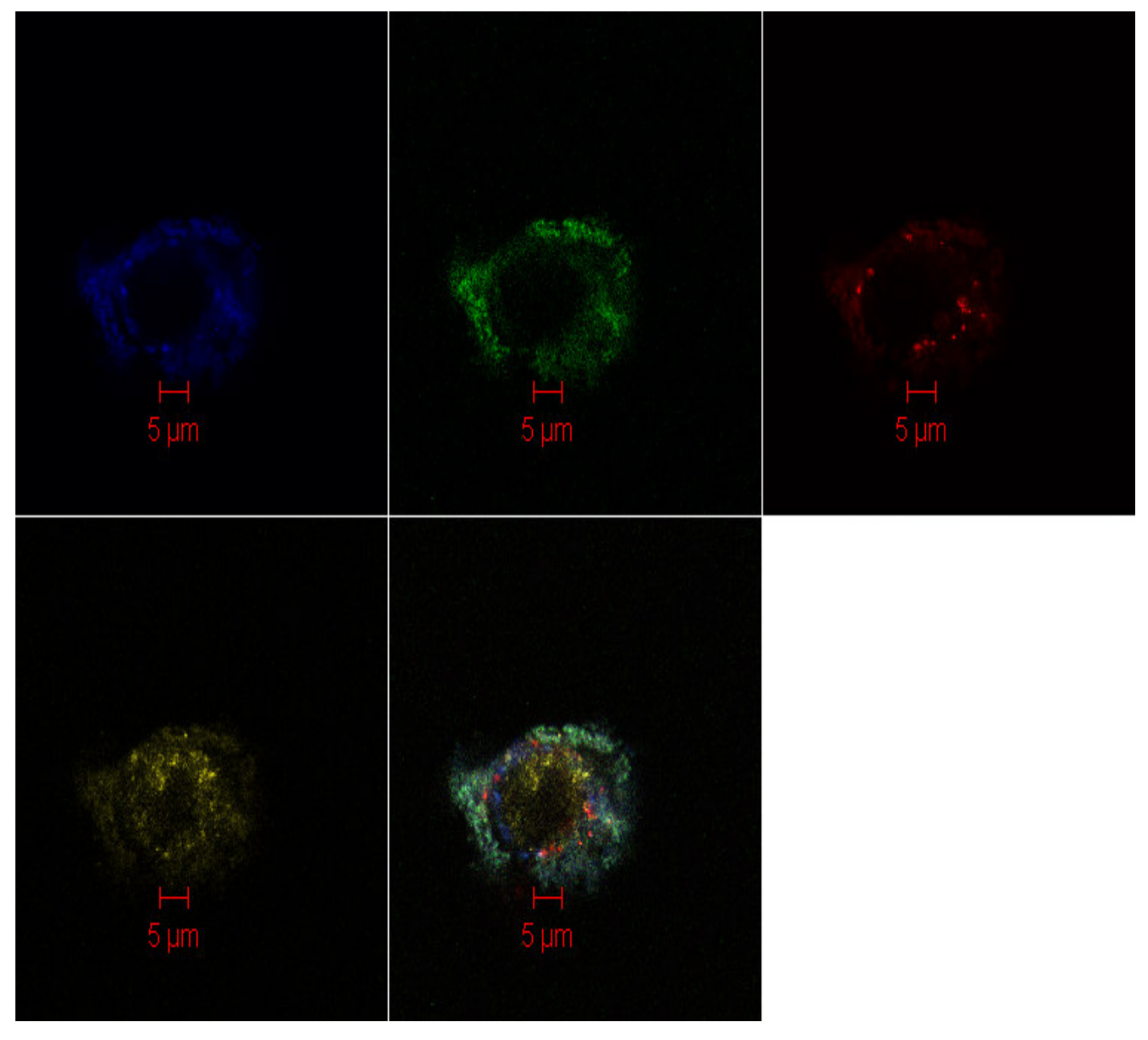

Figure A7. Co-distribution of DHC, sulfate reucing bacteria and Archaea in a sludge granual from the seed reactor observed by confocal microscope after FISH staining with DAPI and DHC fluorescein probe, SRB-555 Alexa probe and Arch-647 Alexa probe together (from right to left first is DAPI stained, second DHC, third SRB (upper row), Archaea and last one is all dyes together (lower row). 